


\section{$((-))$ \\ oen}

AUTARQUIA ASSOCIADA À UNIVERSIDADE DE SÃO PAULO

\section{ESTUDO DA RESPOSTA DE MONITORES DE RADIOPROTEÇÃO EM FEIXES PADRONIZADOS DE RADIAÇÃO X, GAMA E BETA}

\section{FERNANDA BEATRICE CONCEIÇÃO NONATO}

Dissertação apresentada como parte dos requisitos para obtenção do Grau de Mestre em Ciências na Área de Tecnologia Nuclear - Aplicações.

Orientadora:

Profa.Dra. Linda V. E. Caldas

São Paulo

2010 
A minha melhor amiga, minha querida mãe Darlita N. Conceição. 


\section{AGRADECIMENTOS}

Agradeço de todo o meu coração à minha orientadora Dra. Linda V. E. Caldas pela receptividade, acolhida. Por coordenar, sugerir, analisar o desenvolvimento deste trabalho. Obrigada pela atenção, compreensão e amizade. Com certeza considero-me privilegiada de tê-la como orientadora e poder aprender um pouco da riqueza de conhecimentos de que dispõe. Sua sabedoria não se limita apenas à área acadêmica, ela se estende no exemplo de vida que passa a todos nós através das suas atitudes e ações, seja com um bom dia seguido de um sorriso doce, seja pelo abraço carinhoso pela notícia positiva de uma bolsa de estudos. Sempre carinhosa, prestativa e incentivadora e torcedora pelas vitórias dos seus alunos e amigos. Meu coração se enche de alegria pela conclusão deste trabalho que teve todo apoio da senhora em todos os sentidos. Muito obrigada.

Meus sinceros agradecimentos se estendem:

Ao Dr. Alessandro M. da Costa, por ter sido meu orientador na iniciação científica, o que possibilitou o meu interesse na carreira acadêmica, pelo incentivo, pelo apoio e por me apresentar à Dra. Linda V. E. Caldas.

Ao Dr. Vitor Vívolo, pelos comentários, pelas valiosas discussões, pelo fornecimento de documentações para a análise deste trabalho e pela amizade. As suas contribuições foram imprescindíveis para a realização deste trabalho.

Aos Srs. Valdir Souza Carvalho e Rafael Elias Diniz, pelo tempo despendido partilhando o conhecimento e auxiliando nas calibrações nos laboratórios de radiação gama e beta, pelo apoio nas soluções de problemas e pela amizade.

À Dra. Maria da Penha A. Potiens, pela permissão da utilização dos Laboratórios do Departamento de Metrologia das Radiações do IPEN e pela amizade. 
Aos amigos e colegas Amanda Bravim, Eduardo L. Corrêa, Elaine W. Martins, Rodrigo F. Lucena e todos os membros da GMR do IPEN, pelo incentivo e amizade.

Ao IPEN, pela infra-estrutura oferecida para a realização deste trabalho.

Ao Conselho Nacional de Desenvolvimento Científico e Tecnológico, CNPq, e à Comissão Nacional de Energia Nuclear (CNEN), pelo apoio financeiro.

À minha querida amiga Donata C. O. Zanin, um exemplo de mulher, obrigada pela acolhida, pelo carinho e cuidado, pela amizade. Agradeço também à Carolina de Oliveira Zanin e a Áurea Maria de Oliveira, pela amizade.

Ao grupo de amigos muito queridos, Ana Paula Perini, Christianne Cobello Cavinato, Erik Alexandre Brito da Silva, Jonas Oliveira da Silva, Gustavo Villa Barreto, Lucio Pereira Neves, Maíra Tiemi Yoshizumi e Patrícia de Lara Antonio. Obrigada a todos pela amizade, pelo apoio, pela ajuda nos laboratórios e esclarecimentos de informática, pelo carinho, pelas conversas, comemorações e momentos de alegria.

Aos meus amigos, Ana Elena B. Costa, Ariane Camargo, Bruno César Rodrigues, Cecília P. Silva, Felipe Amaral, Karen N. Sakata, Karina Paraventi, Kátia Tanimoto e Raquel A. Pessoa pelo apoio, carinho, incentivo, confiança, atenção e companheirismo. Amigos do coração que sempre me proporcionam momentos de muita felicidade. Obrigada pela amizade sincera.

Aos meus novos e eternos amigos da Federação Espírita de São Paulo, Beatriz Vecchia, Bruno Natale, lasmin H. Fayad, Leane Cabral, Renato Dourado, Rodrigo Terrazas, Thiago Picanço. A este grupo unido pelo coração e pela emoção. De divertidos almoços aos sábados e passeios nos fins de semana. Pelo amor expresso sem medo de ser feliz. Obrigada. 
À minha linda mãe Darlita e ao meu querido pai Celso. Obrigada pela educação, pelo amor incondicional, pelos incentivos e esforços para que eu sempre alcançasse meus objetivos. Mesmo longe, o coração nunca se afastou, seja num pensamento, em um email ou numa simples ligação com o desejo de um lindo dia. Amo vocês de todo coração e de toda minha alma.

À minha querida irmãzinha Karollayne, motivo de muita alegria em minha vida, aos meus irmãos por parte de pai Michelly e João Hélio, obrigada por todo carinho.

À minha prima Luinalva, uma querida amiga irmã, obrigada por todo amor e carinho. Obrigada a toda a minha família, primos e tios, pelo apoio, pela torcida, pelo carinho e amor. Obrigada por fazerem parte da minha vida.

À minha tia Olga, querida Silu, a quem tenho grande admiração, obrigada pela acolhida e receptividade, pelo carinho, pelos finais de semanas divertidos e descontraídos, pelas conversas e desabafos no fim de noite, pela amizade, pelos abraços carinhosos ao final do evangelho no lar, pelos ensinamentos de vida. Meu amor por você é imenso.

Ao meu falecido avô Apolônio, não tenho palavras para expressar o meu imenso e eterno amor e o meu respeito.

E acima de tudo agradeço a Deus, meu pai maior, pela força, pela luz que guia os meus passos. Muito obrigada! 
"Tudo posso naquele que me fortalece." Paulo de Tarso 


\title{
ESTUDO DA RESPOSTA DE MONITORES DE RADIOPROTEÇÃO EM FEIXES PADRONIZADOS DE RADIAÇÃO X, GAMA E BETA
}

\author{
Fernanda Beatrice Conceição Nonato
}

\section{RESUMO}

Foram estudadas as respostas de 76 detectores Geiger-Müller, 4 detectores semicondutores e 34 câmaras de ionização. Muitos deles foram calibrados em feixes de radiação gama $\left({ }^{37} \mathrm{Cs}{ }^{60} \mathrm{Co}\right)$ e alguns foram testados em feixes de radiação beta $\left({ }^{90} \mathrm{Sr}+{ }^{90} \mathrm{Y}\right.$ e $\left.{ }^{204} \mathrm{Tl}\right)$ e $\mathrm{X}(\mathrm{N}-60, \mathrm{~N}-80, \mathrm{~N}-100, \mathrm{~N}-150)$. Para os três tipos de radiação, foram obtidos os fatores de calibração dos instrumentos e foi estudada a dependência tanto energética como angular destes detectores. Para radiação gama e beta foi estudada a dependência angular para ângulos de $0^{0} \mathrm{e} \pm 45^{\circ}$. Foram ainda obtidas as curvas da resposta dos instrumentos em relação a uma varredura angular de $0^{0} \mathrm{e} \pm 90^{\circ}$, para radiação gama, beta e $\mathrm{X}$. Também foram analisados os fatores de calibração obtidos para radiação beta em relação à radiação gama. Para radiação gama, dos 66 detectores Geiger-Müller estudados, 24 apresentaram resultados para a dependência energética de acordo com a recomendação internacional da ISO 4037-2 e 56 estão de acordo com a recomendação brasileira da ABNT 10011. As câmaras de ionização e os semicondutores estão de acordo com as recomendações nacional e internacional. Todos os instrumentos apresentaram dependência angular menor que $40 \%$. Para radiação beta, os instrumentos apresentaram resultados insatisfatórios para a dependência energética e angular; Para radiação $X$, as câmaras de ionização apresentaram resultados para dependência energética de acordo com a recomendação nacional, e a dependência angular foi menor que $40 \%$. 


\title{
STUDY OF RADIATION DETECTORS RESPONSE IN STANDARD X, GAMMA AND BETA RADIATION BEAMS
}

\author{
Fernanda Beatrice Conceição Nonato
}

\begin{abstract}
The response of 76 Geiger-Müller detectors, 4 semiconductor detectors and 34 ionization chambers were studied. Many of them were calibrated with gamma radiation beams $\left({ }^{37} \mathrm{Cs}\right.$ and $\left.{ }^{60} \mathrm{Co}\right)$, and some of them were tested in beta radiation $\left({ }^{90} \mathrm{Sr}+{ }^{90} \mathrm{Y}\right.$ e $\left.{ }^{204} \mathrm{TI}\right)$ and $\mathrm{X}$ radiation (N-60, N-80, N-100, N-150) beams. For all three types of radiation, the calibration factors of the instruments were obtained, and the energy and angular dependences were studied. For beta and gamma radiation, the angular dependence was studied for incident radiation angles of $0^{\circ}$ and $\pm 45^{\circ}$. The curves of the response of the instruments were obtained over an angle interval of $0^{0}$ to $\pm 90^{\circ}$, for gamma, beta and $\mathrm{X}$ radiations. The calibration factors obtained for beta radiation were compared to those obtained for gamma radiation. For gamma radiation, 24 of the 66 tested Geiger-Müller detectors presented results for the energy dependence according to international recommendation of ISO 4037-2 and 56 were in accordance with the Brazilian ABNT 10011 recommendation. The ionization chambers and semiconductors were in accordance to national and international recommendations. All instruments showed angular dependence less than $40 \%$. For beta radiation, the instruments showed unsatisfactory results for the energy dependence and angular dependence; For $\mathrm{X}$ radiation, the ionization chambers presented results for energy dependence according to the national recommendation, and the angular dependence was less than $40 \%$.
\end{abstract}




\section{SUMÁRIO}

1 Introdução

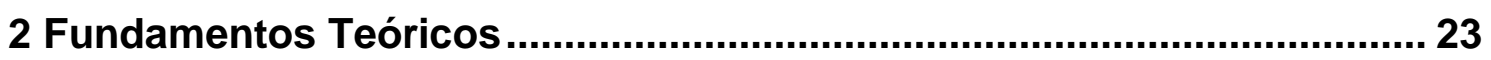

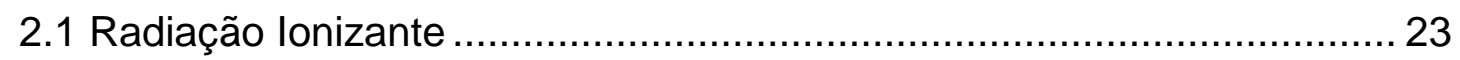

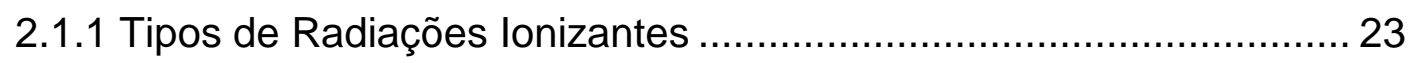

2.2 Interações da Radiação com a Matéria ................................................ 25

2.3 Grandezas e Unidades da Radiação ............................................... 27

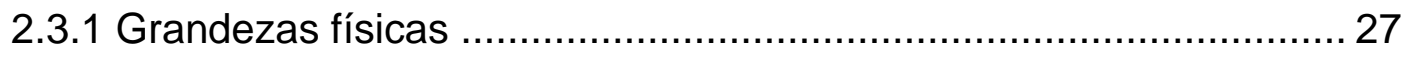

2.3.2 Grandezas de Proteção ........................................................... 29

2.3.3 Grandezas Operacionais.......................................................... 30

2.3.3.1 Coeficientes de conversão .................................................... 33

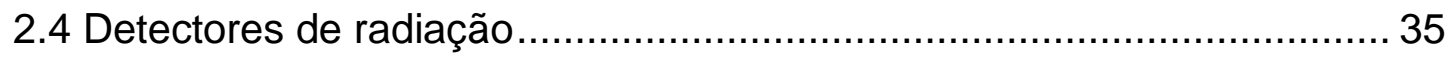

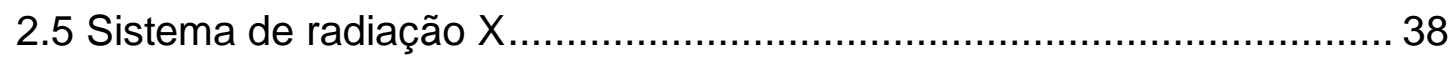

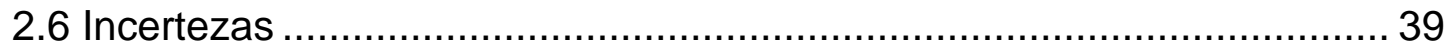

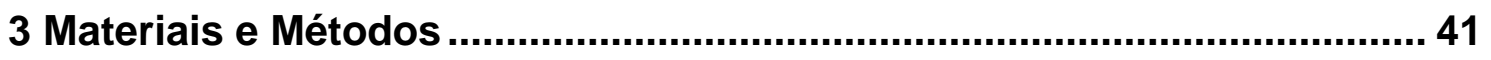

3.1 Equipamentos utilizados no estudo ............................................... 43

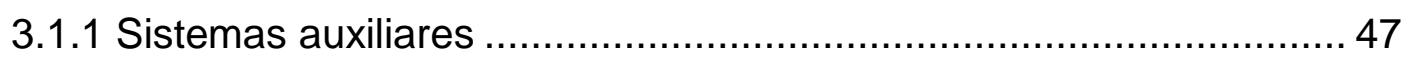

3.2 Sistemas e fontes de radiação utilizados ................................................. 47

3.2.1 Sistema de radiação gama........................................................ 47

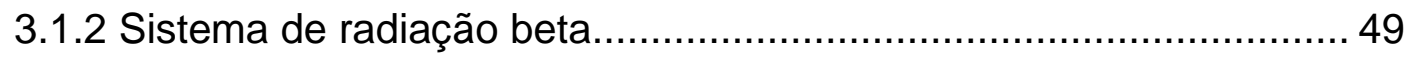

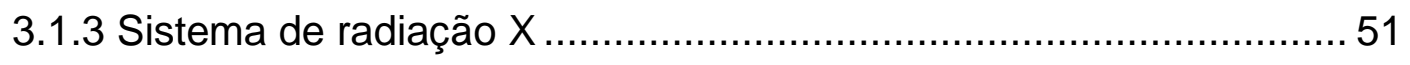

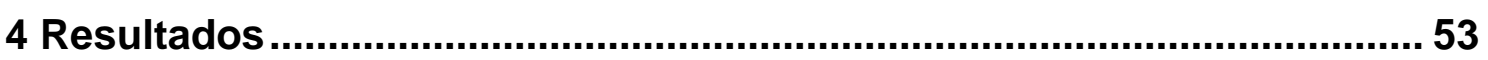

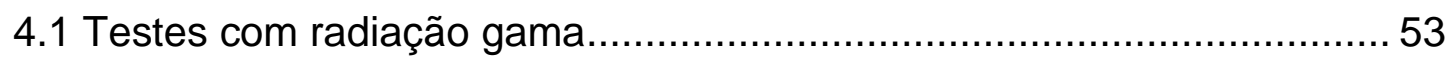

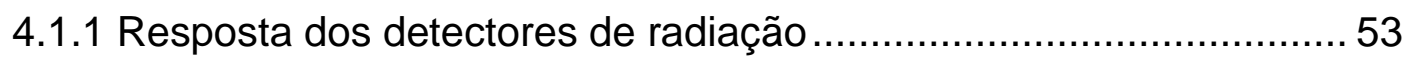

4.1.2 Determinação dos fatores de calibração para radiação gama ......... 59

4.1.3 Dependência energética dos detectores para radiação gama ......... 61

4.1.4 Dependência angular dos detectores para radiação gama ............... 68

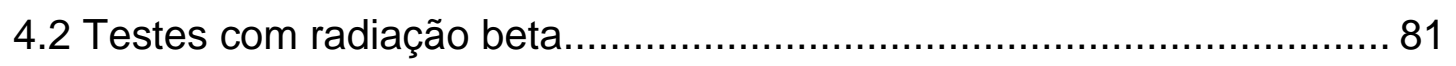

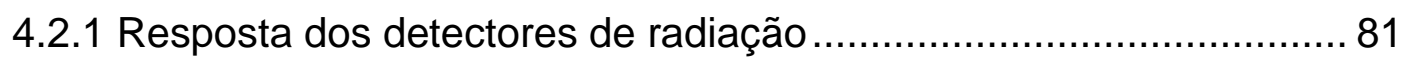

4.2.2 Determinação dos fatores de calibração para radiação beta ............ 84 
4.2.3 Dependência energética dos detectores para radiação beta ........... 86

4.2.4 Dependência angular dos detectores para radiação beta ................ 90

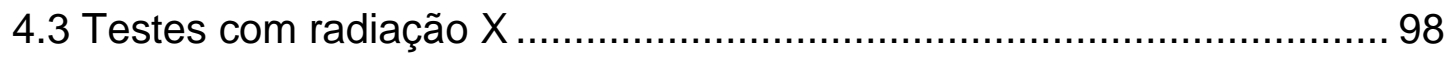

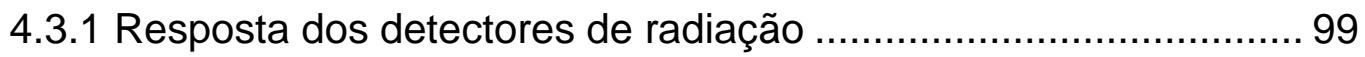

4.3.2 Determinação dos fatores de calibração para radiação $X$........... 100

4.3.3 Dependência energética dos detectores para radiação $X$........... 101

4.3.4 Dependência angular dos detectores para radiação $X$............... 108

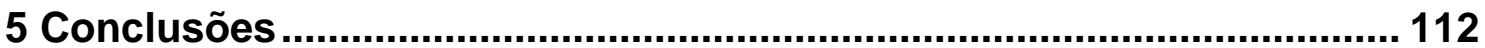

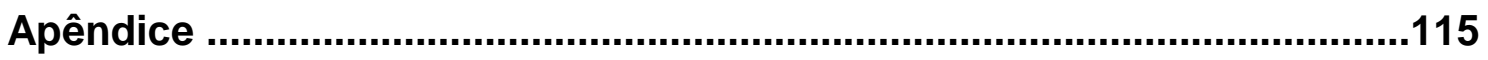

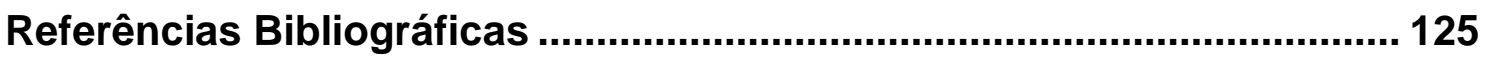




\section{Lista de Tabelas}

Tabela 2.1 Coeficientes de conversão de kerma no ar para equivalente de dose ambiente, de acordo com a norma ISO 4037-3 (ISO, 1999).

Tabela 3.1 Características dos detectores Geiger-Müller e semicondutores estudados neste trabalho.

Tabela 3.2 Características das câmaras de ionização estudadas neste trabalho.

Tabela 3.3 Características das fontes do sistema de radiação gama utilizadas neste trabalho.

Tabela 3.4 Características das fontes de radiação beta do sistema padrão secundário BSS1 do $\mathrm{LCl}$ utilizadas neste trabalho.

Tabela 3.5 Características dos feixes de radiação $X$ (série de espectro estreito), nível radioproteção, estabelecidos no sistema Pantak/Seifert do LCl.......................................

Tabela 4.1 Incertezas das medições dos instrumentos testados/calibrados com radiação gama..

Tabela 4.2 Resposta dos detectores Geiger-Müller (códigos A-V) e de detectores semicondutores (códigos $X$ e $Y$ ), para radiação gama.

Tabela 4.3 Resposta das câmaras de ionização para radiação gama.

Tabela 4.4 Fator de calibração dos detectores Geiger-Müller e detectores semicondutores (X1, X2, X3 e Y1), para radiação gama.

Tabela 4.5 Fator de calibração das câmaras de ionização, para radiação gama.

Tabela 4.6 Dependência energética, DE, da resposta dos detectores Geiger-Müller e dos detectores semicondutores (X1, X2, X3 e Y1) para radiação gama.... 
Tabela 4.7 Dependência energética, DE, da resposta das câmaras de ionização para radiação gama.

Tabela 4.8 Dependência energética, DE, da resposta dos detectores Geiger-Müller, para as grandezas $K_{a r} \mathrm{e}$ $H^{*}(10)$

Tabela 4.9 Dependência energética, DE, da resposta das câmaras de ionização, para as grandezas $K_{a r}$ e $H^{*}(10)$

Tabela 4.10 Incertezas das medições dos instrumentos utilizados para o estudo da dependência angular. 69

Tabela 4.11 Resposta dos detectores Geiger-Müller e do semicondutor $\mathrm{X} 1$, para ângulos diferentes de incidência do feixe de radiação gama $\left({ }^{137} \mathrm{Cs}\right)$.

Tabela 4.12 Resposta das câmaras de ionização, para ângulos diferentes de incidência do feixe de radiação gama $\left({ }^{137} \mathrm{Cs}\right)$.

Tabela 4.13 Dependência angular, DA, dos detectores Geiger-Müller e do detector semicondutor X1, para ângulos diferentes de incidência do feixe de radiação gama $\left({ }^{137} \mathrm{Cs}\right)$.

Tabela 4.14 Dependência angular, DA, das câmaras de ionização, para ângulos diferentes de incidência do feixe de radiação gama $\left({ }^{137} \mathrm{Cs}\right)$.

Tabela 4.15 Incertezas das medições dos instrumentos testados/calibrados com radiação beta.

Tabela 4.16 Resposta dos detectores Geiger-Müller para radiação beta.

Tabela 4.17 Resposta das câmaras de ionização para radiação beta.. 84

Tabela 4.18 Fator de calibração dos detectores Geiger-Müller para radiação beta $\left({ }^{90} \mathrm{Sr}+{ }^{90} \mathrm{Y} \mathrm{e}{ }^{204} \mathrm{TI}\right)$.

Tabela 4.19 Fator de calibração das câmaras de ionização para radiação beta $\left({ }^{90} \mathrm{Sr}+{ }^{90} \mathrm{Y} \mathrm{e}{ }^{204} \mathrm{TI}\right)$.

Tabela 4.20 Dependência energética da resposta dos detectores Geiger-Müller para radiação beta. 
Tabela 4.21 Dependência energética da resposta das câmaras de ionização para radiação beta............................................ 88

Tabela 4.22 Dependência com o tipo de radiação, DT, dos detectores Geiger-Müller, para radiações gama e beta.

Tabela 4.23 Dependência com o tipo de radiação, DT, das câmaras de ionização, para radiações gama e

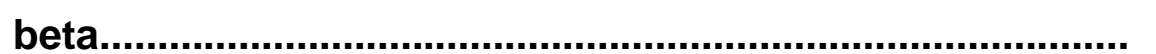

Tabela 4.24 Resposta dos detectores Geiger-Müller para ângulos diferentes de incidência do feixe de radiação beta $\left({ }^{90} \mathrm{Sr}+{ }^{90} \mathrm{Y}\right)$.

Tabela 4.25 Resposta das câmaras de ionização, para ângulos diferentes de incidência do feixe de radiação beta $\left({ }^{90} \mathrm{Sr}+{ }^{90} \mathrm{Y}\right)$.

Tabela 4.26 Dependência angular, DA, dos detectores Geiger-Müller para ângulos diferentes de incidência do feixe de

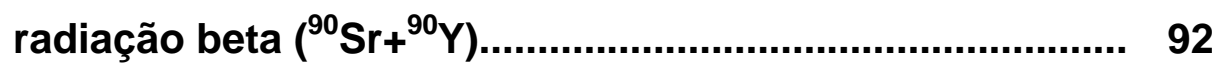

Tabela 4.27 Dependência angular, DA, das câmaras de ionização, para ângulos diferentes de incidência do feixe de

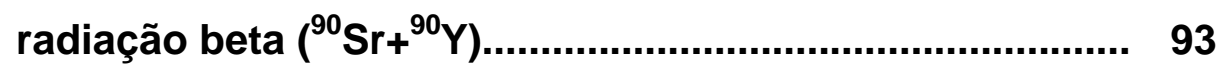

Tabela 4.28 Resposta das câmaras de ionização, para radiação X...... 99

Tabela 4.29 Fatores de calibração das câmaras de ionização para radiação $X$

Tabela 4.30 Dependência energética das câmaras de ionização, nível radioproteção, para raios $X$ (48keV-118keV) 


\section{Lista de Figuras}

Figura 2.1 Representação esquemática dos campos reais e hipotéticos. Campo real (a) com a fluência em um ponto $P$ composto de três direções; campo expandido do ponto $P$ (b) em um círculo; campo expandido e alinhado (c) do ponto $P$ em um círculo (IAEA, 2000)...................................

Figura 2.2 Coeficiente de conversão de $H^{*}(10)$ e $H^{\prime}(0,07, \Omega)$ em relação à kerma no ar, $K_{a}$, em função da energia do fóton, $E_{p h}$, sendo a direção $\Omega$ a $0^{0}$ (IAEA, 2000).

Figura 2.3 Regiões de operação para detectores preenchidos a gás. A amplitude do pulso (em escala logarítima) está apresentada na curva em função da tensão aplicada (KNOLL, 1989).

Figura 2.4 Tubo de raios X e seus componentes (JOHNS, 1983)......... 39

Figura 3.1 Método de calibração para campos conhecidos (IAEA, 2000).

Figura 3.2 Método de calibração por substituição (IAEA, 2000). 42

Figura 3.3 Detectores Geiger-Müller da marca MRA com sonda externa, modelo G1-E (a) e com sonda interna, modelo G1-I (b).

Figura 3.4 Câmaras de ionização: marca Fluke Biomedical, modelo 451P, (a1) e (a2); marca Victoreen, modelo 451B, (b1) e (b2); marca Babyline, modelo 81 (c).

Figura 3.5 Detector semicondutor, marca Rados, modelo Rad-60S.... 46

Figura 3.6 Suporte de placas de acrílico para estudo de dependência angular dos monitores de área

Figura 3.7 Sistema de radiação gama (a), 1-Irradiador, 2-Câmera de circuito interno, 3-Detector Geiger-Müler, 4-Sistema com trilho que determina a distância de calibração; Filtros atenuadores (b). 
Figura 3.8 Sistema irradiador beta (AMBROSI et al, 2007).................... 50

Figura 3.9 Sistema de radiação beta: 1-Blindagem das fontes, 2-Sistema do irradiador, 3-Sistema de acionamento das fontes.

Figura 3.10 Sistema de radiação $X$ : Tubo de raios $X$ (a), Sala de controle e de anotações das medições (b), Sistema de acionamento da radiação $X(c)$.

Figura 4.1 Dependência energética para radiação gama, de alguns detectores Geiger-Müller estudados.

Figura 4.2 Dependência energética para radiação gama, das câmaras de ionização estudadas.

Figura 4.3 Resposta angular dos detectores Geiger-Müller A3, B2 e C5.

Figura 4.4 Resposta angular dos detectores Geiger-Müller E1, E2 e F1.

Figura 4.5 Resposta angular dos detectores Geiger-Müller H2, H3 e H4.

Figura 4.6 Resposta angular dos detectores Geiger-Müller H5, I5 e 16

Figura 4.7 Resposta angular dos detectores Geiger-Müller N3 e S2 e do semicondutor $\mathrm{X} 1$

Figura 4.8 Resposta angular das câmaras de ionização B'1, C'1 e J'1

Figura 4.9 Resposta angular da câmara de ionização K'1

Figura 4.10 Resposta angular dos detectores Geiger-Müller H2, H3 e L13

Figura 4.11 Resposta angular dos detectores Geiger-Müller L14, L15 e L16

Figura 4.12 Resposta angular dos detectores Geiger-Müller L17, L18 e Q8.

Figura 4.13 Resposta angular dos detectores Geiger-Müller Q9 e S2 e da câmara de ionização B'1 
Figura 4.14 Fatores de calibração das câmaras de ionização A'1, B'3 e B'4, para radiação $X$

Figura 4.15 Fatores de calibração das câmaras de ionização C'3, E'1 e E'2, para radiação X....................................................... 103

Figura 4.16 Fatores de calibração das câmaras de ionização E'3 e E'4 e F'1, para radiação X...................................................... 104

Figura 4.17 Fatores de calibração das câmaras de ionização G'1, K'3 e L'6, para radiação X........................................................ 105

Figura 4.18 Fatores de calibração das câmaras de ionização M'2 e M'3, para radiação $X$

Figura 4.19 Fatores de calibração das câmaras de ionização C'2, D'2 e H'1, para radiação $X$ e gama..

Figura 4.20 Resposta angular das câmaras de ionização A'1 e C'3 em feixes de radiação $X(N-150)$.

Figura 4.21 Resposta angular das câmaras de ionização L'7 e L'8 em feixes de radiação $X(N-150)$. 


\section{Introdução}

Desde a descoberta dos raios $\mathrm{X}$ por Wilhelm Conrad Roentgen, em novembro de 1895 (HALL, 2000), o uso da radiação ionizante vem se intensificando e ampliando seus setores de aplicação. O contexto atual das radiações ionizantes na medicina engloba a radiologia diagnóstica, a medicina nuclear, a radioterapia e a radioproteção. Além da área médica, muitos investimentos foram aplicados nas áreas de pesquisa, tecnologia, industrial e agropecuária. Toda essa inovação requer a utilização de irradiadores, equipamentos de raios $\mathrm{X}$, aceleradores de partículas, tomógrafos e fontes radioativas.

Para regulamentar o uso das radiações ionizantes, surgiram a Comissão Internacional de Medidas e Unidades de Radiação (ICRU) e a Comissão Internacional de Proteção Radiológica (ICRP), que têm como objetivo principal recomendar e orientar o uso das radiações ionizantes por meio de normas. As pesquisas sobre os efeitos diretos e indiretos da radiação ionizante (HALL, 2000) se acentuam como uma forma de evitar possíveis danos ao trabalhador e ao público. Com esta percepção de risco e para otimizar a radioproteção criou-se o princípio ALARA ("As Low As Reasonably Achievable") aplicado nas normas pelas comissões de radioproteção.

Uma das formas de controle da radiação ionizante é por meio da utilização de instrumentos de medidas, como dosímetros clínicos e de área, e de detectores portáteis, que quantificam e qualificam a radiação. Existem alguns tipos de dosímetros clínicos com materiais diversos como também tipos diferentes de detectores de radiação, como detectores Geiger-Müller, detectores de cintilação, detectores proporcionais, detectores semicondutores, câmaras de ionização (ATTIX, 1986; KNOLL,1989).

Existem várias publicações sobre campos padronizados de radiação gama, beta, alfa e raios $X$ para diferentes qualidades que relataram 0 comportamento desses instrumentos de medidas, por meio das respostas energética e angular, como por exemplo, dosímetros fotográficos (BARBOSA e CALDAS, 1987), detectores termoluminescentes (CECATTI et al., 2005; MAIA e CALDAS, 2008), detectores de radiação 
utilizados em radiodiagnóstico (POTIENS e CALDAS, 2004), detectores de contaminação em campos de radiação alfa (DIAS e CALDAS, 1991), testes de desempenho para monitores portáteis de radiação (VIVOLO, 2000; VIVOLO e CALDAS, 2002), estudo do desempenho das câmaras de ionização para dependência angular e energética (CALDAS e BATISTELLA, 1988; CALDAS e ALBUQUERQUE, 1991). São todos trabalhos sobre tipos de radiação e detectores diversificados, aplicados em dosimetria e radioproteção.

Trabalhar com detectores de área portáteis requer um controle de qualidade que é garantido em parte pela calibração, que certifica a boa funcionalidade dos equipamentos e oferece confiabilidade em suas medições. A calibração consiste em um conjunto de operações, sob condições especificadas, que relaciona valores de um mensurando com valores indicados por um sistema de medição. A calibração é realizada normalmente em laboratório, onde são estabelecidas condições de referência, denominadas padrões. O resultado da calibração deve ser registrado em um documento específico denominado certificado de calibração. Neste certificado estão contidas as informações do procedimento de calibração e das condições em que a calibração foi realizada. (GONÇALVES e SOUSA, 2008).

Existem quatro métodos de calibração para se obter o fator de calibração, que é um fator multiplicativo que converte o valor indicado nos instrumentos para o que se chama de "valor verdadeiro convencional" da grandeza medida. Os procedimentos para calibração variam de acordo com o tipo de instrumento a ser calibrado, com o tipo de radiação (alfa, beta, gama e X) e com a energia da radiação que este equipamento irá detectar. Os principais métodos de calibração são: 1) Uso de campos de radiação conhecidos; nesta técnica são calibrados em geral os equipamentos utilizados em radioproteção; 2) Uso de campos de radiação menos bem conhecidos: neste caso utiliza-se o método da substituição. Os dosímetros clínicos são calibrados utilizando-se este método (IAEA, 2000; IAEA, 2009).

As comissões ICRU e ICRP definiram grandezas operacionais para uso na radioproteção em monitoramento de área e individual, sendo elas: equivalente de dose ambiente, $H^{*}(d)$, equivalente de dose direcional, $H^{\prime}(d, \Omega)$ e equivalente de dose individual, $H p(d)$. Essas grandezas foram 
desenvolvidas porque as grandezas limitantes não são mensuráveis ou facilmente estimadas, e as grandezas primárias não estão correlacionadas ao equivalente de dose (ICRP, 1995; ICRU, 1993; ICRUa, 1998; ICRUb, 1998).

A maior parte dos países membros da Agência Internacional de Energia Atômica, IAEA, aplica as recomendações vinculadas ao uso das novas grandezas dosimétricas. No entanto, o processo esbarra em situações de caráter tecnológico e na prática da utilização das grandezas antigas.

Apesar das dificuldades de se operar medidas nas novas grandezas, foi desenvolvido um irradiador beta de modelo BSS2 que vem substituindo o modelo BSS1 por ser mais fácil em sua operação, ter um melhor desempenho, além de possuir uma unidade de operação eletrônica com um software especial que permite quantificar as medidas nas novas grandezas equivalente de dose direcional e equivalente de dose pessoal. Os modelos BSS possuem fontes radioativas rastreadas pelo laboratório primário da PTB e estão em conformidade com as recomendações internacionais ISO 6980 (ISOa, 1996) (AMBROSI et al., 2007).

O equivalente de dose ambiente $H^{*}(10)$ é a grandeza mais importante para calibração de monitores de área. Ela mantém o vínculo entre a dose efetiva e o risco para o indivíduo e apresenta um sistema de medida de acordo com o intervalo de energia da radiação incidente.

As novas grandezas operacionais de radioproteção foram definidas com base na esfera ICRU, objeto simulador do corpo humano; e com base em novos conceitos como campos de radiação expandidos e alinhados (ALBERTS et al, 1995; IAEA, 2000). Por meio da esfera ICRU foi possível obter fatores de conversão da grandeza kerma no ar para $H^{*}(10)$ descritos nas publicações SRS 16 (IAEA, 2000) e ISO 4037-3 (ISO, 1999) e compará-los com os fatores de conversão obtidos pela fórmula empírica de Wagner (WAGNER et al, 1985); com exceção da energia de $20 \mathrm{keV}$, os valores obtidos pelos dois métodos são bem próximos.

Nogueira realizou, por meio de medidas experimentais, um estudo sobre a determinação dos fatores de conversão de kerma no ar e de fluência para equivalente de dose ambiente para radiação $X$, obtendo uma incerteza máxima de $7,2 \%$ comparados com os dados da literatura (NOGUEIRA, 1997). 
Guimarães combinou detectores termoluminescentes para formarem monitores de radiação e implementou grandezas operacionais como $H^{*}(10), H^{\prime}(d, \Omega)$ e $H p(10)$. O estudo demonstrou que todos os resultados de testes de desempenho dos monitores estavam dentro dos limites estabelecidos pelas normas internacionais (GUIMARÃES, 2000).

A calibração e os testes de monitores de área exigem instalações apropriadas para sua execução, assim como equipamentos e procedimentos de calibração que cumpram os requerimentos atuais de garantia da qualidade das normas internacionais e nacionais como as da Associação Brasileira de Normas Técnicas, ABNT, (ABNT, 1987; ABNT, 2005). O Laboratório de Calibração de Instrumentos, da Gerência de Metrologia das Radiações do IPEN (LCl) conta com as instalações e os equipamentos apropriados para tal fim. O LCl dispõe de fontes emissoras de radiação gama de ${ }^{60} \mathrm{Co} \mathrm{e}{ }^{137} \mathrm{Cs}$, com diversas atividades, fontes emissoras de radiação beta de ${ }^{90} \mathrm{Sr}+{ }^{90} \mathrm{Y},{ }^{204} \mathrm{TI} \mathrm{e}$ ${ }^{147} \mathrm{Pm}$, sistemas de raios $\mathrm{X}$, para calibração de dosímetros clínicos e de monitores portáteis. Para cada feixe de radiação e intervalo de energia, o LCl dispõe ainda de sistemas de referência (padrões secundários e de trabalho), sendo alguns calibrados nos laboratórios do tipo padrão primário do exterior e outros no Laboratório Nacional de Metrologia das Radiações lonizantes (LNMRI), Instituto de Radioproteção e Dosimetria (IRD), Comissão Nacional de Energia Nuclear, Rio de Janeiro. Este laboratório pertence à rede internacional de laboratórios padrões secundários e os seus sistemas de referência são calibrados rotineiramente no laboratório padrão primário Bureau International des Poids et Mesures (BIPM), França.

Já foi constatado ao longo dos anos que muitos equipamentos calibrados pelo Laboratório de Calibração do IPEN já sofreram alterações consideráveis, como a própria troca do tubo Geiger-Müller, nem sempre substituído por outro de mesmo modelo. Este fato pode levar o usuário a erros de interpretações das medidas. Periodicamente, durante a vida útil dos instrumentos, deverão ser realizados testes, para verificar se eles preservam suas características operacionais, o que indicará o quão próximas do esperado estão as leituras realizadas pelos instrumentos nas condições reais de operação (ANSI, 1997). 
Os testes podem incluir a determinação de características radiológicas e não radiológicas que podem afetar a precisão das medidas em condições operacionais. Os critérios e os métodos para realização de testes de desempenho são determinados por normas e recomendações internacionais (EN, 2004) para radiação beta (ISOa, 1996; ISOa, 2004; ISO, 2006) e para radiação gama e X (ISOb, 1996; ISO, 1997; ISO, 1999; ISOb, 2004).

Foram publicados alguns trabalhos com o estudo das respostas dos monitores portáteis de radioproteção para as novas grandezas operacionais. Thompson estudou as respostas de algumas câmaras de ionização, cintiladores sólidos e detectores Geiger-Müller com o objetivo de implementar as novas grandezas do ICRU. Neste trabalho, Thompson obteve resultados diversificados, com grande variação na resposta da dependência energética, de acordo com o tipo de detector e do modelo utilizado (THOMPSON, 1989). Grecco e colaboradores avaliaram a resposta de um detector Geiger-Müller para $H^{*}(10)$. O aparelho apresentou uma grande dependência energética, fora dos limites estipulados pela norma EN 60846 (EN, 2004) de várias energias normalizadas para ${ }^{137} \mathrm{Cs}$. Para diminuir a dependência energética, os autores desenvolveram filtros compensadores de energia que foram colocados à frente do detector Geiger-Müller, obtendo um melhor resultado da dependência energética, (GRECCO et al, 2001), assim como foi feito por Ramos (RAMOS, 2001), que colocou um filtro compensador de energia para um detector Geiger-Müller, obtendo também resultados melhores para a dependência energética para a grandeza equivalente de dose ambiente comparados com os resultados sem o uso dos filtros compensadores.

O objetivo principal deste trabalho foi o estudo de dependência energética e angular da resposta de monitores de área, como detectores Geiger-Müller, detectores semicondutores e câmaras de ionização para as grandezas de taxa de dose absorvida, taxa de kerma no ar e taxa de equivalente de dose ambiente, como uma forma de assegurar a confiabilidade dos monitores portáteis utilizados em radioproteção. 


\section{Fundamentos Teóricos}

\subsection{Radiação lonizante}

A radiação ionizante é um tipo de radiação que possui energia suficiente para ionizar e excitar átomos ou moléculas. Pode-se classificá-la como radiação indiretamente ionizante e diretamente ionizante. A radiação indiretamente ionizante ocorre quando fótons ou nêutrons transferem sua energia para partículas carregadas, sendo que parte dessa radiação pode passar pelo meio sem sofrer alguma interação. A radiação diretamente ionizante acontece quando partículas carregadas interagem com a matéria, transferindo sua energia para outras partículas carregadas; neste caso, quase toda a radiação interage com o meio, e não há a possibilidade de a radiação passar pelo meio sem que haja alguma interação (ATTIX, 1986).

\subsubsection{Tipos de Radiações lonizantes}

Existem vários tipos de radiação ionizante, como radiação $\mathrm{X}$, alfa, beta, gama, de nêutrons. A seguir foram citados apenas os tipos de radiação utilizados neste trabalho.

\section{Radiação X}

A radiação $X$ é uma radiação eletromagnética de energia alta que pode ter duas origens. O primeiro caso ocorre quando os elétrons são monoenergéticos; as partículas carregadas são freadas formando um espectro contínuo, denominada radiação de freamento (Bremsstrahlung). A fração da energia do elétron convertida em radiação de Bremsstrahlung aumenta com a energia do elétron e é maior para materiais de número atômico, $Z$, maior.

A outra origem dos raios $X$ ocorre quando um elétron se movimenta de uma camada mais energética para uma menos energética liberando energia em forma de raios $X$ característicos, ou seja, o elétron sai da sua configuração normal por algum processo de excitação e caminha para um estado menos 
excitado em um curto período de tempo (ATTIX, 1986; JOHNS e CUNNINGHAM,1983).

\section{Radiação Gama}

A radiação gama é uma radiação de energia alta, que ao invés de ser emitida pela eletrosfera como no caso dos raios $X$, é emitida pelo excesso de energia do núcleo sob a forma de radiação eletromagnética. Geralmente o decaimento gama está associado a outros decaimentos, como a emissão alfa ou beta (KNOLL, 1989).

\section{Radiação Beta}

É muito comum identificar elétrons rápidos que decaem de radioisótopos pelo processo de emissão beta. $O$ processo esquemático de decaimento de partícula beta está descrito a seguir:

$$
{ }_{\mathrm{Z}}^{\mathrm{A}} \mathrm{X} \rightarrow{ }_{\mathrm{Z}+1}^{\mathrm{A}} \mathrm{Y}+\beta^{-1}+\overline{\mathrm{v}}
$$

Um elemento representado por ${ }_{\mathrm{Z}}^{\mathrm{A}} \mathrm{X}$ está com excesso de nêutrons, ou seja, falta de prótons e decai para outro elemento ${ }_{\mathrm{Z}+1}^{\mathrm{A}} \mathrm{Y}$, transformando um nêutron em um próton, representado no elemento $\underset{\mathrm{Z}+1}{\mathrm{~A}} \mathrm{Y}$, mais um elétron, $\beta^{-1}$; este elétron é liberado acompanhado de um antineutrino, $\bar{v}$, equilibrando as forças nucleares. Quando o núcleo está com excesso de prótons, um próton é convertido em um nêutron e emite um pósitron e um neutrino. Os neutrinos e antineutrinos interagem muito pouco com a matéria; na prática, não são identificados. No momento em que ocorre o processo de decaimento beta, o elemento ${ }_{Z+1}^{A} Y$ sofre um pequeno recuo e a energia de recuo consequentemente é pequena (KNOLL, 1989). 


\subsection{Interações da Radiação com a Matéria}

A interação de partículas não carregadas como raios $X$ e radiação gama pode provocar processos de deposição de energia, como o efeito fotoelétrico, o efeito Compton, a produção de pares e a aniquilação de pares elétron-pósitron. No caso de partículas carregadas, pode ainda ocorrer a produção de Bremsstrahlung (EISBERG e RESNICK, 1983).

\section{Efeito Fotoelétrico}

O efeito fotoelétrico ocorre quando se emite uma onda eletromagnética, na região espectral do visível ou próximo a ela, em uma superfície de um material e dele são emitidos elétrons, sendo a energia do fóton, da onda incidente, a soma da energia necessária para arrancar o elétron designada como função trabalho, mais a energia cinética do elétron. Para que se consiga arrancar um elétron, é necessário que a energia do fóton seja no mínimo igual à função trabalho (EISBERG e RESNICK, 1983).

A energia do fóton é dada por:

$$
E=h \cdot \mathrm{v}
$$

onde $h$ é a constante de Planck e vé a frequência do fóton.

\section{$>$ Espalhamento Incoerente ou Efeito Compton}

Quando um conjunto de fótons colide com elétrons livres de um alvo, observa-se por resultados experimentais que qualitativamente existe uma variação no comprimento de onda. Isto se deve ao fato desses fótons sofrerem espalhamento transferindo parte de sua energia $E=h \cdot v$ para os elétrons; com isso, a frequência $v$ torna-se menor $v^{\prime}$ e, por conseguinte, o comprimento de onda que era $\lambda$ torna-se maior $\lambda^{\prime}$. A variação do comprimento de onda está de acordo com a equação do deslocamento Compton, $\Delta$ (EISBERG e RESNICK, 1983): 


$$
\Delta=\lambda^{\prime}-\lambda
$$

\section{Espalhamento Coerente ou Rayleigh}

No caso do espalhamento coerente, o fóton incide sobre um meio e interage com o elétron sem transferir sua energia para o meio. O elétron sofre apenas um pequeno recuo, sendo a direção da radiação espalhada próxima da radiação incidente (EISBERG e RESNICK, 1983).

\section{Produção e Aniquilação de Pares}

Este processo ocorre quando um fóton de alta energia $h \cdot v$ colide com um núcleo do átomo e perde toda a sua energia ao criar um par elétronpósitron. O par é criado na natureza pelos raios cósmicos, ou por fótons de Bremsstrahlung. $\mathrm{O}$ efeito contrário também pode ocorrer, quando um pósitron interage com um elétron; eles se aniquilam e formam na maioria das vezes dois fótons que se movem em sentidos contrários. Mais difícil, mas que também pode ocorrer é a formação de três fótons (EISBERG e RESNICK, 1983). 


\subsection{Grandezas e Unidades da Radiação}

De acordo com o relatório técnico CRU 57 (ICRUa, 1998) são definidos dois tipos de grandezas para o uso em proteção radiológica: as grandezas de proteção, que foram definidas pelo ICRP e as grandezas operacionais definidas pelo ICRU. Serão apresentadas as grandezas físicas: exposição, dose absorvida e kerma; as grandezas de proteção: equivalente de dose, dose equivalente, dose efetiva; e as grandezas operacionais: equivalente de dose ambiente, equivalente de dose direcional e equivalente de dose pessoal.

\subsubsection{Grandezas físicas}

Neste caso, serão definidas apenas as grandezas relevantes para este trabalho.

\section{Exposição}

Exposição, $X$, é definida como a razão entre o valor absoluto de todas as cargas elétricas dos íons de um mesmo sinal produzidos no ar, $d Q$, quando todos os elétrons liberados por fótons num elemento de volume de ar, representado pela massa $d m$, são completamente freados no ar (ICRUb, 1998).

$$
X=\frac{d Q}{d m}
$$

A unidade é dada por coulomb por quilograma $\left(\frac{C}{k g}\right)$, sendo que a unidade antiga era o roentgen $(R)$, onde $1 R=2,58 \cdot 10^{-4} \frac{C}{\mathrm{~kg}}$. 


\section{Dose Absorvida}

A grandeza dose absorvida descreve a energia cedida a matéria, que é descrita pela radiação incidente em um volume, incluindo as partículas carregadas e não carregadas menos a radiação que sai do volume, tanto as partículas carregadas como as não carregadas, sendo que a energia cedida inclui a energia da massa de repouso do núcleo e de partículas elementares. Esta grandeza é dada pela razão da energia média cedida, $d \overline{E_{C}}$, por unidade de massa, $d m$ (IAEA, 2000):

$$
D=\frac{d \overline{E_{C}}}{d m}
$$

A unidade de dose absorvida é joule por quilograma $\left(\frac{J}{k g}\right)$ ou gray $(G y)$.

\section{Kerma}

Kerma, $\mathrm{K}$, é uma grandeza que descreve o processo de dissipação de energia de partículas não carregadas transferida para uma partícula carregada; é a razão da energia transferida, $d E_{T R}$, por unidade de massa, $d m$ (ICRUb, 1998).

$$
K=\frac{d E_{T R}}{d m}
$$

A unidade de kerma no ar é dada por joule por quilograma $\left(\frac{\mathrm{J}}{\mathrm{kg}}\right)$ ou gray (Gy). 


\subsubsection{Grandezas de Proteção}

\section{Equivalente de dose}

Esta grandeza foi criada para limitar a exposição de radiação a que um trabalhador poderia se submeter. Ela é dada pelo produto da dose absorvida em um ponto no tecido, $D$, pelo fator de qualidade, $Q$, que está relacionado ao tipo e à qualidade física das radiações (ICRUa, 1998).

$$
H=D \cdot Q
$$

A unidade desta grandeza é joule por quilograma $\left(\frac{J}{k g}\right)$ ou sievert $(S v)$.

\section{Dose Equivalente}

Determina-se a dose equivalente total, $H_{T}$, em um tecido irradiado por diversos tipos de radiação, $R$, pela soma do produto entre a dose absorvida média, $\bar{D}$, no tecido, $T$, pelo fator de ponderação da radiação $W_{R}$ (ICRUa, 1998).

$$
H_{T}=\sum_{R} \bar{D} \cdot W_{R}
$$

A unidade desta grandeza é joule por quilograma $\left(\frac{J}{k g}\right)$ ou sievert $(S v)$. 


\section{Dose Efetiva}

A dose efetiva, $E$, é a soma das doses equivalentes, $H_{T}$, em cada órgão ou tecido, multiplicada pelo respectivo fator de ponderação do tecido, $W_{T}$ (ICRUa, 1998).

$$
E=\sum H_{T} \cdot W_{T}
$$

A unidade desta grandeza é joule por quilograma $\left(\frac{J}{k g}\right)$ ou sievert $(S v)$.

\subsubsection{Grandezas Operacionais}

Para elaborar o conceito das grandezas operacionais, foi selecionado um objeto simulador que fosse próximo a um simulador de corpo humano denominado de esfera ICRU. De uma esfera de $30 \mathrm{~cm}$ de diâmetro de uma esfera de tecido equivalente, consiste de um material composto por $72,6 \%$ de oxigênio, $11,1 \%$ de carbono, $10,1 \%$ de hidrogênio e 2,6\% de nitrogênio, tendo no total um material com densidade de $1 \mathrm{~g} / \mathrm{cm}^{3}$. Em monitoração de área, é comum utilizar campos de radiação hipotéticos, derivados de campos de radiação real. Surgem os termos de campos alinhados e expandidos como campos hipotéticos. No campo expandido, a fluência, e a distribuição direcional e energética possuem um mesmo valor em relação a um campo real no ponto de referência, dentro de um volume de interesse. No campo expandido e alinhado, a fluência e a distribuição energética comportam-se da mesma forma que o campo expandido, com exceção de que a fluência é unidirecional. A Figura 2.1 mostra os esquemas do campo real e do campo expandido (IAEA, 2000). 
(a)

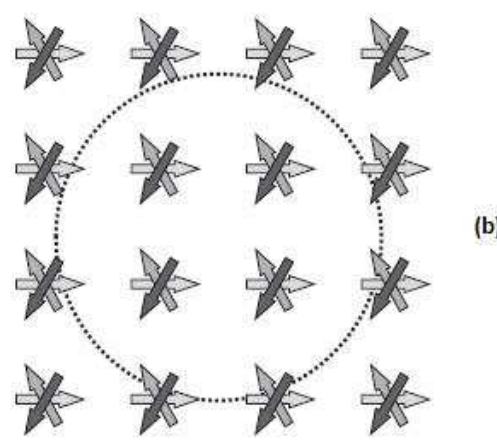

(b)

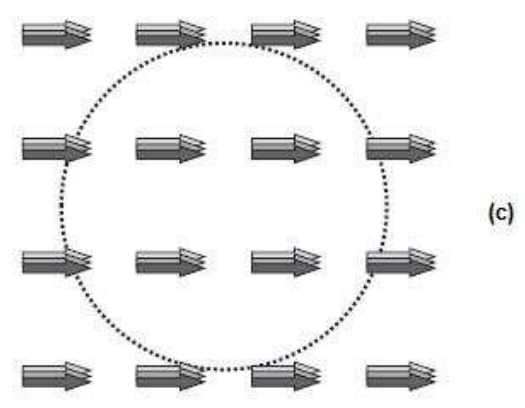

Figura 2.1 Representação esquemática dos campos reais e hipotéticos. Campo real (a) com a fluência em um ponto $P$ composto de três direções; campo expandido do ponto P (b) em um círculo; campo expandido e alinhado (c) do ponto $\mathrm{P}$ em um círculo (IAEA, 2000).

\section{Equivalente de dose ambiente $H^{*}(d)$}

O equivalente de dose ambiente, para um ponto em um campo de radiação, é o equivalente de dose que deveria ser produzido por um campo expandido e alinhado, em uma esfera ICRU, numa profundidade $d$, de raio oposto à direção do campo alinhado. Para uma radiação fortemente penetrante d será considerada uma profundidade de $10 \mathrm{~mm}$, aplicando a notação de $H^{*}(10)$. Para uma radiação fracamente penetrante, a profundidade será de 0,07 $\mathrm{mm}$ para a pele e $3 \mathrm{~mm}$ para os olhos, aplicando-se a notação análoga ao de $10 \mathrm{~mm}: H^{*}(0,07)$ e $H^{*}(3)$ (IAEA, 2000; CNEN, 2005).

A unidade de equivalente de dose ambiente é joule por quilograma $\left(\frac{\mathrm{J}}{\mathrm{kg}}\right)$ ou sievert $(S v)$. 


\section{Equivalente de dose direcional $H^{\prime}(d, \Omega)$}

O equivalente de dose direcional, em um ponto do campo de radiação, é a dose equivalente que seria produzida por um campo expandido, em uma esfera ICRU, à profundidade $d$ e de direção $\Omega$. Para uma radiação fracamente penetrante, a profundidade é de $0,07 \mathrm{~mm}$ para pele e de $3 \mathrm{~mm}$ para os olhos, tendo respectivamente as notações de $H^{\prime}(0,07, \Omega)$ e $H^{\prime}(0,03, \Omega)$. No caso particular do campo ser unidirecional, a direção pode ser especificada em termos de um ângulo, $\alpha$, entre o raio oposto ao campo incidente e a direção especificada $\vec{\Omega}$ (IAEA, 2000, CNEN, 2005).

A unidade de equivalente de dose direcional é joule por quilograma $\left(\frac{J}{k g}\right)$ ou sievert $(S v)$.

\section{Equivalente de dose pessoal $H_{p}(d)$}

Equivalente de dose pessoal é o equivalente de dose em uma esfera ICRU à profundidade $d$ em um ponto específico do corpo. Para uma radiação fracamente penetrante, a profundidade recomendada é de $0,07 \mathrm{~mm}$ para a pele, a grandeza apresenta a notação de $H_{p}(0,07)$ e para os olhos uma profundidade de $3 \mathrm{~mm}$, com notação de $H_{p}(3)$. Para radiação fortemente penetrante a profundidade é de $10 \mathrm{~mm}$, com notação de $H_{p}(10)$. Para a calibração de dosímetros pessoais nesta grandeza é necessário utilizar objetos simuladores (IAEA, 2000, CNEN, 2005).

A unidade de equivalente de dose pessoal é joule por quilograma $\left(\frac{\mathrm{J}}{\mathrm{kg}}\right)$ ou sievert $(S v)$. 


\subsubsection{Coeficientes de conversão}

A maioria dos detectores de radiação para monitoração de área mede nas grandezas taxa de exposição e taxa de kerma no ar. Para se obter as medidas nas novas grandezas operacionais, a publicação ISO 4037-3 (ISO, 1999) determina para cada tipo de radiação coeficientes de conversão das grandezas físicas para as grandezas operacionais. De acordo com o trabalho, as grandezas a serem convertidas serão a de equivalente de dose ambiente para radiação gama no caso das fontes de ${ }^{137} \mathrm{Cs}$ e ${ }^{60} \mathrm{Co}$ e radiação $X$, nível radioproteção, para feixes estreitos. Na Tabela 2.1 são apresentados os coeficientes de conversão para equivalente de dose ambiente e na Figura 2.2 está demonstrado o comportamento dos coeficientes de conversão em uma curva, para as grandezas equivalente de dose ambiente e equivalente de dose direcional.

Wagner e colaboradores publicaram resultados de um estudo em que se determinou pela fórmula empírica de Wagner (Equação 2.9) os coeficientes de conversão de kerma no ar para equivalente de dose ambiente para radiação $X$, nível radioproteção, e para radiação gama no caso das fontes radioativas de ${ }^{137} \mathrm{Cs}$ e ${ }^{60} \mathrm{Co}$. Nota-se pouca variação nas medidas obtidas dos coeficientes de conversão pela equação empírica de Wagner em relação aos valores determinados pela norma ISO 4037-3 (ISO, 1999). A variação mínima foi de 0,01\% para a energia média de $83 \mathrm{keV}$ e a máxima variação foi de $13,04 \%$ para a energia média de $20 \mathrm{keV}$ (WAGNER et. al, 1985). Entretanto, a norma ISO 4037-3 afirma que para energias baixas de até $30 \mathrm{keV}$ existe uma variação de energia que pode influenciar substancialmente os valores dos coeficientes de conversão (ISO, 1999).

$$
\frac{H^{*}(10)}{K_{a r}}=\frac{x}{a \cdot x^{2}+b x+c}+d \cdot \arctan (g \cdot x)\left(\frac{S v}{G y}\right)
$$


Determina-se a variável $x$ por meio da equação $x=\ln \frac{E}{E_{o}}$, sendo que a energia do fóton, $E$, pode variar de $20 \mathrm{keV}<E<10 \mathrm{MeV}$ e a energia inicial apresentar o valor de $E_{o}=9,85 \mathrm{keV}$; as componentes da equação de segundo grau possuem valores de $a=1,465, b=-4,414, c=4,789$ e os valores das outras incógnitas da equação são $d=0,7006 g=0,6519$ (WAGNER et. al, 1985).

Tabela 2.1 Coeficientes de conversão de kerma no ar para equivalente de dose ambiente, de acordo com a norma ISO 4037-3 (ISO, 1999).

\begin{tabular}{c|c|c|c} 
Radiação & $\begin{array}{c}\text { Qualidade de } \\
\text { radiação }\end{array}$ & $\begin{array}{c}\text { Coeficiente } \\
\text { de } \\
\text { fonte-detector }\end{array}$ & $\begin{array}{c}\text { conversão } \\
\boldsymbol{H}^{*}(\mathbf{1 0})\end{array}\left(\frac{\boldsymbol{S} \boldsymbol{v}}{\boldsymbol{G} \boldsymbol{y}}\right)$ \\
\hline \multirow{4}{*}{$\mathbf{X}$} & $\mathrm{N}-25$ & $1,0-2,0$ & 0,52 \\
& $\mathrm{~N}-30$ & $1,0-2,0$ & 0,80 \\
& $\mathrm{~N}-40$ & $1,0-3,0$ & 1,18 \\
& $\mathrm{~N}-60$ & $1,0-3,0$ & 1,59 \\
& $\mathrm{~N}-80$ & $1,0-3,0$ & 1,73 \\
& $\mathrm{~N}-100$ & $1,0-3,0$ & 1,71 \\
& $\mathrm{~N}-120$ & $1,0-3,0$ & 1,64 \\
& $\mathrm{~N}-150$ & $1,0-3,0$ & 1,58 \\
& $\mathrm{~N}-200$ & $1,0-3,0$ & 1,46 \\
& $\mathrm{~N}-250$ & $1,0-3,0$ & 1,39 \\
& $\mathrm{~N}-300$ & $1,0-3,0$ & 1,35 \\
\hline \multirow{2}{*}{ Gama } & $\mathrm{S}-\mathrm{Cs}$ & $1,0-3,0$ & 1,20 \\
& $\mathrm{~S}-\mathrm{Co}$ & $1,0-3,0$ & 1,16 \\
\hline
\end{tabular}




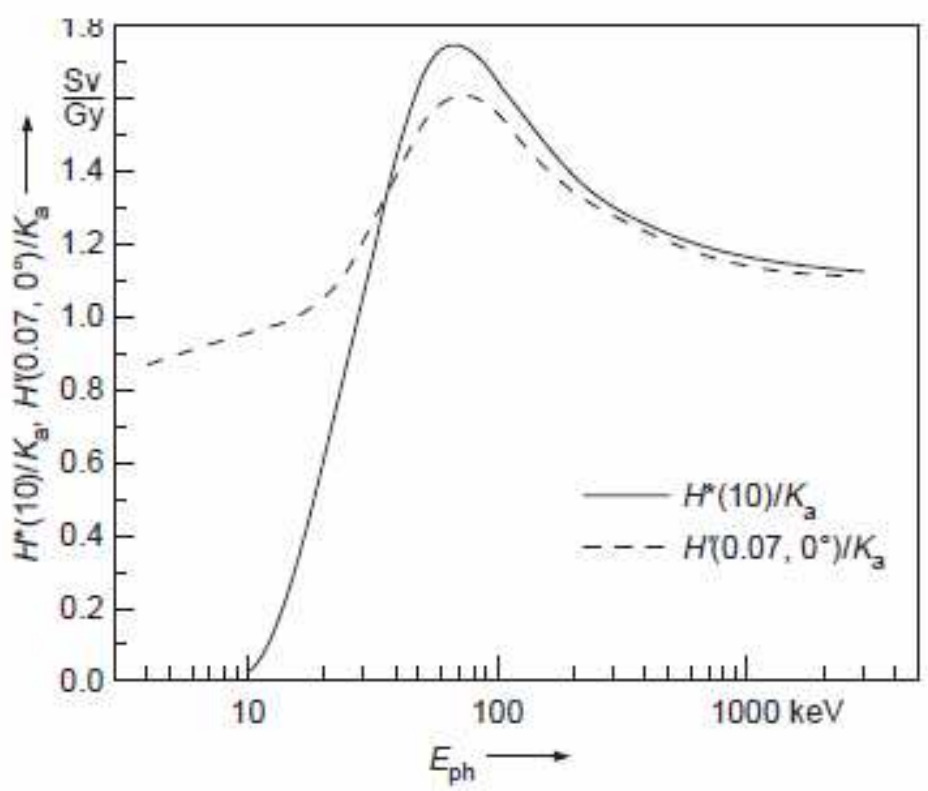

Figura 2.2 Coeficiente de conversão de $H^{*}(10)$ e $H^{\prime}(0,07, \Omega)$ em relação à kerma no ar, $K_{a}$, em função da energia do fóton, $E_{p h}$, sendo a direção $\Omega$ a $0^{0}$ (IAEA, 2000).

\subsection{Detectores de radiação}

Neste item serão descritos somente os detectores utilizados neste trabalho. Dentre eles, estão os detectores a gás e os detectores semicondutores. Os detectores a gás, de acordo com a tensão aplicada entre o anodo e o catodo, podem ser qualificados como câmaras de ionização, detectores Geiger-Müller ou contadores proporcionais, que têm como princípio de funcionamento a produção de íons pela interação da radiação ionizante com um volume de um gás, como pode ser observado na Figura 2.3. 


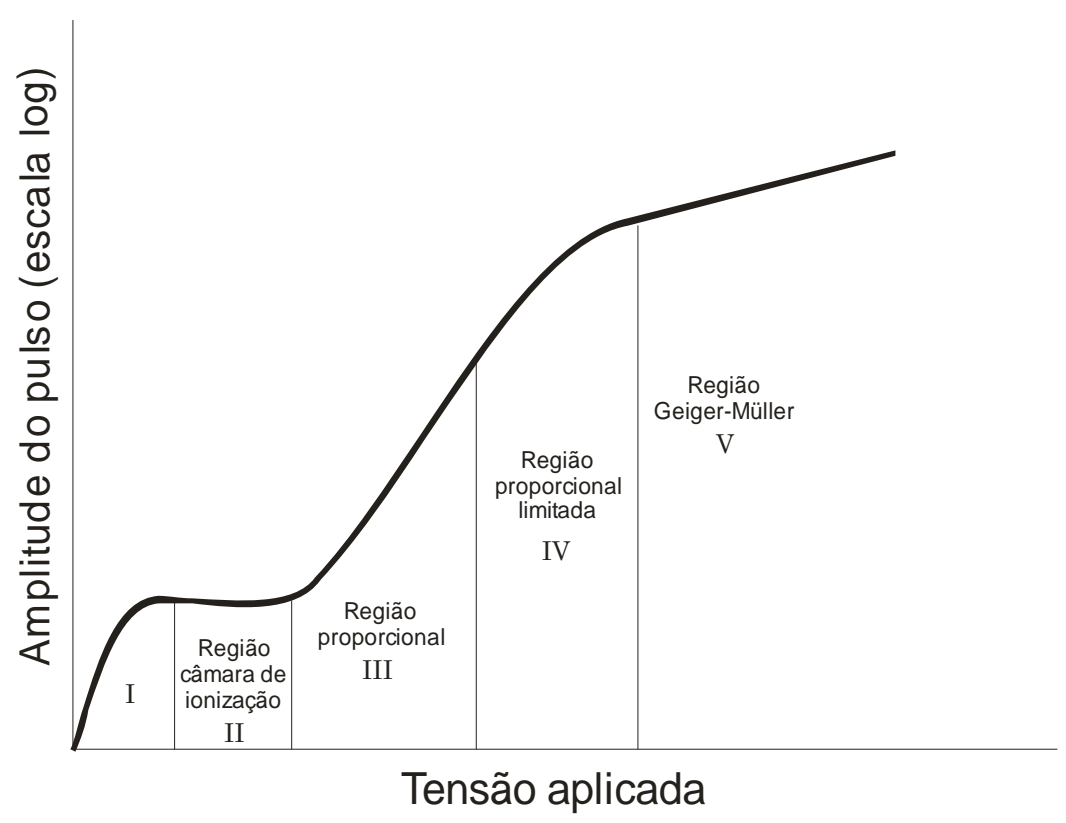

Figura 2.3 Regiões de operação para detectores preenchidos a gás. A amplitude do pulso (em escala logarítima) está apresentada na curva em função da tensão aplicada (KNOLL, 1989).

\section{> Câmara de ionização}

Uma câmara de ionização é um detector simples, preenchido a gás. Tem como princípio de funcionamento, sob um feixe de radiação, a coleta de todas as cargas criadas pela ionização direta do gás por meio da aplicação de um campo elétrico. As câmaras de ionização podem ser operadas no modo corrente ou no modo pulsado. A maioria delas é utilizada no modo corrente, com dispositivo dc. Este fato diferencia as câmaras de ionização em relação aos detectores Geiger-Müller e detectores proporcionais, que são sempre utilizados no modo pulsado. A geração dos pares de íons ocorre quando uma partícula carregada com alta velocidade passa pelo gás; ela produz interações que excitam e ionizam moléculas ao longo do caminho. Quando a molécula neutra é ionizada, ela produz um íon positivo e um elétron livre, que constituem um par de íons. A geometria da câmara de ionização pode variar de acordo com o tipo de aplicação, desde que o campo elétrico mantenha a produção de íons no gás. Um exemplo de câmara de ionização é a câmara de ionização de placas paralelas, com o campo elétrico uniforme entre as placas. De acordo 
com a Figura 2.3 a região de operação da câmara de ionização é a região II (KNOLL, 1989).

\section{Detector Geiger-Müller}

O detector Geiger-Müller é um dos tipos de detectores mais antigos que existe, foi introduzido por Geiger e Müller em 1928; é um tipo de detector simples, de baixo custo, entretanto ele apenas detecta a radiação incidente. De acordo com a Figura 2.3, a região de operação do detector é a região V. Os detectores Geiger-Müller e os detectores proporcionais multiplicam o número de cargas originalmente formados pelos pares de íons criados ao longo do caminho da radiação, formando uma avalanche de ionizações; entretanto, em um contador proporcional cada elétron produz uma avalanche que é independente das outras avalanches formadas por outros elétrons. No tubo do detector Geiger-Müller a tensão elétrica é substancialmente alta, o que aumenta a intensidade de cada avalanche; com isso uma avalanche pode criar uma outra avalanche em uma outra posição dentro do tudo do detector Geiger-Müller. Dependendo do valor da tensão do campo elétrico, provoca-se um número crescente de avalanches, de forma exponencial, em um curto intervalo de tempo. O detector Geiger-Müller não consegue discriminar energias, porque os pulsos de saída do tubo têm a mesma amplitude, independente do número de pares de íons produzidos originalmente; por isso ele não qualifica o tipo de radiação (KNOLL, 1989).

\section{Detector semicondutor}

Os detectores de radiação formados por semicondutores são detectores sólidos bem menores do que os detectores a gás, devido a sua densidade ser 1.000 vezes maior que a densidade de um gás. A propriedade de um semicondutor baseia-se na teoria de bandas de energia. Os cristais sólidos possuem níveis de energias denominadas bandas permitidas separadas por bandas proibidas; o tamanho da banda proibida determina se 0 cristal é um condutor, semicondutor ou um isolante. As bandas que são completamente ocupadas por elétrons ligados ao cristal são denominadas 
bandas de valência e as bandas parcialmente preenchidas por elétrons são denominadas bandas de condução; neste caso, os elétrons são considerados livres, podendo transitar pelo cristal. A condutividade de um semicondutor se dá pela passagem dos elétrons da banda de valência para a banda de condução. $O$ intervalo de energia típico, neste caso, entre a banda de valência e a de condução é de $1 \mathrm{eV}$ (KNOLL, 1989).

\subsection{Sistema de radiação $X$}

Um sistema de radiação $\mathrm{X}$ tem como componente principal o tudo de raios $\mathrm{X}$ que é composto por estruturas, dentre elas o catodo e o anodo. Estes componentes estão localizados dentro de uma ampola de vidro a vácuo. No catodo está o filamento pequeno em espiral de tungstênio. Quando este filamento é aquecido, elétrons são liberados na superfície do tungstênio. Como o anodo consiste na parte positiva em relação ao catodo, os elétrons seguem em direção ao anodo, constituindo uma corrente de elétrons, que é medido em miliampères. A corrente do tubo depende da tensão aplicada ao equipamento. Para tensões baixas, a corrente também é pequena devido a uma nuvem de elétrons que se forma ao redor do filamento de tungstênio. Ao se aumentar a tensão entre o anodo e o catodo, esta nuvem é desfeita, fazendo com que os elétrons sigam em direção ao anodo. Quando os elétrons com alta velocidade são freados pelo anodo, a radiação $X$ é emitida em todas as direções como mostrado na Figura 2.4. Grande parte da radiação $X$ é absorvida pelo alvo, uma pequena parte é focalizada em um cone, componente do tubo que emite $o$ feixe primário. Para a tensão utilizada em radiologia radiodiagnostica, apenas $1 \%$ da energia é convertida em radiação X; os $99 \%$ restantes da energia são transformados em calor (JOHNS, 1983). 


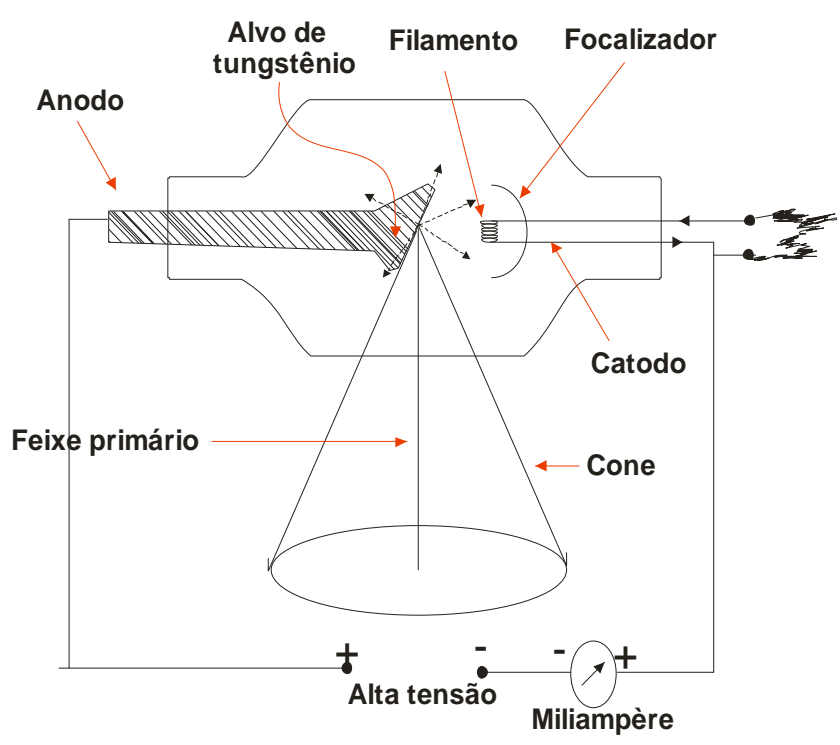

Figura 2.4 Tubo de raios $X$ e seus componentes (JOHNS, 1983).

\subsection{Incertezas}

As medições efetuadas pelo operador podem ser diretas e indiretas. Quando apenas um sistema de medição está envolvido, considera-se sistema de medição direta. (Como exemplo, tem-se a medição do comprimento de uma placa com uma régua ou a tensão elétrica de uma pilha com um voltímetro digital.) Nas medições indiretas são envolvidas várias operações matemáticas para se calcular o valor do mensurando. (Como por exemplo, tem-se a área de um terreno retangular que é obtida pelo produto do comprimento e da largura) (GONÇALVES e SOUSA, 2008).

O processo de medição envolve vários fatores como o meio de medição, o procedimento de medição, o operador, o método de medição e a definição do mensurando. Esses fatores podem gerar incertezas na medição. É importante avaliar a influência que o fator terá sobre o valor de medição e obter um fator de correção. Este fator pode ser obtido de acordo com procedimentos estatísticos ou não-estatísticos. A incerteza do tipo A faz parte de um procedimento estatístico; é estimada a partir de medições repetidas do mesmo mensurando. Quando o mensurando é variável, a incerteza do tipo A é obtida de acordo com a Equação 2.10 que é a incerteza-padrão (GONÇALVES e SOUSA, 2008): 


$$
u(A)=\sqrt{\frac{\sum_{k=1}^{n}\left(I_{K}-\bar{I}\right)^{2}}{n-1}},
$$

onde $u(A)$ descreve a incerteza-padrão das indicações calculadas a partir de "n" medições repetidas, sendo $I_{k}$ a k-ésima indicação, $\bar{I}$ a média de "n" indicações e $n$ o número de indicações repetidas efetuadas.

O número de graus de liberdade é determinado pelo número de dados, $n$, utilizados para calcular o desvio padrão. Os procedimentos não-estatísticos são denominados incertezas do tipo B e de acordo com as informações sobe 0 fenômeno, calcula-se a incerteza de acordo com a distribuição de probabilidade utilizada para modelar as fontes de incerteza. A distribuição utilizada para este trabalho foi a uniforme ou retangular (GONÇALVES e SOUSA, 2008).

Sendo a variável a a metade da resolução, a incerteza $u(B)$ da distribuição do tipo B é caracterizada pela equação 2.11 .

$$
u(B)=\frac{a}{\sqrt{3}}
$$

A incerteza combinada, $U_{c}$, é calculada pelo desvio padrão da ação combinada das componentes aleatórias de todas as fontes de incerteza, $u$, que afetam um processo de medição. Esta incerteza está caracterizada pela Equação 2.12.

$$
U_{c}^{2}=u_{1}^{2}+u_{2}^{2}+\ldots+u_{n}
$$

A incerteza expandida, $U$, resulta da ação conjunta de todas as fontes de incerteza, de acordo com a norma internacional ISO 15572 (ISO, 1998) e a nacional Edição Brasileira (ISO, 2003), o fator de abrangência é k=2 para o nível de confiança de $95,45 \%$.

$$
U=U_{c} \cdot k
$$




\section{Materiais e Métodos}

Nesta seção serão apresentadas as características dos monitores de radiação estudados, os sistemas e as fontes de radiação utilizadas, o método de calibração para a determinação dos fatores de calibração, e os métodos dos estudos de dependência angular e energética dos monitores calibrados.

O método de calibração utilizado nos sistemas de radiação gama e beta foi o "uso de campos de radiação conhecidos". Neste caso o instrumento é colocado alinhado com o campo de radiação de acordo com a Figura 3.1.

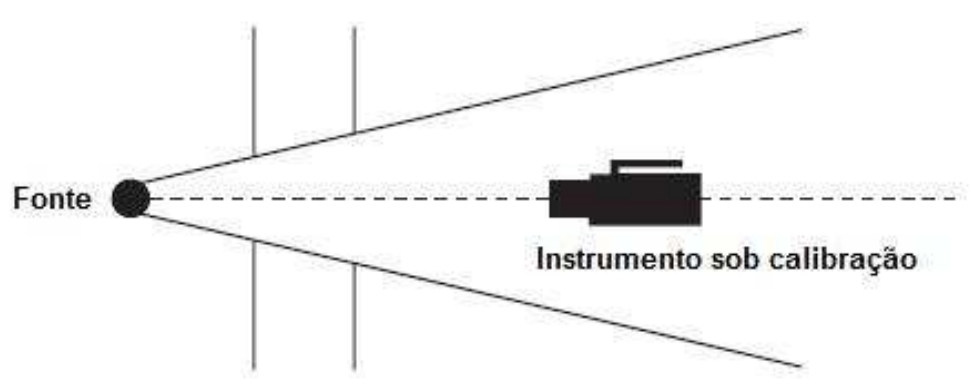

Figura 3.1 Método de calibração para campos conhecidos (IAEA, 2000).

No sistema de radiação $X$, o método de calibração utilizado é o método da substituição. Inicialmente é colocado o instrumento de referência alinhado ao campo e são tomadas as medições. Depois o instrumento de referência é substituído pelo instrumento que se deseja calibrar, de acordo com a Figura 3.2. Depois mede-se novamente 0 campo de radiação com 0 instrumento de referência. A taxa de kerma no ar é determinada utilizando-se a média dos valores obtidos nestas duas situações.

No caso do Laboratório de Calibração de Instrumentos do IPEN (LCI), a câmara monitora localizada à frente do tubo de raios $X$ no feixe foi calibrada contra $O$ instrumento de referência (padrão secundário), tornando-se uma câmara monitora padrão de trabalho. 


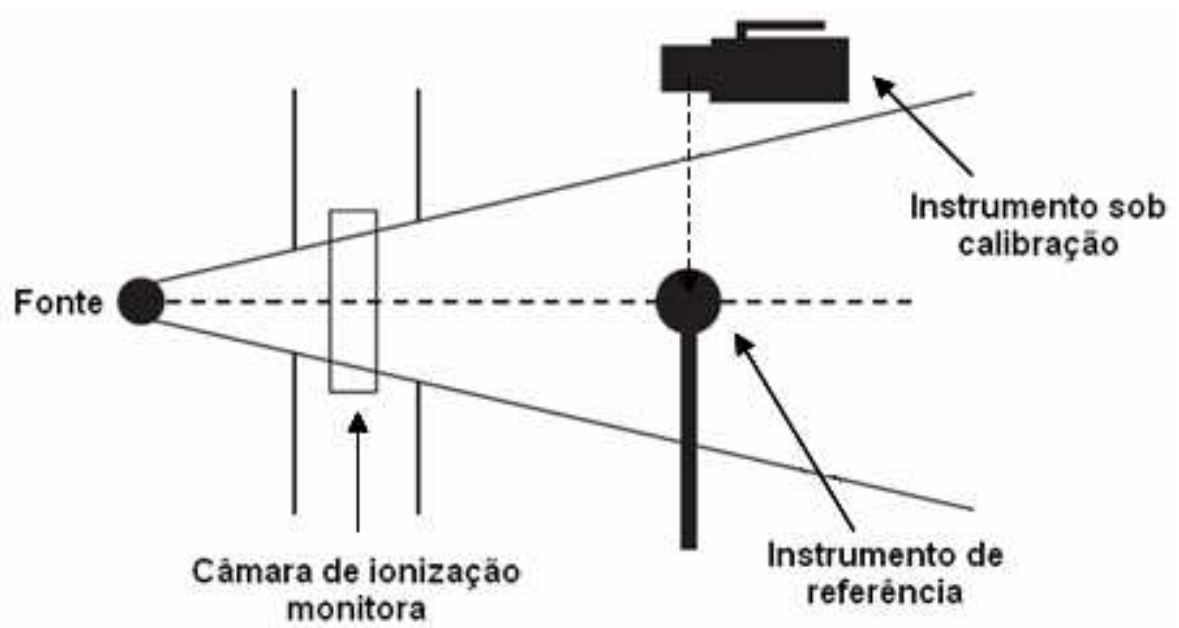

Figura 3.2 Método de calibração por substituição (IAEA, 2000).

O fator de calibração, para os dois métodos de calibração apresentados, é determinado pela razão entre o valor verdadeiro convencional (de referência), $V_{c}$, e o valor medido (indicado) $M$ pelo detector de radiação, de acordo com a Equação 3.1. Os detectores foram calibrados em campos padronizados de radiação gama, beta e $X($ IAEA, 2000).

$$
f_{c}=\frac{V_{c}}{M}
$$

A calibração de instrumentos requer alguns cuidados, como a preparação do laboratório para as condições favoráveis. De acordo com a norma internacional (ISO, 1997), as condições ambientais de referência de um laboratório de calibração devem ser: temperatura entre $18{ }^{\circ} \mathrm{C}$ e $22{ }^{\circ} \mathrm{C}$, pressão entre $86 \mathrm{kPa}$ e $106 \mathrm{kPa}$ e umidade relativa do ar entre 50\% e 75\%; e deve-se dar atenção aos processos de manipulação dos instrumentos a serem calibrados (neste caso os monitores de radiação), que começam desde 0 momento em que se recebe cada instrumento, o período em que se obtêm as medições, a elaboração do certificado de calibração até a devolução dos detectores aos proprietários. Tudo deve estar de acordo com: as normas internacionais ou nacionais; o certificado de calibração; e manual de instrução do fabricante do instrumento. 
Os monitores de radiação encaminhados ao Laboratório de Calibração de Instrumentos (LCI) do IPEN são calibrados por técnicos treinados e com conhecimento em proteção radiológica. Primeiramente é realizada uma inspeção visual do equipamento, certificando-se das condições físicas dele. $O$ equipamento é ligado na função de leitura da bateria para verificação nominal das baterias por meio do próprio galvanômetro ou display, ou ainda por meio de um multímetro. Caso haja necessidade, é realizada uma substituição de baterias. $O$ instrumento é ligado por aproximadamente quinze minutos para a sua estabilização, antes do início dos testes. Existe, nos laboratórios de radiação gama, beta e $\mathrm{X}$, uma planilha eletrônica em que são preenchidas as informações sobre a data de calibração, a marca, o modelo e o número de série do instrumento e da sonda, quando existir. Também é anotado o nome da empresa responsável pelo instrumento, assim como o número do protocolo no qual o instrumento é identificado pelo LCl.

Para a calibração, o instrumento é posicionado alinhado ao campo de radiação, é selecionada a grandeza de referência de acordo o equipamento sob calibração, e é selecionada a unidade de cada escala. São anotadas as condições ambientes de temperatura, pressão e umidade.

Após a calibração, é emitido um certificado de calibração; se o equipamento for aprovado em todos os testes realizados nos laboratórios, ele recebe uma etiqueta de calibração do $\mathrm{LCl}$. Os testes de calibração serão especificados de acordo com o tipo de radiação em que o instrumento é calibrado.

\subsection{Equipamentos utilizados no estudo}

Os monitores de área estudados neste trabalho estão descritos nas Tabelas 3.1 e 3.2 . 
Tabela 3.1 Características dos detectores Geiger-Müller e semicondutores estudados neste trabalho.

\begin{tabular}{|c|c|c|c|c|c|c|}
\hline Marca & Modelo & Código & Detecta & Faixa de leitura & Escalas & Sonda \\
\hline \multicolumn{7}{|c|}{ Detectores Geiger-Müller } \\
\hline Automess & 6150 AD 5 & A1...A4 & gama, $X$ & $0.01 \mu \mathrm{Sv} / \mathrm{h}$ a $9.99 \mathrm{mSv} / \mathrm{h}$ & digital & interna \\
\hline Bicron & 50TM & B1 e B2 & $\alpha, \beta$, gama, $X$ & 0 a $50 \mathrm{mR} / \mathrm{h}$ & X 1; X 10; X 100 & externa \\
\hline \multirow{3}{*}{ Dosimeter } & 3100 & C1...C5 & gama, $X$ & 0 a $3,5 \mathrm{R} / \mathrm{h}$ & digital & externa \\
\hline & 3007-A & D1 & $\alpha, \beta$, gama, $X$ & $\begin{array}{l}0 \text { a } 50 \mathrm{mR} / \mathrm{h} \text { ou } \\
0 \text { a } 500 \mu \mathrm{Sv} / \mathrm{h}\end{array}$ & X 1; X 10; X 100 & externa \\
\hline & $3090-3$ & E1 e E2 & gama, $X$ & $\begin{array}{c}1 \mathrm{mR} / \mathrm{h} \text { a } 100 \mathrm{R} / \mathrm{h} \text { ou } \\
0,01 \mathrm{mSv} / \mathrm{h} \text { a } 1000 \mathrm{mSv} / \mathrm{h}\end{array}$ & Única escala & interna \\
\hline Eberline & E 520 & F1 & $\beta$, gama & 0 a 2 R/h & $\begin{array}{c}X 0.1 ; X 1 ; \\
X 10 ; X 100 ; X 1000 \\
\end{array}$ & externa \\
\hline $\begin{array}{l}\text { Eurami } \\
\text { Group }\end{array}$ & $\begin{array}{c}\text { Gamma } \\
\text { Scout }\end{array}$ & G1...G7 & $\alpha, \beta$, gama & $0,01 \mathrm{mSv} / \mathrm{h}$ a $1000 \mu \mathrm{Sv} / \mathrm{h}$ & digital & interna \\
\hline \multirow{4}{*}{ Ludlum } & 3 & H1...H5 & $\alpha, \beta$, gama & $\begin{array}{c}0 \text { a } 0,2 \mathrm{R} / \mathrm{h} \\
\text { ou } 0 \mathrm{mSv} \text { a } 2 \mathrm{mSv}\end{array}$ & $\begin{array}{r}X 0.1 ; X 1 ; \\
\text { X10; X } 100\end{array}$ & externa \\
\hline & 5 & $|1 \ldots| 6$. & gama & 0 a 2 R/h & $\begin{array}{r}\mathrm{X} 0.1, \mathrm{X} 1, \mathrm{X} 10 \\
\mathrm{X} 100, \mathrm{X} 1000 \\
\end{array}$ & interna \\
\hline & 6 & J1 & gama & 0 a $0,01 \mathrm{~Sv} / \mathrm{h}$ ou 0 a $1 \mathrm{R} / \mathrm{h}$ & X 1; X 10; X 100 & interna \\
\hline & $2241-2$ & K1 & $\alpha, \beta$, gama & $0.0 \mu R / h$ a $9999 R / h$ & digital & externa \\
\hline \multirow{4}{*}{ MRA } & G1-E & L1...L18 & $\alpha, \beta$, gama, $X$ & $\begin{array}{l}0,02 \mathrm{mR} / \mathrm{h} \text { a } 1 \mathrm{R} / \mathrm{h} \text { ou } \\
0,2 \mu \mathrm{Sv} / \mathrm{h} \text { a } 10 \mathrm{mSv} / \mathrm{h}\end{array}$ & $\begin{array}{c}X 1 ; \times 10 ; \\
\times 100 ; \times 1000 \\
\end{array}$ & externa \\
\hline & G1-I & M1 & gama, $X$ & 0 a $1 \mathrm{R} / \mathrm{h}$ & $X 1 ; X 10 ;$ X 100 & interna \\
\hline & G1-Plus & N1...N3 & $\alpha, \beta$, gama & $0,02 \mathrm{mR} / \mathrm{h}$ a $1 \mathrm{R} / \mathrm{h}$ & $\begin{array}{c}X 1 ; \times 10 ; \\
\times 100 ; \times 1000 \\
\end{array}$ & externa \\
\hline & GP 500 & 01 & $\alpha, \beta$, gama, $X$ & $\begin{array}{c}0,05 \mu S v / h \text { a } 10 \mathrm{mSv} / \mathrm{h} \text { ou } \\
5 \mu \mathrm{R} / \mathrm{h} \text { a } 1 \mathrm{R} / \mathrm{h}\end{array}$ & $\begin{array}{c}X 1 ; \times 10 \\
\times 100 ; \times 1000 \\
\end{array}$ & externa \\
\hline $\begin{array}{c}\text { NDS } \\
\text { Products }\end{array}$ & ND 2000 & P1 & gama, $X$ & 0 a $1 \mathrm{R} / \mathrm{h}$ & X 1; X 10; X 100 & interna \\
\hline \multirow{2}{*}{$\begin{array}{c}\mathrm{SE} \\
\text { International }\end{array}$} & 4 & Q1...Q9 & $\alpha, \beta$, gama & $\begin{array}{l}0 \text { a } 0,5 \mathrm{R} / \mathrm{h} \text { ou } \\
0 \text { a } 500 \mu \mathrm{Sv} / \mathrm{h}\end{array}$ & X 1; X 10; X 100 & interna \\
\hline & mc1k & R1...R3 & gama, $X$ & $\begin{array}{l}0 \text { a } 1 \mathrm{R} / \mathrm{h} \text { ou } \\
0 \text { a } 10 \mathrm{mSv} / \mathrm{h}\end{array}$ & $\begin{array}{c}X 1, X 10, X 100 \\
\text { X1000. }\end{array}$ & interna \\
\hline \multirow{3}{*}{ Victoreen } & 290 & S1 e S2 & $\alpha, \beta$, gama, $X$ & 0 a 1 R/h & 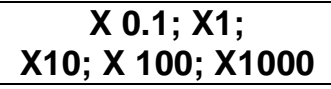 & externa \\
\hline & 491 & T1 & $\alpha, \beta$, gama & 0 a $0,1 \mathrm{R} / \mathrm{h}$ & $\begin{array}{c}X 0.1 ; X 1 ; X 10 \\
\quad \times 100 \\
\end{array}$ & externa \\
\hline & 493 & U1 & $\beta$, gama, $X$ & 0 a $1 \mathrm{R} / \mathrm{h}$ & $\begin{array}{c}\text { X 0.1; X1; X10; } \\
\text { X } 100 \\
\end{array}$ & externa \\
\hline $\begin{array}{l}\text { Thermo } \\
\text { Eberline }\end{array}$ & $\begin{array}{c}\text { FH } 41 \text { B- } \\
10\end{array}$ & V1 & gama & $0.1 \mu \mathrm{Sv} / \mathrm{h}$ a $10 \mathrm{mSv} / \mathrm{h}$ & digital & interna \\
\hline \multicolumn{7}{|c|}{ Detectores Semicondutores } \\
\hline \multirow{2}{*}{ Rados } & Rad-60S & $X 1 \ldots X 3$ & gama, $X$ & $5 \mu \mathrm{Sv} / \mathrm{h}$ a $3 \mathrm{~Sv} / \mathrm{h}$ & digital & interna \\
\hline & Rad-50S & Y1 & gama,X & $5 \mu \mathrm{Sv} / \mathrm{h}$ a $3 \mathrm{~Sv} / \mathrm{h}$ & digital & interna \\
\hline
\end{tabular}


Tabela 3.2 Características das câmaras de ionização estudadas neste trabalho.

\begin{tabular}{|c|c|c|c|c|c|c|}
\hline Marca & Modelo & Código & Detecta & Faixa de Leitura & Escalas & $\begin{array}{c}\text { Volume } \\
\left(\mathrm{cm}^{3}\right)\end{array}$ \\
\hline \multicolumn{7}{|c|}{ Câmaras de lonização } \\
\hline Babyline & 81 & $A^{\prime} 1$ & $\beta$, gama, $X$ & 0 a $100 \mathrm{R} / \mathrm{h}$ & $\begin{array}{c}X 1 ; \times 10 ; \\
\times 100\end{array}$ & 515 \\
\hline $\begin{array}{c}\text { Fluke } \\
\text { Biomedical }\end{array}$ & 451 B-ryr & $B^{\prime} 1 \ldots B^{\prime} 4$ & $\beta$, gama, $X$ & $\begin{array}{l}0 \text { a } 50 \mathrm{R} / \mathrm{h} \text { ou } \\
0 \text { a } 500 \mathrm{mSv} / \mathrm{h}\end{array}$ & digital & 349 \\
\hline \multirow{2}{*}{ Inovision } & 451P & C'1...C'3 & gama, $X$ & $\begin{array}{l}0 \text { a } 5 \mathrm{R} / \mathrm{h} \text { ou } \\
0 \text { a } 50 \mathrm{mSv} / \mathrm{h}\end{array}$ & digital & 300 \\
\hline & 451B & D'1 e D'2 & $\alpha, \boldsymbol{\beta}$, gama, $X$ & $\begin{array}{l}0 \text { a } 50 \mathrm{R} / \mathrm{h} \text { ou } \\
0 \text { a } 500 \mathrm{mSv} / \mathrm{h}\end{array}$ & digital & 349 \\
\hline \multirow{3}{*}{ Radcal } & $\begin{array}{c}9010 / 10 \times 5- \\
1800 \\
\end{array}$ & E'1...E'4 & $\mathbf{x}$ & $0,01 \mathrm{mR} / \mathrm{h}$ a $65 \mathrm{R} / \mathrm{h}$ & digital & 1800 \\
\hline & $\begin{array}{c}9015 / 10 \times 5- \\
1800\end{array}$ & $F^{\prime} 1$ & $\mathbf{x}$ & $0,01 \mathrm{mR} / \mathrm{h}$ a $65 \mathrm{R} / \mathrm{h}$ & digital & 1800 \\
\hline & $\begin{array}{c}2026 \mathrm{C} / 20 \times 6- \\
180 \\
\end{array}$ & G'1 & $\mathbf{x}$ & $1 \mathrm{mR} / \mathrm{h}$ a $1 \mathrm{kR} / \mathrm{h}$ & digital & 180 \\
\hline \multirow[t]{3}{*}{ Step } & RGD 27091 & H'1 & gama, $X$ & $\begin{array}{c}20 \mathrm{mSv} / \mathrm{h} \text { a } 2000 \\
\mathrm{mSv} / \mathrm{h}\end{array}$ & digital & 600 \\
\hline & 450 & l'1 & $\alpha, \beta$, gama, $X$ & 0 a $50 \mathrm{R} / \mathrm{h}$ & digital & 200 \\
\hline & $450 B$ & J'1 & gama, $X$ & $\begin{array}{c}0 \text { a } 50 \mathrm{R} / \mathrm{h} \text { ou } \\
0 \text { a } 0,5 \mathrm{~Sv} / \mathrm{h}\end{array}$ & digital & 349 \\
\hline \multirow[t]{3}{*}{ Victoreen } & $450 \mathrm{P}$ & K'1...K’3 & gama, $X$ & 0 a $5 \mathrm{R} / \mathrm{h}$ & digital & 300 \\
\hline & 451B & L'1...L'8 & $\alpha, \beta$, gama, $X$ & 0 a $50 \mathrm{R} / \mathrm{h}$ & digital & 349 \\
\hline & $451 P$ & M'1...M'4 & gama, $X$ & $\begin{array}{l}0 \text { a } 5 \mathrm{R} / \mathrm{h} \text { ou } \\
0 \text { a } 50 \mathrm{mSv} / \mathrm{h}\end{array}$ & digital & 300 \\
\hline
\end{tabular}

A maioria dos detectores é rotineiramente calibrada com radiação gama; apenas os instrumentos com janela ou com sonda externa podem ser calibrados com radiação beta. No caso da radiação $X$, somente as câmaras de ionização puderam ser calibradas no sistema de radiação $X$ utilizado no $\mathrm{LCl}$. Nas Figuras 3.3, 3.4 e 3.5 são apresentados alguns dos monitores de radioproteção de marcas e modelos diferentes estudados neste trabalho. 


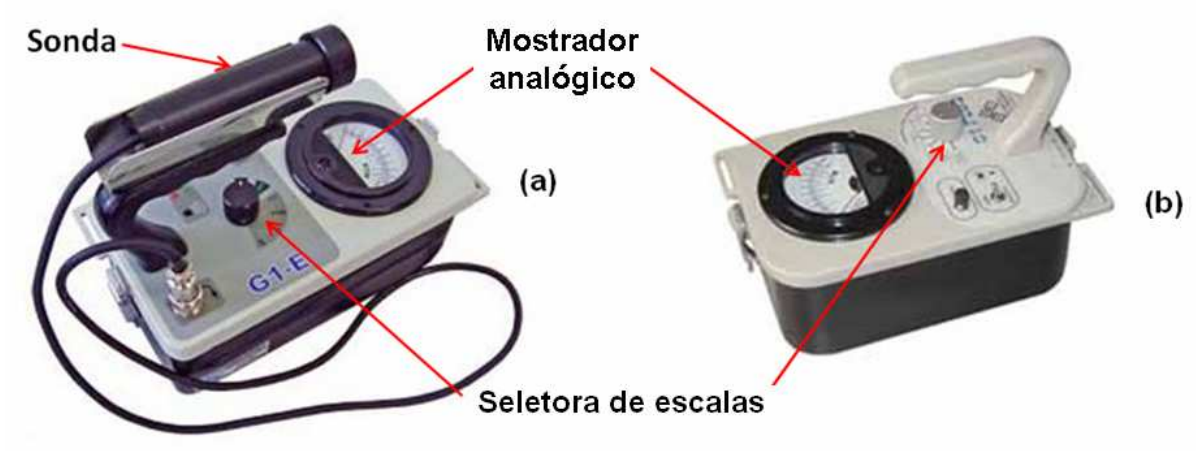

Figura 3.3 Detectores Geiger-Müller da marca MRA com sonda externa, modelo G1-E (a) e com sonda interna, modelo G1-I (b).
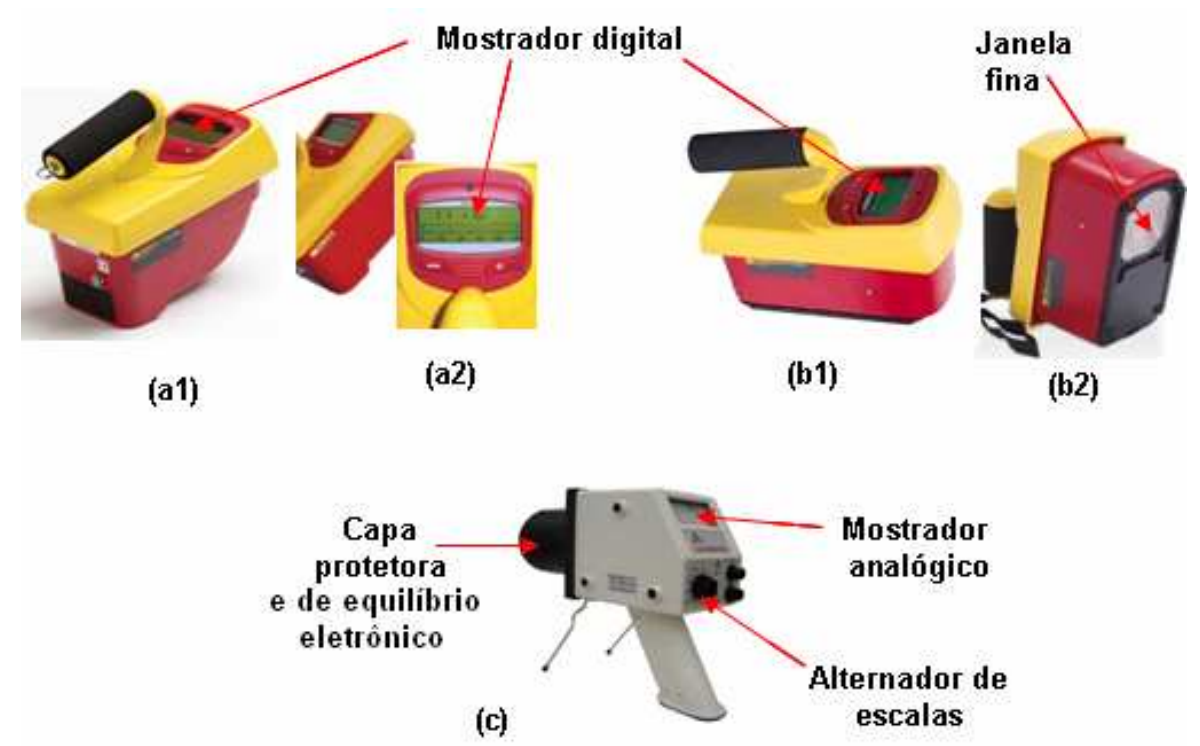

Figura 3.4 Câmaras de ionização: marca Fluke Biomedical, modelo 451P, (a1) e (a2); marca Victoreen, modelo 451B, (b1) e (b2); marca Babyline, modelo 81 (c).

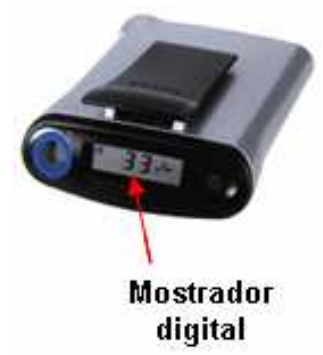

Figura 3.5 Detector semicondutor, marca Rados, modelo Rad-60S. 


\subsubsection{Sistemas auxiliares}

Para controle e registro das condições ambientais do laboratório foram utilizados sistemas auxiliares e acessórios: barômetros, termômetros, higrômetros, desumificadores e climatizadores de ambiente.

Foi construído pela Oficina Mecânica do IPEN um suporte de placas de acrílico apresentado na Figura 3.6 para exercer a função de um goniômetro para os estudos da dependência angular nos aparelhos calibrados com radiação gama, beta e X. Este goniômetro é constituído por uma parte retangular de $21 \mathrm{~cm}$ de largura, $30 \mathrm{~cm}$ de comprimento e $1 \mathrm{~cm}$ de espessura; sobre a placa de acrílico retangular foi acoplada uma placa circular de acrílico de $26 \mathrm{~cm}$ de diâmetro e $1 \mathrm{~cm}$ de espessura; o centro do círculo foi posicionado no centro do retângulo.

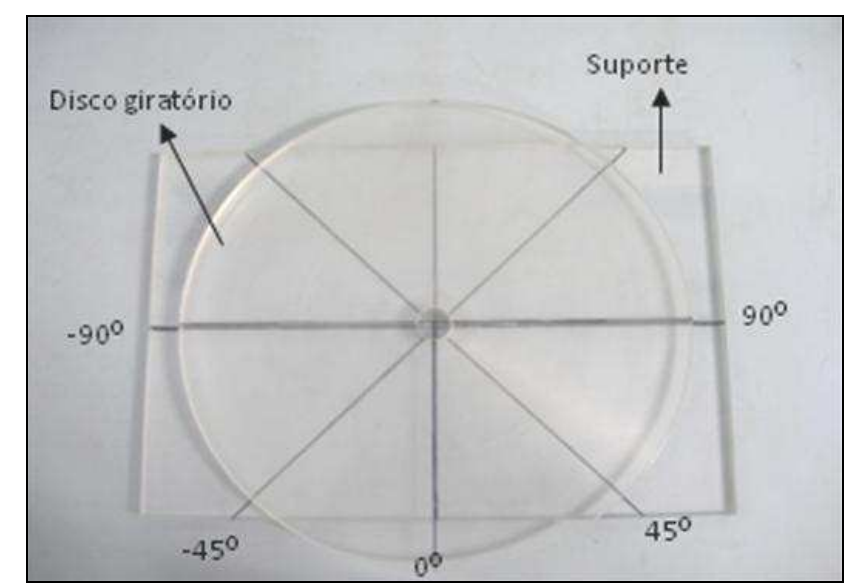

Figura 3.6 Suporte de placas de acrílico para estudo de dependência angular dos monitores de área.

\subsection{Sistemas e fontes de radiação utilizados}

\subsubsection{Sistema de radiação gama}

O irradiador gama utilizado neste trabalho foi fabricado pela Steuerungstechnik \& Strahlenschutz $\mathrm{GmbH}$, modelo OB85, Alemanha. Este sistema possui absorvedores com formato de discos de chumbo com $22 \mathrm{~mm}$ de 
espessura, modelo ํo OB85.10.2, $18 \mathrm{~mm}$ de espessura, modelo $\mathrm{n}^{\circ}$ OB85.10.3 e $26 \mathrm{~mm}$ de espessura, este último fabricado no IPEN. O absorvedor no OB85.10.2 corresponde a um fator de atenuação de 1/10; em conjunto com - absorvedor no OB85.10.3, o fator de atenuação alcança 1/100 e aproximadamente $1 / 1000$ utilizando todos os três absorvedores em conjunto para a fonte de ${ }^{137} \mathrm{Cs}$. Os absorvedores permitem a redução da intensidade dos feixes, possibilitando a calibração de monitores portáteis em diversas escalas. Este sistema de radiação gama contém fontes radioativas de ${ }^{60} \mathrm{Co},{ }^{137} \mathrm{Cs},{ }^{226} \mathrm{Ra}$ e ${ }^{241} \mathrm{Am}$, fabricadas pela Amersham Buchler, Alemanha. O deslocamento da fonte para o ponto central do irradiador é realizado por um sistema pneumático e um painel de controle, localizado na sala de comando, externamente à sala do irradiador.

A dosimetria dos feixes de radiação gama para fontes de ${ }^{60} \mathrm{Co} \mathrm{e}{ }^{137} \mathrm{Cs}$ foi realizada por uma câmara de ionização da marca PTW, modelo W32002 - 035 calibrada pelo Instituto de Radioproteção e Dosimetria, IRD, Rio de Janeiro (IRD, 2007). Para este trabalho foram utilizadas apenas duas fontes de radiação gama, apresentadas na Tabela 3.3.

O sistema de radiação gama pode ser observado na Figura 3.7.

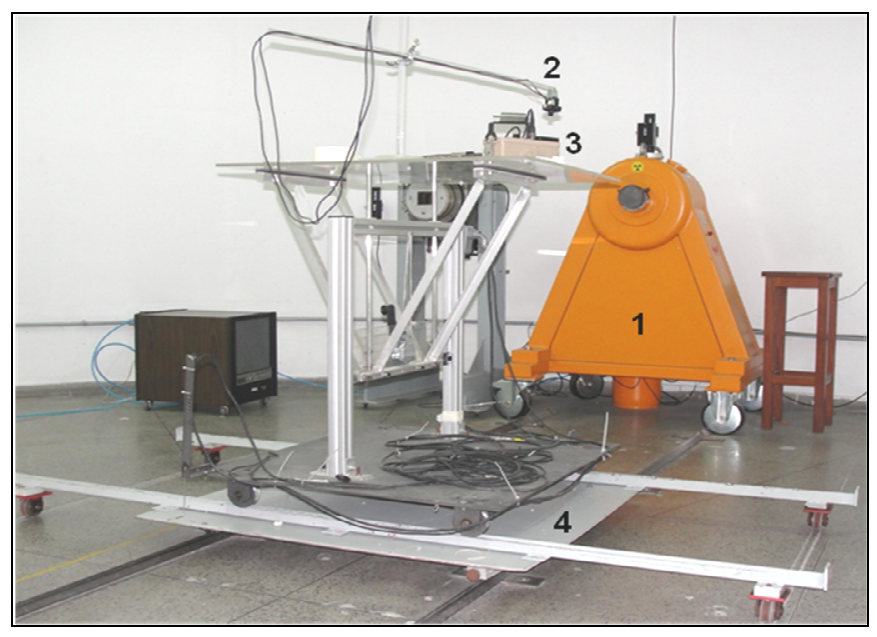

(a)

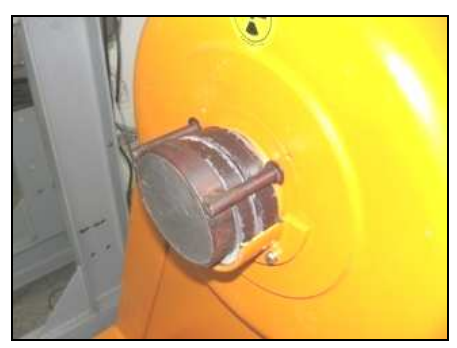

(b)

Figura 3.7 Sistema de radiação gama (a), 1-Irradiador, 2-Câmera de circuito interno, 3-Detector Geiger-Müler, 4-Sistema com trilho que determina a distância de calibração; Filtros atenuadores $(b)$. 
Tabela 3.3 Características das fontes do sistema de radiação gama utilizadas neste trabalho.

\begin{tabular}{|c|c|c|c|c|c|}
\hline \multirow[t]{2}{*}{ Fonte } & \multirow{2}{*}{$\begin{array}{l}\text { Energia média } \\
\qquad(\mathrm{keV})\end{array}$} & \multicolumn{2}{|c|}{$\begin{array}{c}\text { Taxa de kerma no ar } \\
(G y / h)\end{array}$} & \multirow[t]{2}{*}{ Data } & \multirow{2}{*}{$\begin{array}{l}\text { Meia vida } \\
\quad(\text { anos })\end{array}$} \\
\hline & & Mínimo & Máximo & & \\
\hline${ }^{137} \mathrm{Cs}$ & 662 & $1,92 \times 10^{-5}$ & $2,73 \times 10^{-2}$ & $22 / 02 / 05$ & 30,00 \\
\hline${ }^{60} \mathrm{Co}$ & 1.250 & $3,80 \times 10^{-5}$ & $2,10 \times 10^{-3}$ & $23 / 02 / 05$ & 5,26 \\
\hline
\end{tabular}

\subsubsection{Sistema de radiação beta}

Após a calibração dos monitores em feixes de radiação gama, uma parte dos detectores e das câmaras de ionização foi testada em feixes padronizados de radiação beta, de um sistema padrão secundário, marca Buchler, modelo BSS1. Este sistema possui quatro fontes: duas fontes de ${ }^{90} \mathrm{Sr}+{ }^{90} \mathrm{Y}$ com atividades diferentes, uma fonte de ${ }^{204} \mathrm{Tl}$ e uma fonte de ${ }^{147} \mathrm{Pm}$, com certificados de calibração do laboratório primário alemão Physikalisch-Technische Bundesanstalt (PTB). Para o estudo dos detectores com fontes de radiação beta, neste trabalho foram utilizadas apenas as fontes de radiação de ${ }^{90} \mathrm{Sr}+{ }^{90} \mathrm{Y}$ e de ${ }^{204} \mathrm{TI}$, porque a atividade da fonte de ${ }^{147} \mathrm{Pm}$ já está muito baixa; portanto os detectores não conseguem medir a quantidade de radiação emitida por esta fonte. $O$ sistema de radiação beta é um sistema padrão secundário, ou seja de referência.

O irradiador beta modelo BSS1 é constituído por um suporte onde são posicionadas as fontes e os filtros atenuadores que homogenizam o campo de radiação, como mostrado na Figura 3.8. Todas as fontes foram calibradas utilizando-se os filtros uniformizadores de campo de radiação. As características das fontes utilizadas estão descritas na Tabela 3.4 e seus componentes apresentados na Figura 3.9. 


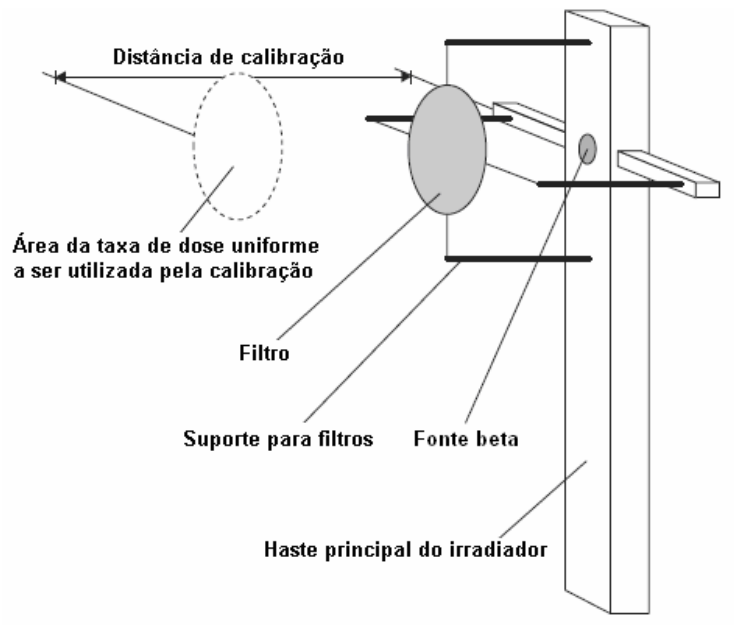

Figura 3.8 Sistema irradiador beta (AMBROSI et al, 2007).

Tabela 3.4 Características das fontes de radiação beta do sistema padrão secundário BSS1 do LCl utilizadas neste trabalho.

\begin{tabular}{ccccc}
\hline Fonte & Atividade & $\begin{array}{c}\text { Data da } \\
\text { calibração } \\
(\mathbf{P T B})\end{array}$ & $\begin{array}{c}\text { Distância } \\
\text { fonte - detector } \\
(\mathrm{cm})\end{array}$ & $\begin{array}{c}\text { Taxa de dose } \\
\text { absorvida no ar } \\
\left(\mu G y \cdot \mathbf{s}^{-1}\right)\end{array}$ \\
\hline${ }^{90} \mathrm{Sr}+{ }^{90} \mathrm{Y}$ & 74,07 & $12 / 1 / 1981$ & 30 & 1,71 \\
\hline${ }^{204} \mathrm{TI}$ & 18,50 & $09 / 06 / 1990$ & 30 & 0,41 \\
\hline
\end{tabular}

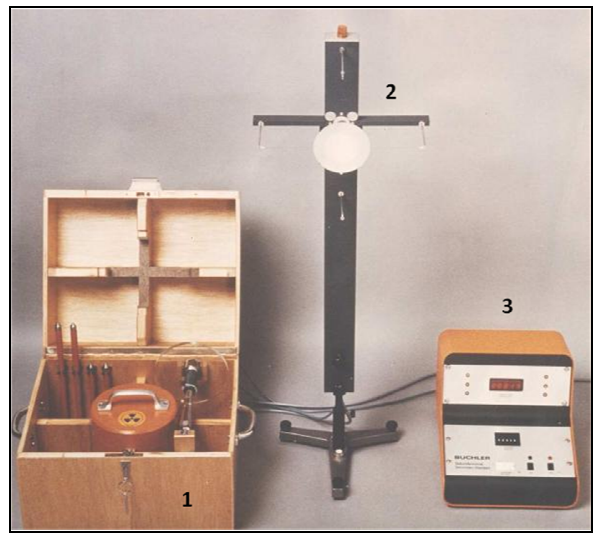

Figura 3.9 Sistema de radiação beta: 1-Blindagem das fontes, 2-Sistema do irradiador, 3-Sistema de acionamento das fontes. 


\subsubsection{Sistema de radiação $X$}

O sistema de radiação $X$ do $\mathrm{LCl}$ é formado por um equipamento Pantak/Seifert, modelo ISOVOLT HS 160, com energias médias de $48 \mathrm{keV}$ a $118 \mathrm{keV}$. As características dos feixes de radiação $X$ estão descritas na Tabela 3.5 e seus componentes estão apresentados na Figura 3.10.

A dosimetria dos feixes de radiação $\mathrm{X}$, nível radioproteção, foi realizada utilizando-se a câmara de ionização PTW, modelo w32002 - 35, calibrada no laboratório alemão, Deutscher Kalibrierdienst (DKD), Alemanha, para as qualidades de radiação N-60, N-80, N-100, N-150, N-200 e N-250 (DKD, 1995).

Tabela 3.5 Características dos feixes de radiação $X$ (série de espectro estreito), nível radioproteção, estabelecidos no sistema Pantak/Seifert do LCl.

\begin{tabular}{|c|c|c|c|c|}
\hline $\begin{array}{l}\text { Qualidade da } \\
\text { radiação } \\
(I S O-4037)\end{array}$ & $\begin{array}{c}\text { Energia } \\
\text { média } \\
(k e V)\end{array}$ & $\begin{array}{c}\text { Tensão } \\
(k V)\end{array}$ & $\begin{array}{c}\text { Camada } \\
\text { semi-redutora } \\
(C S R) \\
(\mathrm{mmCu})\end{array}$ & $\begin{array}{l}\text { Filtração adicional } \\
\qquad(\mathrm{mm})\end{array}$ \\
\hline $\mathrm{N}-60$ & 48 & 60 & 0,25 & $0,6(\mathrm{Cu})+4 \mathrm{~mm}(\mathrm{Al})$ \\
\hline $\mathrm{N}-80$ & 65 & 80 & 0,61 & $2,0(\mathrm{Cu})+4 \mathrm{~mm}(\mathrm{Al})$ \\
\hline $\mathrm{N}-100$ & 83 & 100 & 1,14 & $5,0(\mathrm{Cu})+4 \mathrm{~mm}(\mathrm{Al})$ \\
\hline$N-150$ & 118 & 150 & 2,40 & $2,5(\mathrm{Sn})+4 \mathrm{~mm}(\mathrm{Al})$ \\
\hline
\end{tabular}




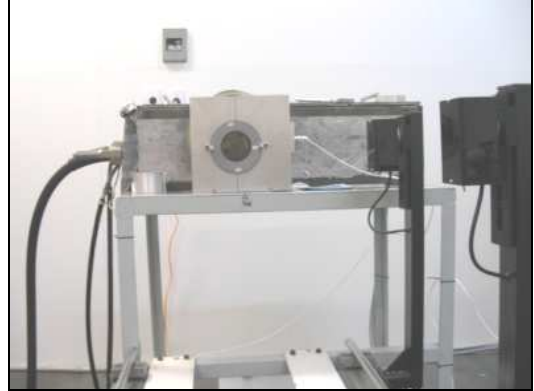

(a)

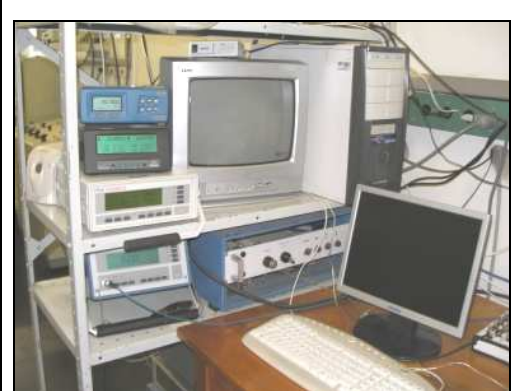

(b)

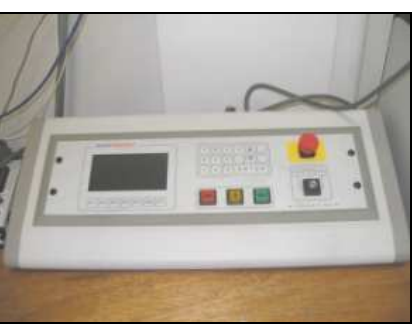

(c)

Figura 3.10 Sistema de radiação X: Tubo de raios $X(a)$, Sala de controle e de anotações das medições (b), Sistema de acionamento da radiação $X(c)$.

De acordo com o certificado de calibração do LCl para radiação gama, beta e $\mathrm{X}$, as incertezas padrão foram calculadas de acordo com as recomendações da Edição Brasileira da ISO (ISO, 2003) para um fator de abrangência k=2 e nível de confiança de 95,45\%. 


\section{Resultados}

Alguns dos detectores Geiger-Müller e das câmaras de ionização estudados neste trabalho foram testados nos três campos de radiação: gama, beta e X. Os detectores semicondutores foram testados somente em campos de radiação gama. A partir dos valores verdadeiros convencionais e das medições obtidas pelos instrumentos sob calibração, foi possível obter os fatores de calibração e assim analisar a dependência energética de cada instrumento. Também foi determinada a dependência angular de alguns monitores de radiação por meio das medições realizadas para ângulos de $0^{\circ} \mathrm{e}$ $\pm 45^{\circ}$, de acordo com as Equações 4.1 e 4.2. Além disso, foi ainda analisada a dependência angular em gráficos, por meio das medições obtidas por alguns instrumentos em relação ao ângulo de incidência da radiação, com uma varredura de $0^{\circ}$ a $\pm 90^{\circ}$.

$$
\begin{gathered}
D A_{+}=\frac{M\left(0^{0}\right)}{M\left(+45^{0}\right)} \\
D A_{-}=\frac{M\left(0^{0}\right)}{M\left(-45^{0}\right)}
\end{gathered}
$$

\subsection{Testes com radiação gama}

Foram testados/calibrados com radiação gama sessenta e seis detectores Geiger-Müller de onze marcas e vinte e dois modelos diferentes; quatro detectores semicondutores de dois modelos de uma mesma marca; e treze câmaras de ionização de três marcas e oito modelos diferentes.

\subsubsection{Resposta dos detectores de radiação}

No procedimento de calibração de um monitor portátil, primeiramente é medida a radiação de fundo e são anotadas as condições ambientais de temperatura, pressão e umidade. Caso o instrumento permita ajustes, eles são 
feitos a $50 \%$ das escalas ou de acordo com a recomendação do fabricante, em campo de radiação gama. São tomadas dez medições para cada posição de irradiação correspondente a um valor de escala do instrumento e é calculada a média das medições. O valor médio obtido, a $50 \%$ do valor da escala, não deverá variar mais que $\pm 10 \%$ em relação ao valor verdadeiro convencional, $V_{c}$, (IRD, 2004), determinado pela distância entre a fonte e o ponto de calibração e pela data de calibração. Quando o detector de radiação é calibrado a $20 \%$ ou a $80 \%$ do valor da escala, o valor médio das medidas pode variar até $\pm 20 \%$ em relação ao valor verdadeiro convencional (IRD, 2004). Essas comparações são realizadas em relação à fonte de referência de ${ }^{137} \mathrm{Cs}$. Após a coleta de dados para a fonte de césio, é escolhida uma das escalas e são tomadas dez medições em campo de radiação de cobalto e, a seguir, é obtida a média dos valores.

Foram calculadas as incertezas das medições obtidas na calibração de cada instrumento de acordo com a Tabela 4.1. Foram estimadas três incertezas do tipo B; a primeira incerteza foi determinada para 0 posicionamento do centro do volume sensor do tubo Geiger-Müller, com uma régua em $\mathrm{cm}$; a segunda incerteza foi calculada para a distância do instrumento em relação à fonte, dada pela incerteza do ponteiro em relação à escala (fita métrica metálica) sob o trilho; e a terceira incerteza foi determinada para as câmaras de ionização, cujas respostas necessitam de correção para as condições normais de temperatura e pressão.

De acordo com o tipo do aparelho, as medições foram obtidas nas grandezas taxa de exposição ou taxa de equivalente de dose. Os instrumentos representados pelo código $G$ indicam suas medições na grandeza taxa de equivalente de dose para fótons e foram convertidos para taxa de equivalente de dose ambiente, $H^{*}(10)$. 
Tabela 4.1 Incertezas das medições dos instrumentos testados/calibrados com radiação gama.

\begin{tabular}{ccccc}
\hline & Fontes de incerteza & Resolução & $\mathbf{1 / 2}$ Resolução & Incerteza \\
\hline Símbolo & Descrição & & & \\
\hline $\boldsymbol{u}(\boldsymbol{A})$ & $\begin{array}{c}\text { Incerteza tipo A/ } \\
\text { Desvio padrão }\end{array}$ & - & - & - \\
\hline $\boldsymbol{u}(\boldsymbol{B})_{\boldsymbol{I}}$ & $\begin{array}{c}\text { Incerteza tipo B/ } \\
\text { Posição do tubo Geiger-Müller (cm) }\end{array}$ & $0,50 \times 10^{-1}$ & $0,25 \times 10^{-1}$ & $0,14 \times 10^{-1}$ \\
\hline $\boldsymbol{u}(\boldsymbol{B})_{2}$ & $\begin{array}{c}\text { Incerteza tipo B/ } \\
\text { Distância fonte-detector (cm) }\end{array}$ & $1,00 \times 10^{-1}$ & $0,50 \times 10^{-1}$ & $0,29 \times 10^{-1}$ \\
\hline $\boldsymbol{u}(\boldsymbol{B})_{3}$ & $\begin{array}{c}\text { Incerteza tipo B/ } \\
\text { Fator de temperatura e pressão }\end{array}$ & $0,02 \times 10^{-1}$ & $0,01 \times 10^{-1}$ & $5,77 \times 10^{-4}$ \\
\hline $\boldsymbol{u}\left(\boldsymbol{V}_{\boldsymbol{c}}\right)$ & $\begin{array}{c}\text { Incerteza do valor } \\
\text { verdadeiro convencional }\end{array}$ & - & - & - \\
\hline $\boldsymbol{u}(\boldsymbol{f} \boldsymbol{c})$ & Incerteza do fator de calibração & - & - & - \\
\hline $\boldsymbol{U}_{\boldsymbol{c}}$ & Incerteza combinada & - & - & - \\
\hline $\boldsymbol{U}$ & Incerteza expandida & - & - & - \\
\hline
\end{tabular}

Na Tabela 4.2 são apresentadas as médias das medições, M, obtidas das respostas dos detectores Geiger-Müller e dos detectores semicondutores representados pelos códigos $\mathrm{X}$ e $\mathrm{Y}$. No caso das câmaras de ionização, suas medições são apresentadas na Tabela 4.3.

As medições apresentadas nas Tabelas 4.2 e 4.3 foram obtidas a $50 \%$ das escalas dos instrumentos, com exceção dos detectores de radiação de códigos E1 e V1, presentes na Tabela 4.2, que apresentam medições a 80\% da escala do instrumento. 
Tabela 4.2 Resposta dos detectores Geiger-Müller (códigos A-V) e de detectores semicondutores (códigos $X$ e $Y$ ), para radiação gama.

\begin{tabular}{|c|c|c|c|c|c|c|c|c|c|}
\hline \multicolumn{10}{|c|}{$V_{c}:$ Valor verdadeiro convencional } \\
\hline \multicolumn{10}{|c|}{$M:$ Valor médio das medições } \\
\hline Código & $\begin{array}{c}V_{c} \\
\left({ }^{137} C s\right.\end{array}$ & $\begin{array}{r}u\left(V_{c}\right) \\
\left.e^{60} \mathrm{Co}\right)\end{array}$ & $\begin{array}{c}M \\
\left({ }^{137} C s\right)\end{array}$ & $\begin{array}{c}U_{c} \\
\left({ }^{137} C s\right)\end{array}$ & $\begin{array}{c}u(A) \\
\left({ }^{137} C s\right)\end{array}$ & $\begin{array}{c}M \\
\left({ }^{60} \mathrm{Co}\right)\end{array}$ & $\begin{array}{c}U_{c} \\
\left({ }^{60} \mathrm{Co}\right)\end{array}$ & $\begin{array}{c}u(A) \\
\left({ }^{60} \mathrm{Co}\right)\end{array}$ & Unidade \\
\hline A1 & 500,00 & 7,60 & 509,30 & 7,93 & 7,93 & 534,50 & 3,54 & 3,54 & $\mu \mathrm{Sv} / \mathrm{h}$ \\
\hline A2 & 500,00 & 7,60 & 476,80 & 4,36 & 4,36 & 546,00 & 3,53 & 3,53 & $\mu S v / h$ \\
\hline A3 & 500,00 & 7,60 & 503,70 & 3,60 & 3,60 & 554,30 & 5,85 & 5,85 & $\mu \mathrm{Sv} / \mathrm{h}$ \\
\hline A4 & 500,00 & 7,62 & 498,00 & 2,64 & 2,64 & 569,50 & 3,52 & 3,52 & $\mu \mathrm{Sv} / \mathrm{h}$ \\
\hline B1 & 25,00 & 0,38 & 25,40 & 0,17 & 0,16 & 30,30 & 0,22 & 0,21 & $\mathrm{mR} / \mathrm{h}$ \\
\hline B2 & 25,00 & 0,40 & 25,30 & 0,16 & 0,15 & 30,60 & 0,17 & 0,16 & $\mathrm{mR} / \mathrm{h}$ \\
\hline C1 & 50,00 & 0,76 & 48,74 & 0,11 & 0,10 & 54,91 & 0,18 & 0,17 & $\mathrm{mR} / \mathrm{h}$ \\
\hline C2 & 50,00 & 0,76 & 50,06 & 0,20 & 0,20 & 54,94 & 0,21 & 0,21 & $\mathrm{mR} / \mathrm{h}$ \\
\hline C3 & 50,00 & 0,76 & 48,92 & 0,24 & 0,24 & 61,16 & 0,39 & 0,39 & $\mathrm{mR} / \mathrm{h}$ \\
\hline C4 & 50,00 & 0,76 & 49,70 & 0,23 & 0,23 & 61,50 & 0,51 & 0,51 & $\mathrm{mR} / \mathrm{h}$ \\
\hline C5 & 50,00 & 0,76 & 52,52 & 0,18 & 0,17 & 67,10 & 0,21 & 0,21 & $\mathrm{mR} / \mathrm{h}$ \\
\hline D1 & 25,00 & 0,38 & 24,30 & 0,17 & 0,17 & 32,70 & 0,16 & 0,16 & $\mathrm{mR} / \mathrm{h}$ \\
\hline E1 & 20,00 & 0,31 & 18,00 & 0,82 & 0,82 & 28,50 & 0,76 & 0,76 & $\mathrm{mR} / \mathrm{h}$ \\
\hline E2 & 20,00 & 0,31 & 20,00 & 0,03 & 0,00 & 22,00 & 0,82 & 0,82 & $\mathrm{mR} / \mathrm{h}$ \\
\hline F1 & 100,00 & 1,52 & 100,00 & 0,03 & 0,00 & 135,00 & 0,03 & 0,00 & $\mathrm{mR} / \mathrm{h}$ \\
\hline G1 & 100,00 & 1,53 & $\overline{77,94}$ & 0,10 & 0,10 & 104,46 & 0,05 & 0,04 & $m R / h$ \\
\hline G2 & 100,00 & 1,53 & 86,59 & 0,13 & 0,13 & 110,72 & 0,09 & 0,09 & $\mathrm{mR} / \mathrm{h}$ \\
\hline G3 & 100,00 & 1,53 & 82,75 & 0,10 & 0,09 & 114,34 & 0,07 & 0,06 & $\mathrm{mR} / \mathrm{h}$ \\
\hline G4 & 100,00 & 1,53 & 82,47 & 0,15 & 0,15 & 107,89 & 0,09 & 0,09 & $\mathrm{mR} / \mathrm{h}$ \\
\hline G5 & 100,00 & 1,53 & 81,34 & 0,25 & 0,25 & 106,57 & 0,14 & 0,13 & $\mathrm{mR} / \mathrm{h}$ \\
\hline G6 & 100,00 & 1,53 & 80,83 & 0,13 & 0,13 & 104,80 & 0,16 & 0,15 & $\mathrm{mR} / \mathrm{h}$ \\
\hline G7 & 100,00 & 1,53 & 123,68 & 0,44 & 0,44 & 159,58 & 0,21 & 0,21 & $\mathrm{mR} / \mathrm{h}$ \\
\hline H1 & 10,00 & 0,15 & 9,85 & 0,08 & 0,08 & 12,35 & 0,08 & 0,08 & $\mathrm{mR} / \mathrm{h}$ \\
\hline $\mathrm{H} 2$ & 10,00 & 0,15 & 9,95 & 0,03 & 0,00 & 12,45 & 0,03 & 0,00 & $\mathrm{mR} / \mathrm{h}$ \\
\hline H3 & 100,00 & 1,52 & 100,00 & 0,03 & 0,00 & 125,00 & 0,03 & 0,00 & $\mathrm{mR} / \mathrm{h}$ \\
\hline H4 & 1000,00 & 15,20 & 1000,00 & 0,03 & 0,00 & 1400,00 & 0,03 & 0,00 & $\mu \mathrm{Sv} / \mathrm{h}$ \\
\hline H5 & 10,00 & 0,15 & 9,90 & 0,07 & 0,07 & 12,50 & 0,08 & 0,07 & $\mathrm{mR} / \mathrm{h}$ \\
\hline I1 & 100,00 & 1,52 & 98,50 & 0,76 & 0,76 & 112,50 & 0,83 & 0,83 & $\mathrm{mR} / \mathrm{h}$ \\
\hline 12 & 100,00 & 1,52 & 100,00 & 0,03 & 0,00 & 115,00 & 0,03 & 0,00 & $\mathrm{mR} / \mathrm{h}$ \\
\hline 13 & 100,00 & 1,52 & 100,00 & 0,03 & 0,00 & 110,00 & 0,03 & 0,00 & $\mathrm{mR} / \mathrm{h}$ \\
\hline 14 & 100,00 & 1,52 & 100,00 & 0,03 & 0,00 & 110,50 & 0,90 & 0,90 & $\mathrm{mR} / \mathrm{h}$ \\
\hline 15 & 100,00 & 1,52 & 100,00 & 0,03 & 0,00 & 110,00 & 0,03 & 0,00 & $\mathrm{mR} / \mathrm{h}$ \\
\hline 16 & 100,00 & 1,52 & 105,00 & 0,03 & 0,00 & 120,00 & 0,03 & 0,00 & $\mathrm{mR} / \mathrm{h}$ \\
\hline J1 & 50,00 & 0,76 & 47,00 & 1,11 & 1,11 & 53,00 & 0,82 & 0,82 & $\mathrm{mR} / \mathrm{h}$ \\
\hline K1 & 50,00 & 0,76 & 50,63 & 0,04 & 0,02 & 62,96 & 0,06 & 0,05 & $\mathrm{mR} / \mathrm{h}$ \\
\hline L1 & 50,00 & 0,76 & 51,20 & 0,33 & 0,33 & 65,20 & 0,33 & 0,33 & $\mathrm{mR} / \mathrm{h}$ \\
\hline L2 & 50,00 & 0,76 & 51,60 & 0,27 & 0,27 & 65,80 & 0,36 & 0,36 & $\mathrm{mR} / \mathrm{h}$ \\
\hline L3 & 50,00 & 0,78 & 51,80 & 0,33 & 0,33 & 66,20 & 0,20 & 0,20 & $\mathrm{mR} / \mathrm{h}$ \\
\hline L4 & 50,00 & 0,76 & 55,20 & 0,33 & 0,33 & 74,20 & 0,47 & 0,47 & $\mathrm{mR} / \mathrm{h}$ \\
\hline L5 & 50,00 & 0,76 & 53,00 & 0,33 & 0,33 & 70,00 & 0,03 & 0,00 & $\mathrm{mR} / \mathrm{h}$ \\
\hline L6 & 50,00 & 0,76 & 51,40 & 0,31 & 0,31 & 68,80 & 0,33 & 0,33 & $\mathrm{mR} / \mathrm{h}$ \\
\hline L7 & 50,00 & 0,76 & 51,40 & 0,31 & 0,31 & 64,00 & 0,42 & 0,42 & $\mathrm{mR} / \mathrm{h}$ \\
\hline L8 & 50,00 & 0,76 & 50,00 & 0,03 & 0,00 & 65,40 & 0,31 & 0,31 & $\mathrm{mR} / \mathrm{h}$ \\
\hline L9 & 50,00 & 0,76 & 53,80 & 0,36 & 0,36 & 70,40 & 0,40 & 0,40 & $\mathrm{mR} / \mathrm{h}$ \\
\hline L10 & 50,00 & 0,76 & 50,00 & 0,03 & 0,00 & 64,00 & 0,03 & 0,00 & $\mathrm{mR} / \mathrm{h}$ \\
\hline M1 & 50,00 & 0,76 & 50,60 & 0,27 & 0,27 & 57,80 & 0,20 & 0,20 & $\mathrm{mR} / \mathrm{h}$ \\
\hline N1 & 50,00 & 0,76 & 51,00 & 0,33 & 0,33 & 66,00 & 0,03 & 0,00 & $\mathrm{mR} / \mathrm{h}$ \\
\hline
\end{tabular}


Continuação da Tabela 4.2.

Tabela 4.2 Resposta dos detectores Geiger-Müller (códigos A-V) e de detectores semicondutores (códigos $X$ e $Y$ ), para radiação gama.

\begin{tabular}{|c|c|c|c|c|c|c|c|c|c|}
\hline \multicolumn{10}{|c|}{$V_{c}:$ Valor verdadeiro convencional } \\
\hline \multicolumn{10}{|c|}{$M$ : Valor médio das medições } \\
\hline Código & $\begin{array}{c}V_{c} \\
\left({ }^{137} C s\right.\end{array}$ & $\begin{array}{l}u\left(V_{c}\right) \\
\left.{ }^{60} \mathrm{Co}\right)\end{array}$ & $\begin{array}{c}M \\
\left({ }^{137} \mathrm{Cs}\right)\end{array}$ & $\begin{array}{c}U_{c} \\
\left({ }^{137} \mathrm{Cs}\right)\end{array}$ & $\begin{array}{c}u(A) \\
\left({ }^{137} C s\right)\end{array}$ & $\begin{array}{c}M \\
\left({ }^{60} \mathrm{Co}\right)\end{array}$ & $\begin{array}{c}U_{c} \\
\left({ }^{60} \mathrm{Co}\right)\end{array}$ & $\begin{array}{c}u(A) \\
\left({ }^{60} \mathrm{Co}\right)\end{array}$ & Unidade \\
\hline N2 & 50,00 & 0,76 & 48,60 & 0,43 & 0,43 & 62,60 & 0,31 & 0,31 & $\mathrm{mR} / \mathrm{h}$ \\
\hline N3 & 50,00 & 0,76 & 52,40 & 0,27 & 0,27 & 66,00 & 0,03 & 0,00 & $\mathrm{mR} / \mathrm{h}$ \\
\hline 01 & 50,00 & 0,76 & 55,00 & 0,33 & 0,33 & 72,40 & 0,27 & 0,27 & $\mathrm{mR} / \mathrm{h}$ \\
\hline P1 & 50,00 & 0,76 & 50,60 & 0,52 & 0,52 & 53,60 & 0,40 & 0,40 & $\mathrm{mR} / \mathrm{h}$ \\
\hline Q1 & 2,50 & 0,15 & 2,56 & 0,05 & 0,04 & 3,14 & 0,04 & 0,03 & $\mathrm{mR} / \mathrm{h}$ \\
\hline Q2 & 2,50 & 0,15 & 2,46 & 0,04 & 0,03 & 3,05 & 0,06 & 0,05 & $\mathrm{mR} / \mathrm{h}$ \\
\hline Q3 & 2,50 & 0,15 & 2,74 & 0,09 & 0,08 & 3,30 & 0,06 & 0,05 & $\mathrm{mR} / \mathrm{h}$ \\
\hline Q4 & 2,50 & 0,15 & 2,46 & 0,04 & 0,03 & 3,05 & 0,06 & 0,05 & $\mathrm{mR} / \mathrm{h}$ \\
\hline Q5 & 2,50 & 0,15 & 2,46 & 0,05 & 0,04 & 2,86 & 0,05 & 0,04 & $\mathrm{mR} / \mathrm{h}$ \\
\hline Q6 & 2,50 & 0,15 & 2,74 & 0,05 & 0,04 & 3,78 & 0,06 & 0,05 & $\mathrm{mR} / \mathrm{h}$ \\
\hline Q7 & 2,50 & 0,15 & 2,74 & 0,09 & 0,08 & 3,30 & 0,06 & 0,05 & $\mathrm{mR} / \mathrm{h}$ \\
\hline R1 & 50,00 & 0,76 & 50,00 & 0,42 & $\overline{0,42}$ & 55,90 & 0,46 & 0,46 & $\mathrm{mR} / \mathrm{h}$ \\
\hline R2 & 5,00 & 0,08 & 4,95 & 0,10 & 0,10 & 5,47 & 0,10 & 0,09 & $\mathrm{mR} / \mathrm{h}$ \\
\hline R3 & 5,00 & 0,08 & 5,30 & 0,12 & 0,12 & 6,45 & 0,10 & 0,10 & $\mathrm{mR} / \mathrm{h}$ \\
\hline S1 & 50,00 & 0,76 & 54,60 & 0,31 & 0,31 & 69,80 & 0,47 & 0,47 & $\mathrm{mR} / \mathrm{h}$ \\
\hline S2 & 50,00 & 0,76 & 50,80 & 0,33 & 0,33 & 70,40 & 0,27 & 0,27 & $\mathrm{mR} / \mathrm{h}$ \\
\hline T1 & 5,00 & 0,08 & 5,50 & 0,03 & 0,00 & 7,35 & 0,05 & 0,04 & $\mathrm{mR} / \mathrm{h}$ \\
\hline U1 & 2,50 & 0,15 & 2,47 & 0,06 & 0,05 & 3,09 & 0,05 & 0,04 & $\mathrm{mR} / \mathrm{h}$ \\
\hline V1 & 80,00 & 1,22 & 81,36 & 0,20 & 0,20 & 105,10 & 0,24 & 0,23 & $\mu \mathrm{Sv} / \mathrm{h}$ \\
\hline$\overline{X 1}$ & 500,00 & 7,60 & 463,40 & 6,09 & 6,09 & 444,90 & 6,71 & 6,71 & $\mu \mathrm{Sv} / \mathrm{h}$ \\
\hline $\mathrm{X} 2$ & 500,00 & 7,60 & 440,70 & 2,34 & 2,34 & 480,30 & 11,69 & 11,69 & $\mu S v / h$ \\
\hline $\mathrm{X} 3$ & 500,00 & 7,60 & 439,80 & 3,50 & 3,50 & 465,10 & 7,40 & 7,40 & $\mu \mathrm{Sv} / \mathrm{h}$ \\
\hline Y1 & 500,00 & 7,60 & 479,00 & 2,16 & 2,16 & 435,80 & 6,68 & 6,68 & $\mu \mathrm{Sv} / \mathrm{h}$ \\
\hline
\end{tabular}


Tabela 4.3 Resposta das câmaras de ionização para radiação gama.

\begin{tabular}{|c|c|c|c|c|c|c|c|c|c|}
\hline \multicolumn{10}{|c|}{$V_{c}:$ Valor verdadeiro convencional } \\
\hline \multicolumn{10}{|c|}{$M:$ Valor médio das medições } \\
\hline Código & $\begin{array}{c}V_{c} \\
\left({ }^{137} \mathrm{Cs}\right.\end{array}$ & $\begin{array}{l}u\left(V_{c}\right) \\
\left.{ }^{60} \mathrm{Co}\right)\end{array}$ & $\begin{array}{c}M \\
\left({ }^{137} \mathrm{Cs}\right)\end{array}$ & $\begin{array}{c}U_{c} \\
\left({ }^{137} C s\right)\end{array}$ & $\begin{array}{c}u(A) \\
\left({ }^{137} C s\right)\end{array}$ & $\begin{array}{c}M \\
\left({ }^{60} \mathrm{Co}\right)\end{array}$ & $\begin{array}{c}U_{c} \\
\left({ }^{60} \mathrm{Co}\right)\end{array}$ & $\begin{array}{c}u(A) \\
\left({ }^{60} \mathrm{Co}\right)\end{array}$ & Unidade \\
\hline B'1 & 25,00 & 0,38 & 25,45 & 0,16 & 0,17 & 25,67 & 0,16 & 0,17 & $\mathrm{mR} / \mathrm{h}$ \\
\hline$B^{\prime} 2$ & 25,00 & 0,38 & 24,59 & 0,16 & 0,17 & 25,67 & 0,16 & 0,17 & $\mathrm{mR} / \mathrm{h}$ \\
\hline$C^{\prime} 1$ & 25,00 & 0,38 & 22,50 & 0,22 & 0,23 & 22,80 & 0,13 & 0,14 & $\mathrm{mR} / \mathrm{h}$ \\
\hline D'1 & 25,00 & 0,38 & 28,20 & 0,00 & 0,03 & 28,20 & 0,00 & 0,03 & $\mathrm{mR} / \mathrm{h}$ \\
\hline l'1 & 25,00 & 0,38 & 27,51 & 0,10 & 0,11 & 27,84 & 0,16 & 0,17 & $\mathrm{mR} / \mathrm{h}$ \\
\hline J'1 & 25,00 & 0,38 & 24,00 & 0,00 & 0,03 & 24,00 & 0,00 & 0,03 & $\mathrm{mR} / \mathrm{h}$ \\
\hline $\mathrm{K}^{\prime} 1$ & 500,00 & 7,60 & 417,00 & 1,53 & 1,53 & 446,00 & 1,63 & 1,63 & $\mu \mathrm{Sv} / \mathrm{h}$ \\
\hline$K^{\prime} 2$ & 50,00 & 0,76 & 42,40 & 0,16 & 0,17 & 44,80 & 0,13 & 0,14 & $\mathrm{mR} / \mathrm{h}$ \\
\hline L'1 & 25,00 & 0,38 & 30,69 & 0,11 & 0,11 & 30,63 & 0,18 & 0,19 & $\mathrm{mR} / \mathrm{h}$ \\
\hline L'2 & 25,00 & 0,38 & 29,59 & 0,00 & 0,03 & 30,69 & 0,17 & 0,17 & $\mathrm{mR} / \mathrm{h}$ \\
\hline L'3 & 25,00 & 0,38 & 29,59 & 0,00 & 0,03 & 29,59 & 0,00 & 0,03 & $\mathrm{mR} / \mathrm{h}$ \\
\hline L'4 & 25,00 & 0,38 & 27,00 & 0,00 & 0,03 & 27,00 & 0,00 & 0,03 & $\mathrm{mR} / \mathrm{h}$ \\
\hline M'1 & 25,00 & 0,38 & 23,00 & 0,10 & 0,11 & 23,20 & 0,13 & 0,14 & $\mathrm{mR} / \mathrm{h}$ \\
\hline
\end{tabular}

Foi observado na Tabela 4.2 que a maioria dos detectores, calibrados à $50 \%$ da escala, seriam aprovados no teste de calibração para radiação gama utilizando a fonte de césio, por variarem menos que $\pm 10 \%$ em relação ao valor verdadeiro convencional, $V_{c}$, (IRD, 2004). Os detectores de radiação de códigos G1, G2, G3, G4, G5, G6, G7, X2 e X3 não seriam aprovados no teste de calibração. Os detectores E1 e V1 calibrados a $80 \%$ das escalas mostram valores de medições próximos ao valor verdadeiro convencional, apresentando uma diferença menor que 20\% (IRD, 2004). Todas as câmaras de ionização apresentadas na Tabela 4.3 possuem valores menores que 10\% em relação ao valor verdadeiro convencional, portanto todas elas seriam aprovadas neste tipo de teste. As medições com fonte de cobalto, nas Tabelas 4.2 e 4.3, foram utilizadas para o estudo da dependência energética da resposta dos detectores de radiação entre cobalto e césio. 


\subsubsection{Determinação dos fatores de calibração para radiação gama}

A partir dos dados obtidos, foram determinados os fatores de calibração, $f_{c}$, dos instrumentos, apresentados nas Tabelas 4.4 e 4.5 . O fator de calibração, $f_{c}$, é obtido de acordo com a Equação 3.1, em taxa de exposição ou em taxa de equivalente de dose ambiente, de acordo com a grandeza mensurada pelo instrumento.

Tabela 4.4 Fator de calibração dos detectores Geiger-Müller e detectores semicondutores (X1, X2, X3 e Y1), para radiação gama.

\begin{tabular}{|c|c|c|c|c|c|c|c|c|c|}
\hline Código & $\begin{array}{c}f_{c} \\
\left({ }^{137} C s\right)\end{array}$ & $\begin{array}{l}u(f c) \\
\left({ }^{137} C s\right)\end{array}$ & $\begin{array}{c}f_{c} \\
\left({ }^{60} \mathrm{Co}\right)\end{array}$ & $\begin{array}{l}u(f c) \\
\left({ }^{60} \mathrm{Co}\right)\end{array}$ & Código & $\begin{array}{c}f_{c} \\
\left({ }^{137} \mathrm{Cs}\right)\end{array}$ & $\begin{array}{l}u(f c) \\
\left({ }^{137} C s\right)\end{array}$ & $\begin{array}{c}f_{c} \\
\left({ }^{60} \mathrm{Co}\right)\end{array}$ & $\begin{array}{l}u(f c) \\
\left({ }^{60} \mathrm{Co}\right)\end{array}$ \\
\hline A1 & 0,98 & 0,02 & 0,94 & 0,02 & L1 & 0,98 & 0,02 & 0,77 & 0,01 \\
\hline A2 & 1,05 & 0,02 & 0,92 & 0,02 & L2 & 0,97 & 0,02 & 0,76 & 0,01 \\
\hline A3 & 0,99 & 0,02 & 0,90 & 0,02 & L3 & 0,98 & 0,02 & 0,77 & 0,01 \\
\hline A4 & 1,01 & 0,02 & 0,88 & 0,01 & L4 & 0,91 & 0,01 & 0,67 & 0,01 \\
\hline B1 & 0,98 & 0,02 & 0,83 & 0,01 & L5 & 0,94 & 0,02 & 0,71 & 0,01 \\
\hline B2 & 1,03 & 0,02 & 0,85 & 0,01 & L6 & 0,97 & 0,02 & 0,73 & 0,01 \\
\hline C1 & 1,03 & 0,02 & 0,91 & 0,01 & L7 & 0,97 & 0,02 & 0,78 & 0,01 \\
\hline C2 & 1,00 & 0,02 & 0,91 & 0,01 & L8 & 1,00 & 0,02 & 0,76 & 0,01 \\
\hline C3 & 1,02 & 0,02 & 0,82 & 0,01 & L9 & 0,93 & 0,02 & 0,71 & 0,01 \\
\hline C4 & 1,01 & 0,02 & 0,81 & 0,01 & L10 & 1,00 & 0,02 & 0,78 & 0,01 \\
\hline C5 & 0,95 & 0,01 & 0,75 & 0,01 & M1 & 0,99 & 0,02 & 0,87 & 0,01 \\
\hline D1 & 1,03 & 0,02 & 0,76 & 0,01 & N1 & 0,98 & 0,02 & 0,76 & 0,01 \\
\hline E1 & 1,11 & 0,05 & $\overline{0,70}$ & 0,02 & N2 & 1,03 & 0,02 & 0,80 & 0,01 \\
\hline E2 & 1,00 & 0,02 & 0,91 & 0,04 & N3 & 0,95 & 0,02 & 0,76 & 0,01 \\
\hline F1 & 1,00 & 0,02 & 0,74 & 0,01 & 01 & 0,91 & 0,01 & 0,69 & 0,01 \\
\hline G1 & 1,28 & 0,02 & 0,96 & 0,01 & P1 & 0,99 & 0,02 & 0,93 & 0,02 \\
\hline G2 & 1,15 & 0,02 & 0,90 & 0,01 & Q1 & 0,98 & 0,06 & 0,80 & 0,05 \\
\hline G3 & 1,21 & 0,02 & 0,87 & 0,01 & Q2 & 1,02 & 0,06 & 0,82 & 0,05 \\
\hline G4 & 1,21 & 0,02 & 0,93 & 0,01 & Q3 & 0,91 & 0,06 & 0,76 & 0,05 \\
\hline G5 & 1,23 & 0,02 & 0,94 & 0,01 & Q4 & 1,02 & 0,06 & 0,82 & 0,05 \\
\hline G6 & 1,24 & 0,02 & 0,95 & 0,01 & Q5 & 1,02 & 0,06 & 0,87 & 0,05 \\
\hline G7 & 0,81 & 0,01 & 0,63 & 0,01 & Q6 & 0,91 & 0,06 & 0,66 & 0,04 \\
\hline H1 & 1,02 & 0,02 & 0,81 & 0,01 & Q7 & 0,91 & 0,06 & 0,76 & 0,05 \\
\hline $\mathrm{H} 2$ & 1,01 & 0,02 & 0,80 & 0,01 & $\mathbf{R 1}$ & 1,00 & 0,02 & 0,89 & 0,02 \\
\hline H3 & 1,00 & 0,02 & 0,80 & 0,01 & R2 & 1,01 & 0,03 & 0,91 & 0,02 \\
\hline H4 & 1,00 & 0,02 & 0,71 & 0,01 & R3 & 0,94 & 0,03 & 0,78 & 0,02 \\
\hline H5 & 1,01 & 0,02 & 0,80 & 0,01 & S1 & 0,92 & 0,01 & 0,72 & 0,01 \\
\hline I1 & 1,02 & 0,02 & 0,89 & 0,02 & S2 & 0,98 & 0,02 & 0,71 & 0,01 \\
\hline 12 & 1,00 & 0,02 & 0,87 & 0,01 & T1 & 0,91 & 0,01 & 0,68 & 0,01 \\
\hline 13 & 1,00 & 0,02 & 0,91 & 0,01 & U1 & 1,01 & 0,06 & 0,81 & 0,05 \\
\hline 14 & 1,00 & 0,02 & 0,90 & 0,02 & V1 & 0,98 & 0,02 & 0,76 & 0,01 \\
\hline 15 & 1,00 & 0,02 & 0,91 & 0,01 & X1 & 1,08 & 0,02 & 1,12 & 0,02 \\
\hline 16 & 0,95 & 0,01 & 0,83 & 0,01 & $\mathrm{X} 2$ & 1,13 & 0,02 & 1,04 & 0,03 \\
\hline J1 & 1,06 & 0,03 & 0,94 & 0,02 & X3 & 1,14 & 0,02 & 1,08 & 0,02 \\
\hline K1 & 0,99 & 0,02 & 0,79 & 0,01 & Y1 & 1,04 & 0,02 & 1,15 & 0,02 \\
\hline
\end{tabular}


Observa-se na Tabela 4.4 que a maioria dos fatores de calibração para ${ }^{137} \mathrm{Cs}$ está próxima de um, o que mostra que os instrumentos estão indicando valores de medida próximos ao valor verdadeiro convencional (referência). Este fato era esperado uma vez que os equipamentos foram ajustados para esta radiação, durante o processo de calibração. Apenas os detectores identificados pelos códigos G1, G2, G3, G4, G5, G6, G7, X2 e X3 apresentaram fatores de calibração para ${ }^{137} \mathrm{Cs}$ maiores que $10 \%$. Os detectores de código $X$ são calibrados em feixe de ${ }^{60} \mathrm{Co}$ pelo fabricante. Os instrumentos quando expostos à radiação de ${ }^{60} \mathrm{Co}$ apresentaram valores de medida, $\mathrm{M}$, maiores em relação ao valor verdadeiro convencional, $\mathrm{Vc}$, apresentando uma diferença de até $34 \%$, obtida pelo instrumento de código Q6. O fator de calibração dos instrumentos para ${ }^{60} \mathrm{Co}$, em sua maioria, foi menor que um.

Nota-se que os fatores de calibração variam para um mesmo modelo de monitor de área, concluindo-se que os detectores de uma mesma marca podem apresentar respostas muito diferentes. O maior fator de calibração para ${ }^{137} \mathrm{Cs}$ foi do instrumento $\mathrm{G} 1(1,28 \pm 0,02)$, mostrando que ele apresenta $28 \%$ de diferença em relação ao valor verdadeiro convencional e para $0^{60} \mathrm{Co}$ foi $\mathrm{o}$ instrumento Q6 $(0,66 \pm 0,04)$, mostrando que ele apresenta 34\% de diferença em relação ao valor verdadeiro convencional.

Tabela 4.5 Fator de calibração das câmaras de ionização, para radiação gama.

\begin{tabular}{c|cc|cc}
\hline Código & $\begin{array}{c}f_{\boldsymbol{c}} \\
\left({ }^{137} \boldsymbol{C s}\right)\end{array}$ & $\begin{array}{c}\boldsymbol{u}(\boldsymbol{f c}) \\
\left({ }^{\mathbf{1 3 7}} \boldsymbol{C s}\right)\end{array}$ & $\begin{array}{c}f_{\boldsymbol{c}} \\
\left({ }^{60} \boldsymbol{C o}\right)\end{array}$ & $\begin{array}{c}\boldsymbol{u}(f \boldsymbol{c}) \\
\left({ }^{\mathbf{6 0}} \boldsymbol{C o}\right)\end{array}$ \\
\hline B'1 & 0,98 & 0,02 & 0,97 & 0,02 \\
B'2 & 1,02 & 0,02 & 0,97 & 0,02 \\
\hline C'1 & 1,11 & 0,02 & 1,10 & 0,02 \\
\hline D'1 & 0,89 & 0,01 & 0,89 & 0,01 \\
\hline I'1 & 0,91 & 0,01 & 0,90 & 0,01 \\
\hline J'1 & 1,04 & 0,02 & 1,04 & 0,02 \\
\hline K'1 & 1,20 & 0,02 & 1,12 & 0,02 \\
K'2 & 1,18 & 0,02 & 1,12 & 0,02 \\
\hline L'1 & 0,81 & 0,01 & 0,82 & 0,01 \\
L'2 & 0,84 & 0,01 & 0,81 & 0,01 \\
L'3 & 0,84 & 0,01 & 0,84 & 0,01 \\
L'4 & 0,93 & 0,01 & 0,93 & 0,01 \\
\hline M'1 & 1,09 & 0,02 & 1,08 & 0,02 \\
\hline
\end{tabular}


De acordo com os valores obtidos na Tabela 4.5, os fatores de calibração das câmaras de ionização tanto para ${ }^{137} \mathrm{Cs}$ e ${ }^{60} \mathrm{Co}$ estão igualmente próximos do valor 1 . Para ${ }^{137} \mathrm{Cs}$, o maior fator de calibração foi do instrumento K'1 $(1,20 \pm 0,02)$, com $20 \%$ de diferença entre a resposta do instrumento e seu valor verdadeiro convencional, e para ${ }^{60} \mathrm{Co}$, o maior fator de calibração foi do instrumento L'2 $(0,81 \pm 0,01)$ com $19 \%$ de diferença entre a resposta do instrumento e seu valor verdadeiro convencional.

\subsubsection{Dependência energética dos detectores para radiação gama}

Foi determinada a dependência energética para radiação gama $\left({ }^{137} \mathrm{Cs}\right.$ e ${ }^{60} \mathrm{Co}$ ) para os detectores Geiger-Müller, os detectores semicondutores e as câmaras de ionização, na grandeza taxa de kerma no ar, $\dot{K}_{a r}$ (para os instrumentos que medem na grandeza taxa de exposição, $\dot{X})$ e na grandeza taxa de equivalente de dose ambiente $H^{*}(10)$ (para os instrumentos que já medem nessa grandeza); os resultados estão apresentados nas Tabelas $4.6 \mathrm{e}$ 4.7. A dependência energética foi determinada em cada caso pela razão entre os fatores de calibração para césio e cobalto, de acordo com a Equação 4.3:

$$
D E=\frac{f_{c}\left({ }^{137} C s\right)}{f_{c}\left({ }^{60} C o\right)}
$$

Foram escolhidos alguns detectores, de códigos A, C, G, H, I, L, Q, para visualização da dependência energética, por modelo de detector Geiger-Müller, na Figura 4.1. No caso das câmaras de ionização, todos os modelos calibrados com radiação gama foram apresentados na Figura 4.2. 
Tabela 4.6 Dependência energética, DE, da resposta dos detectores Geiger-Müller e dos detectores semicondutores (X1, X2, X3 e Y1) para radiação gama.

\begin{tabular}{|c|c|c|c|c|c|c|c|}
\hline Código & $D E$ & $U$ & Grandeza & Código & $D E$ & $U$ & Grandeza \\
\hline A1 & 1,05 & 0,06 & $\mathrm{H}^{*}(10)$ & L1 & 1,27 & 0,06 & $\mathrm{~K}_{\mathrm{ar}}$ \\
\hline A2 & 1,15 & 0,06 & $H^{*}(10)$ & L2 & 1,28 & 0,06 & $\mathrm{~K}_{\mathrm{ar}}$ \\
\hline A3 & 1,10 & 0,06 & $H^{*}(10)$ & L3 & 1,28 & 0,06 & $\mathrm{~K}_{\mathrm{ar}}$ \\
\hline A4 & 1,14 & 0,05 & $\mathrm{H}^{*}(10)$ & L4 & 1,34 & 0,06 & $\mathrm{~K}_{\mathrm{ar}}$ \\
\hline B1 & 1,19 & 0,06 & $\mathrm{~K}_{\mathrm{ar}}$ & L5 & 1,32 & 0,06 & $\mathrm{~K}_{\mathrm{ar}}$ \\
\hline B2 & 1,21 & 0,06 & $\mathrm{~K}_{\mathrm{ar}}$ & L6 & 1,34 & 0,06 & $\mathrm{~K}_{\mathrm{ar}}$ \\
\hline $\mathrm{C} 1$ & 1,13 & 0,05 & $\mathrm{~K}_{\mathrm{ar}}$ & L7 & 1,25 & 0,06 & $\mathrm{~K}_{\mathrm{ar}}$ \\
\hline $\mathrm{C} 2$ & 1,10 & 0,05 & $\mathrm{~K}_{\mathrm{ar}}$ & L8 & 1,31 & 0,06 & $\mathrm{~K}_{\mathrm{ar}}$ \\
\hline C3 & 1,25 & 0,06 & $\mathrm{~K}_{\mathrm{ar}}$ & L9 & 1,31 & 0,06 & $\mathrm{~K}_{\mathrm{ar}}$ \\
\hline $\mathrm{C} 4$ & 1,24 & 0,06 & $\mathrm{~K}_{\mathrm{ar}}$ & L10 & 1,28 & 0,06 & $\mathrm{~K}_{\mathrm{ar}}$ \\
\hline $\mathrm{C} 5$ & 1,28 & 0,06 & $\mathrm{~K}_{\mathrm{ar}}$ & M1 & 1,14 & 0,05 & $\mathrm{~K}_{\mathrm{ar}}$ \\
\hline D1 & 1,35 & 0,06 & $\mathrm{~K}_{\mathrm{ar}}$ & N1 & 1,29 & 0,06 & $\mathrm{~K}_{\mathrm{ar}}$ \\
\hline E1 & 1,58 & 0,18 & $\mathrm{~K}_{\mathrm{ar}}$ & N2 & 1,29 & 0,06 & $\mathrm{~K}_{\mathrm{ar}}$ \\
\hline E2 & 1,10 & 0,09 & $\mathrm{~K}_{\mathrm{ar}}$ & N3 & 1,26 & 0,06 & $\mathrm{~K}_{\mathrm{ar}}$ \\
\hline F1 & 1,35 & 0,06 & $\mathrm{~K}_{\mathrm{ar}}$ & 01 & 1,32 & 0,06 & $\mathrm{~K}_{\mathrm{ar}}$ \\
\hline G1 & 1,13 & 0,05 & $\mathrm{~K}_{\mathrm{ar}}$ & P1 & 1,06 & 0,05 & $\mathrm{~K}_{\mathrm{ar}}$ \\
\hline G2 & 1,10 & 0,05 & $\mathrm{~K}_{\mathrm{ar}}$ & Q1 & 1,23 & 0,21 & $\mathrm{~K}_{\mathrm{ar}}$ \\
\hline G3 & 1,25 & 0,06 & $\mathrm{~K}_{\mathrm{ar}}$ & Q2 & 1,24 & 0,21 & $\mathrm{~K}_{\mathrm{ar}}$ \\
\hline G4 & 1,24 & 0,06 & $\mathrm{~K}_{\mathrm{ar}}$ & Q3 & 1,20 & 0,22 & $\mathrm{~K}_{\mathrm{ar}}$ \\
\hline G5 & 1,28 & 0,06 & $\mathrm{~K}_{\mathrm{ar}}$ & Q4 & 1,24 & 0,21 & $\mathrm{~K}_{\mathrm{ar}}$ \\
\hline G6 & 1,13 & 0,05 & $\mathrm{~K}_{\mathrm{ar}}$ & Q5 & 1,16 & 0,20 & $\mathrm{~K}_{\mathrm{ar}}$ \\
\hline G7 & 1,10 & 0,05 & $\mathrm{~K}_{\mathrm{ar}}$ & Q6 & 1,38 & 0,24 & $\mathrm{~K}_{\mathrm{ar}}$ \\
\hline $\mathrm{H} 1$ & 1,25 & 0,06 & $\mathrm{~K}_{\mathrm{ar}}$ & Q7 & 1,20 & 0,22 & $\mathrm{~K}_{\mathrm{ar}}$ \\
\hline H2 & 1,13 & 0,05 & $\mathrm{~K}_{\mathrm{ar}}$ & R1 & 1,12 & 0,05 & $\mathrm{~K}_{\mathrm{ar}}$ \\
\hline H3 & 1,10 & 0,05 & $\mathrm{~K}_{\mathrm{ar}}$ & R2 & 1,11 & 0,08 & $\mathrm{~K}_{\mathrm{ar}}$ \\
\hline $\mathrm{H} 4$ & 1,25 & 0,06 & $\mathrm{H}^{*}(10)$ & R3 & 1,22 & 0,09 & $\mathrm{~K}_{\mathrm{ar}}$ \\
\hline H5 & 1,24 & 0,06 & $\mathrm{~K}_{\mathrm{ar}}$ & S1 & 1,28 & 0,06 & $\mathrm{~K}_{\mathrm{ar}}$ \\
\hline 11 & 1,13 & 0,05 & $\mathrm{~K}_{\mathrm{ar}}$ & S2 & 1,39 & 0,06 & $\mathrm{~K}_{\mathrm{ar}}$ \\
\hline 12 & 1,10 & 0,05 & $\mathrm{~K}_{\mathrm{ar}}$ & T1 & 1,34 & 0,06 & $\mathrm{~K}_{\mathrm{ar}}$ \\
\hline 13 & 1,25 & 0,06 & $\mathrm{~K}_{\mathrm{ar}}$ & U1 & 1,25 & 0,22 & $\mathrm{~K}_{\mathrm{ar}}$ \\
\hline 14 & 1,24 & 0,06 & $\mathrm{~K}_{\mathrm{ar}}$ & V1 & 1,29 & 0,06 & $H^{*}(10)$ \\
\hline 15 & 1,13 & 0,05 & $\mathrm{~K}_{\mathrm{ar}}$ & $\mathrm{X} 1$ & 0,96 & 0,06 & $\mathrm{H}^{*}(10)$ \\
\hline 16 & 1,10 & 0,05 & $\mathrm{~K}_{\mathrm{ar}}$ & $\mathrm{X} 2$ & 1,09 & 0,07 & $H^{*}(10)$ \\
\hline J1 & 1,13 & 0,08 & $\mathrm{~K}_{\mathrm{ar}}$ & $\mathrm{X3}$ & 1,06 & 0,06 & $H^{*}(10)$ \\
\hline K1 & 1,24 & 0,05 & $\mathrm{~K}_{\mathrm{ar}}$ & $\mathrm{Y1}$ & 0,91 & 0,05 & $\mathrm{H}^{*}(10)$ \\
\hline
\end{tabular}


A Tabela 4.6 foi discriminada por cores para identificar se $o$ instrumento está de acordo com as normas. A seleção considerou o valor da dependência energética e sua incerteza, com o objetivo de selecionar o maior número de detectores. A cor azul claro identifica os detectores que estão de acordo com a norma internacional ISO 4037-2 (ISO, 1997), que estabelece que a dependência energética dos instrumentos para energias médias superiores a $30 \mathrm{keV}$ não pode ultrapassar $10 \%$. A cor branca identifica os detectores que estão de acordo somente com a norma nacional ABNT NBR 10011 (ABNT, 1987), que estabelece que a dependência energética pode variar até $25 \%$, portanto esta norma abrange os detectores tanto de cor branca como de cor azul claro. Os detectores marcados com cinza estão fora dos padrões normativos. De acordo com a Tabela 4.6, alguns instrumentos de mesmo modelo estão de acordo com a norma nacional (ABNT, 1987), mas não de acordo com a norma internacional (ISO, 1997); como exemplo, tem-se os detectores de código $G$. Os detectores de código L possuem instrumentos que não estão de acordo com nenhuma norma e outros que estão de acordo com a norma nacional (ISO, 1997). Esta constatação confirma os dados apresentados e discutidos da Tabela 4.4, na qual instrumentos de mesmo modelo podem apresentar respostas diferentes. Dos 64 detectores Geiger-Müller estudados, 10 detectores não estão de acordo nem com a norma nacional nem com a norma internacional. Todos os detectores semicondutores apresentaram valores de dependência energética menor que 25\%. A maior dependência energética foi de $58 \%$ do detector Geiger-Müller E1 $(1,58 \pm 0,18)$. Apesar do maior valor da dependência energética obtida, a maior parte dos resultados foram semelhantes aos dados obtidos por Vivolo (Vivolo, 2000) em seu trabalho, onde os detectores Geiger-Müller apresentaram uma variação de até $33 \%$ na dependência energética, apesar dos modelos de detectores analisados terem sido diferentes. 
Tabela 4.7 Dependência energética, DE, da resposta das câmaras de ionização para radiação gama.

\begin{tabular}{c|cc|c}
\hline Código & $\boldsymbol{D} \boldsymbol{E}$ & $\boldsymbol{U}$ & Grandeza \\
\hline B'1 & 1,01 & 0,05 & $\mathrm{~K}_{\mathrm{ar}}$ \\
B'2 & 1,04 & 0,05 & $\mathrm{~K}_{\mathrm{ar}}$ \\
\hline C'1 $^{\prime}$ & 1,01 & 0,05 & $\mathrm{~K}_{\mathrm{ar}}$ \\
\hline $\mathbf{D}^{\prime} \mathbf{1}$ & 1,00 & 0,04 & $\mathrm{~K}_{\mathrm{ar}}$ \\
\hline I'1 & 1,01 & 0,05 & $\mathrm{~K}_{\mathrm{ar}}$ \\
\hline J'1 & 1,00 & 0,04 & $\mathrm{~K}_{\mathrm{ar}}$ \\
\hline K'1 & 1,07 & 0,05 & $\mathrm{H}^{*}(10)$ \\
K'2 & 1,06 & 0,05 & $\mathrm{~K}_{\mathrm{ar}}$ \\
\hline $\mathbf{L}^{\prime} \mathbf{1}$ & 1,00 & 0,05 & $\mathrm{~K}_{\mathrm{ar}}$ \\
L'2 & 1,04 & 0,05 & $\mathrm{~K}_{\mathrm{ar}}$ \\
L'3 & 1,00 & 0,04 & $\mathrm{~K}_{\mathrm{ar}}$ \\
L'4 & 1,00 & 0,04 & $\mathrm{~K}_{\mathrm{ar}}$ \\
\hline M'1 & 1,01 & 0,05 & $\mathrm{~K}_{\mathrm{ar}}$ \\
\hline
\end{tabular}

De acordo com a Tabela 4.7, as câmaras de ionização apresentaram uma dependência energética menor que 10\% e consequentemente estão de acordo com a norma internacional ISO 4037-2 (ISO, 1997) e com a norma nacional ABNT NBR 10011 (ABNT, 1987). Das treze câmaras de ionização, três apresentaram $0 \%$ de dependência energética, caso das câmaras de ionização D'1 $(1,00 \pm 0,04)$, J'1 $(1,00 \pm 0,04)$ e L'1 $(1,00 \pm 0,05)$. O maior valor de dependência energética neste caso foi de $7 \%$, no caso da câmara de ionização K'1 $(1,07 \pm 0,05)$. Os resultados da Tabela 4.7 foram semelhantes aos resultados obtidos por Vivolo (Vivolo, 2000); em seu trabalho, as câmaras de ionização apresentaram uma variação na dependência energética de até $8,4 \%$. 


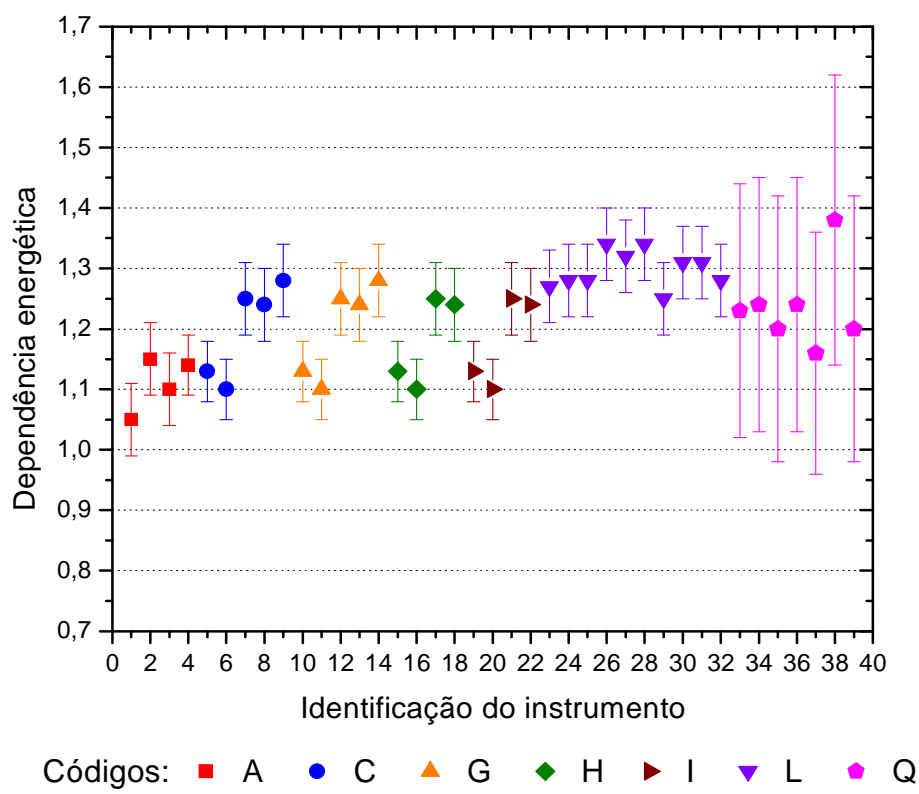

Figura 4.1 Dependência energética para radiação gama, de alguns detectores Geiger-Müller estudados.

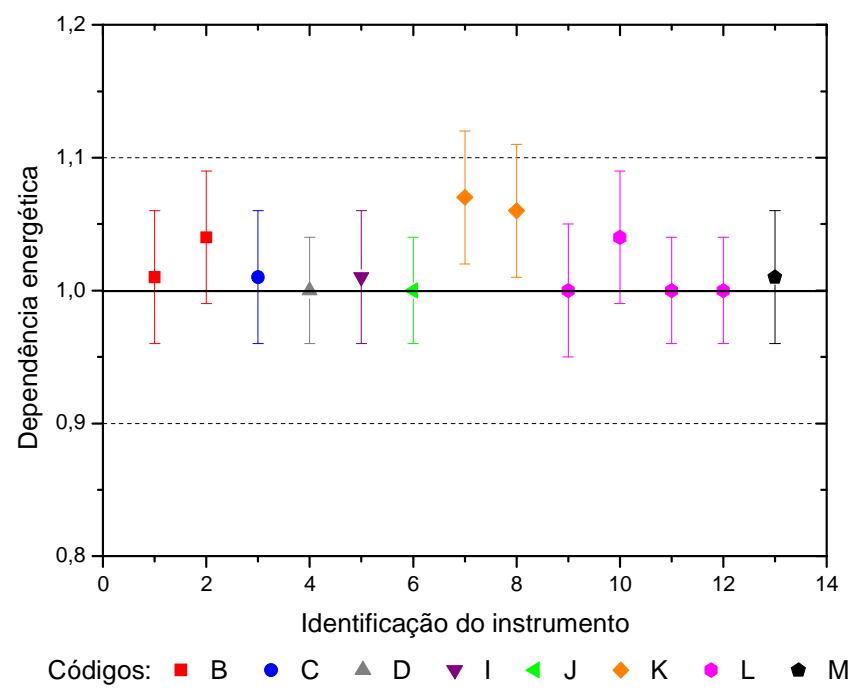

Figura 4.2 Dependência energética para radiação gama, das câmaras de ionização estudadas.

De acordo com a Figura 4.1, pode-se também observar uma variação no comportamento da dependência energética para detectores de mesmo modelo. As incertezas dos instrumentos pertencentes à marca identificada pelo código 
Q são maiores, devido à oscilação dos valores medidos pelos detectores, portanto o desvio padrão da incerteza do tipo $A$ foi maior.

$\mathrm{Na}$ Figura 4.2, as câmaras de ionização apresentaram comportamentos semelhantes em suas respostas para a dependência energética, sendo que a maioria das câmaras de ionização mostram dependência energética igual a um, ou seja, independência com a energia da radiação gama.

Também foi realizada uma comparação da dependência energética da taxa de kerma no ar, $\dot{K}_{a r}$, em relação à taxa de equivalente de dose ambiente, $H^{*}(10)$. Pode-se observar estes resultados na Tabela 4.8 para os detectores Geiger-Müller e na Tabela 4.9 para as câmaras de ionização. 
Tabela 4.8 Dependência energética, DE, da resposta dos detectores Geiger-Müller, para as grandezas $K_{a r}$ e $H^{*}(10)$.

\begin{tabular}{|c|c|c|c|c|c|c|c|c|c|}
\hline Código & $\begin{array}{c}D E \\
\left(K_{a r}\right)\end{array}$ & $\boldsymbol{U}$ & $\begin{array}{c}D E \\
\left(H^{*}(10)\right)\end{array}$ & $U$ & Código & $\begin{array}{c}D E \\
\left(K_{a r}\right)\end{array}$ & $U$ & $\begin{array}{c}D E \\
\left(H^{*}(10)\right)\end{array}$ & $U$ \\
\hline B1 & 1,19 & 0,06 & 1,15 & 0,05 & L1 & 1,27 & 0,06 & 1,23 & 0,06 \\
\hline B2 & 1,21 & 0,06 & 1,17 & 0,05 & L2 & 1,28 & 0,06 & 1,23 & 0,06 \\
\hline C1 & 1,13 & 0,05 & 1,09 & 0,05 & L3 & 1,28 & 0,06 & 1,24 & 0,06 \\
\hline C2 & 1,10 & 0,05 & 1,06 & 0,05 & L4 & 1,34 & 0,06 & 1,30 & 0,06 \\
\hline C3 & 1,25 & 0,06 & 1,21 & 0,06 & L5 & 1,32 & 0,06 & 1,28 & 0,06 \\
\hline C4 & 1,24 & 0,06 & 1,20 & 0,06 & L6 & 1,34 & 0,06 & 1,29 & 0,06 \\
\hline C5 & 1,28 & 0,06 & 1,24 & 0,05 & L7 & 1,25 & 0,06 & 1,20 & 0,06 \\
\hline D1 & 1,35 & 0,06 & 1,30 & 0,06 & L8 & 1,31 & 0,06 & 1,26 & 0,06 \\
\hline E1 & 1,58 & 0,18 & 1,53 & 0,17 & L9 & 1,31 & 0,06 & 1,26 & 0,06 \\
\hline E2 & 1,10 & 0,09 & 1,06 & 0,09 & L10 & 1,28 & 0,06 & 1,24 & 0,05 \\
\hline F1 & 1,35 & 0,06 & 1,31 & 0,06 & M1 & 1,14 & 0,05 & 1,10 & 0,05 \\
\hline G1 & 1,34 & 0,06 & 1,30 & 0,06 & N1 & 1,29 & 0,06 & 1,25 & 0,06 \\
\hline G2 & 1,28 & 0,06 & 1,24 & 0,05 & N2 & 1,29 & 0,06 & 1,25 & 0,06 \\
\hline G3 & 1,38 & 0,06 & 1,34 & 0,06 & N3 & 1,26 & 0,06 & 1,22 & 0,05 \\
\hline G4 & 1,31 & 0,06 & 1,26 & 0,05 & 01 & 1,32 & 0,06 & 1,27 & 0,06 \\
\hline G5 & 1,31 & 0,06 & 1,27 & 0,06 & P1 & 1,06 & 0,05 & 1,02 & 0,05 \\
\hline G6 & 1,30 & 0,06 & 1,25 & 0,05 & Q1 & 1,23 & 0,21 & 1,19 & 0,20 \\
\hline G7 & 1,29 & 0,06 & 1,25 & 0,05 & Q2 & 1,24 & 0,21 & 1,20 & 0,21 \\
\hline H1 & 1,25 & 0,06 & 1,21 & 0,06 & Q3 & 1,20 & 0,22 & 1,16 & 0,21 \\
\hline $\mathrm{H} 2$ & 1,25 & 0,06 & 1,21 & 0,05 & Q4 & 1,24 & 0,21 & 1,20 & 0,21 \\
\hline H3 & 1,25 & 0,05 & 1,21 & 0,05 & Q5 & 1,16 & 0,20 & 1,12 & 0,20 \\
\hline H5 & 1,26 & 0,06 & 1,22 & 0,06 & Q6 & 1,38 & 0,24 & 1,33 & 0,23 \\
\hline I1 & 1,14 & 0,05 & 1,10 & 0,05 & Q7 & 1,20 & 0,22 & 1,16 & 0,21 \\
\hline 12 & 1,15 & 0,05 & 1,11 & 0,05 & R1 & 1,12 & 0,05 & 1,08 & 0,05 \\
\hline 13 & 1,10 & 0,05 & 1,06 & 0,05 & R2 & 1,11 & 0,08 & 1,07 & 0,07 \\
\hline 14 & 1,11 & 0,05 & 1,07 & 0,05 & R3 & 1,22 & 0,09 & 1,18 & 0,08 \\
\hline 15 & 1,10 & 0,05 & 1,06 & 0,05 & S1 & 1,28 & 0,06 & 1,24 & 0,06 \\
\hline 16 & 1,14 & 0,05 & 1,10 & 0,05 & S2 & 1,39 & 0,06 & 1,34 & 0,06 \\
\hline J1 & 1,13 & 0,08 & 1,09 & 0,08 & T1 & 1,34 & 0,06 & 1,29 & 0,06 \\
\hline K1 & 1,24 & 0,05 & 1,20 & 0,05 & U1 & 1,25 & 0,22 & 1,21 & 0,21 \\
\hline
\end{tabular}

A dependência energética para a grandeza de taxa de equivalente de dose ambiente foi menor do que a dependência energética para taxa de kerma no ar para os detectores Geiger-Müller, devido ao fator de conversão, especificado na Tabela 2.1, para cobalto ser menor do que césio, sendo um fator multiplicativo de aproximadamente de 0,97. Este fator diminui o valor da dependência energética para equivalente de dose ambiente. Enquanto o maior valor da dependência energética para kerma no ar foi de $(1,58 \pm 0,18)$ para 0 
detector Geiger-Müller E1, para a grandeza equivalente de dose ambiente o maior valor foi de $(1,53 \pm 0,17)$ para o mesmo instrumento.

Tabela 4.9 Dependência energética, DE, da resposta das câmaras de ionização, para as grandezas $K_{a r}$ e $H^{*}(10)$.

\begin{tabular}{c|cc|cc}
\hline Código & $\begin{array}{c}\boldsymbol{D E} \\
\left(\boldsymbol{K}_{a \boldsymbol{r}}\right)\end{array}$ & $\boldsymbol{U}$ & $\begin{array}{c}\boldsymbol{D} \boldsymbol{E} \\
\left(\boldsymbol{H}^{*}(\mathbf{1 0})\right)\end{array}$ & $\boldsymbol{U}$ \\
\hline B'1 & 1,01 & 0,05 & 0,97 & 0,05 \\
B'2 & 1,04 & 0,05 & 1,01 & 0,05 \\
\hline C'1 & 1,01 & 0,05 & 0,98 & 0,05 \\
\hline D'1 & 1,00 & 0,04 & 0,97 & 0,04 \\
\hline I'1 & 1,01 & 0,05 & 0,98 & 0,04 \\
\hline J'1 & 1,00 & 0,04 & 0,97 & 0,04 \\
\hline K'2 & 1,06 & 0,05 & 1,02 & 0,05 \\
\hline L'1 & 1,00 & 0,05 & 0,97 & 0,04 \\
L'2 & 1,04 & 0,05 & 1,00 & 0,04 \\
L'3 & 1,00 & 0,04 & 0,97 & 0,04 \\
L'4 & 1,00 & 0,04 & 0,97 & 0,04 \\
\hline M '1 & 1,01 & 0,05 & 0,98 & 0,04 \\
\hline
\end{tabular}

As câmaras de ionização apresentaram pouca ou nenhuma dependência energética para taxa de kerma no ar; aplicando-se os fatores de conversão da Tabela 2.1, para taxa de equivalente de dose ambiente, a dependência energética sofreu um pequeno aumento, apresentando valores menores que um. Levando-se em conta as incertezas das medições, os resultados ficaram dentro do esperado e bem próximos à dependência obtida para taxa de kerma no ar.

\subsubsection{Dependência angular dos detectores para radiação gama}

Para o estudo de dependência angular dos detectores de radiação, foi inicialmente escolhida a escala em que cada instrumento apresentasse uma leitura estável. Foram selecionados alguns detectores Geiger-Müller, detectores semicondutores e câmaras de ionização para o estudo da dependência angular, aplicando-se as Equações 4.1 e 4.2.

As incertezas das medições obtidas na calibração de cada instrumento estão esquematizadas de acordo com a Tabela 4.10. Além da incerteza do tipo 
A, representado pelo desvio padrão das medições, foram determinadas cinco incertezas do tipo B: a primeira incerteza foi determinada para 0 posicionamento do centro do volume sensível do tubo Geiger-Müller, com uma régua em $\mathrm{cm}$; a segunda incerteza foi calculada para a distância do instrumento em relação à fonte, dada pela incerteza do ponteiro em relação à fita métrica sob o trilho; a terceira incerteza foi determinada para as câmaras de ionização, cujas respostas necessitam de correção para as condições normais de temperatura e pressão; a quarta e a quinta incertezas representam a parte da marcação dos ângulos no goniômetro por meio de um transferidor e a centralização da parte circular do goniômetro por meio de uma régua.

Tabela 4.10 Incertezas das medições dos instrumentos utilizados para o estudo da dependência angular.

\begin{tabular}{ccccc}
\hline & Fontes de incerteza & Resolução & $\mathbf{1 / 2}$ Resolução & Incerteza \\
\hline Símbolo & Descrição & & & - \\
\hline $\boldsymbol{u}(\boldsymbol{A})$ & $\begin{array}{c}\text { Incerteza tipo A/ } \\
\text { Desvio padrão }\end{array}$ & - & - & - \\
\hline $\boldsymbol{u}(\boldsymbol{B})_{\boldsymbol{1}}$ & $\begin{array}{c}\text { Incerteza tipo B/ } \\
\text { Posição do tubo Geiger-Müller }(\mathrm{cm})\end{array}$ & $0,50 \times 10^{-1}$ & $0,25 \times 10^{-1}$ & $0,14 \times 10^{-1}$ \\
\hline $\boldsymbol{u}(\boldsymbol{B})_{2}$ & $\begin{array}{c}\text { Incerteza tipo B/ } \\
\text { Distância fonte-detector (cm) }\end{array}$ & $1,00 \times 10^{-1}$ & $0,50 \times 10^{-1}$ & $0,29 \times 10^{-1}$ \\
\hline $\boldsymbol{u}(\boldsymbol{B})_{3}$ & $\begin{array}{c}\text { Incerteza tipo B/ } \\
\text { Fator de temperatura e pressão }\end{array}$ & $0,02 \times 10^{-1}$ & $0,01 \times 10^{-1}$ & $5,77 \times 10^{-4}$ \\
\hline $\boldsymbol{u}(\boldsymbol{B})_{4}$ & $\begin{array}{c}\text { Incerteza tipo B/ } \\
\text { Transferidor }\end{array}$ & $0,28 \times 10^{-2}$ & $0,14 \times 10^{-2}$ & $0,81 \times 10^{-3}$ \\
\hline $\boldsymbol{u}(\boldsymbol{B})_{5}$ & $\begin{array}{c}\text { Incerteza tipo B/ } \\
\text { Régua }\end{array}$ & $0,50 \times 10^{-1}$ & $0,25 \times 10^{-1}$ & $0,14 \times 10^{-1}$ \\
\hline $\boldsymbol{U}_{\boldsymbol{c}}$ & Incerteza combinada & - & - & - \\
\hline $\boldsymbol{U}$ & Incerteza expandida & - & - & - \\
\hline
\end{tabular}

As medições $\mathrm{M}\left(0^{0}\right), \mathrm{M}\left(+45^{0}\right)$ e $\mathrm{M}\left(-45^{0}\right)$ foram realizadas em campo de radiação de ${ }^{137} \mathrm{Cs}$ e estão apresentadas nas Tabelas 4.11 e 4.12 . Os resultados da dependência angular estão apresentados nas Tabelas $4.13 \mathrm{e}$ 4.14 .

Alguns desses instrumentos foram selecionados para a realização de uma varredura angular, com medições para ângulos de $0^{\circ}, \pm 15^{\circ}, \pm 30^{\circ}, \pm 45^{\circ}$, $\pm 60^{\circ}$ e $\pm 90^{\circ}$, com o objetivo de analisar a resposta angular em curvas representadas nas Figuras 4.3 a 4.9 . 
Tabela 4.11 Resposta dos detectores Geiger-Müller e do semicondutor X1, para ângulos diferentes de incidência do feixe de radiação gama $\left({ }^{137} \mathrm{Cs}\right)$.

\begin{tabular}{|c|c|c|c|c|c|c|c|c|c|c|}
\hline \multicolumn{11}{|c|}{ Medições para ângulos } \\
\hline Código & $\begin{array}{c}M \\
\left(0^{0}\right)\end{array}$ & $\begin{array}{c}U_{c} \\
\left(0^{0}\right)\end{array}$ & $\begin{array}{c}u(A) \\
\left(0^{0}\right)\end{array}$ & $\begin{array}{c}M \\
\left(+45^{0}\right)\end{array}$ & $\begin{array}{c}U_{c} \\
\left(+45^{0}\right)\end{array}$ & $\begin{array}{c}u(A) \\
\left(+45^{\circ}\right)\end{array}$ & $\begin{array}{c}M \\
\left(-45^{0}\right)\end{array}$ & $\begin{array}{c}U_{c} \\
\left(-45^{0}\right)\end{array}$ & $\begin{array}{c}u(A) \\
\left(-45^{0}\right)\end{array}$ & Unidade \\
\hline A3 & 522,50 & 11,36 & 11,36 & 478,90 & 8,67 & 8,67 & 488,40 & 4,72 & 4,72 & $\mu S v / h$ \\
\hline B2 & 26,00 & 0,53 & 0,53 & 25,00 & 0,50 & 0,50 & 27,00 & 0,44 & 0,44 & $\mathrm{mR} / \mathrm{h}$ \\
\hline C1 & 4,79 & 0,09 & 0,09 & 4,49 & 0,04 & 0,03 & 4,53 & 0,07 & 0,06 & $\mathrm{mR} / \mathrm{h}$ \\
\hline C2 & 4,92 & 0,06 & 0,06 & 4,56 & 0,13 & 0,13 & 4,93 & 0,05 & 0,04 & $\mathrm{mR} / \mathrm{h}$ \\
\hline C3 & 4,72 & 0,15 & 0,15 & 4,47 & 0,12 & 0,12 & 4,71 & 0,07 & 0,07 & $\mathrm{mR} / \mathrm{h}$ \\
\hline C5 & 51,20 & 0,50 & 0,50 & 47,02 & 0,49 & 0,49 & 47,03 & 0,63 & 0,63 & $\mathrm{mR} / \mathrm{h}$ \\
\hline D1 & 2,57 & 0,23 & 0,23 & 2,36 & 0,29 & 0,29 & 2,31 & 0,20 & 0,20 & $\mathrm{mR} / \mathrm{h}$ \\
\hline E1 & 15,00 & 0,67 & 0,67 & 12,50 & 1,13 & 1,13 & 14,00 & 1,51 & 1,51 & $\mathrm{mR} / \mathrm{h}$ \\
\hline E2 & 20,40 & 0,70 & 0,70 & 19,90 & 0,88 & 0,88 & 17,30 & 1,57 & 1,57 & $\mathrm{mR} / \mathrm{h}$ \\
\hline F1 & 106,90 & 1,45 & 1,45 & 100,00 & 0,02 & 0,00 & 100,60 & 0,52 & 0,52 & $\mathrm{mR} / \mathrm{h}$ \\
\hline G1 & 64,95 & 0,25 & 0,25 & 88,16 & 0,22 & 0,22 & 86,37 & 0,18 & 0,18 & $\mathrm{mR} / \mathrm{h}$ \\
\hline G2 & 72,16 & 0,33 & 0,33 & 86,68 & 0,36 & 0,36 & 85,55 & 0,25 & 0,25 & $\mathrm{mR} / \mathrm{h}$ \\
\hline G3 & 68,96 & 0,24 & 0,24 & 86,97 & 0,51 & 0,51 & 86,10 & 2,10 & 2,10 & $\mathrm{mR} / \mathrm{h}$ \\
\hline H1 & 9,85 & 0,24 & 0,24 & 10,00 & 0,02 & 0,00 & 10,00 & 0,02 & 0,00 & $\mathrm{mR} / \mathrm{h}$ \\
\hline H2 & 10,50 & 0,02 & 0,00 & 9,71 & 0,21 & 0,21 & 9,63 & 0,19 & 0,19 & $\mathrm{mR} / \mathrm{h}$ \\
\hline H3 & 105,00 & 5,27 & 5,27 & 100,00 & 0,02 & 0,00 & 100,00 & 0,02 & 0,00 & $\mathrm{mR} / \mathrm{h}$ \\
\hline H4 & 400,00 & 0,02 & 0,00 & 366,00 & 21,19 & 21,19 & 400,00 & 0,02 & 0,00 & $\mu \mathrm{Sv} / \mathrm{h}$ \\
\hline H5 & 10,77 & 0,21 & 0,21 & 10,77 & 0,21 & 0,21 & 9,67 & 0,36 & 0,36 & $\mathrm{mR} / \mathrm{h}$ \\
\hline 15 & 100,00 & 0,02 & 0,00 & 97,20 & 0,92 & 0,92 & 91,20 & 0,42 & 0,42 & $\mathrm{mR} / \mathrm{h}$ \\
\hline 16 & 102,40 & 1,90 & 1,90 & 93,10 & 1,60 & 1,60 & 97,10 & 1,37 & 1,37 & $\mathrm{mR} / \mathrm{h}$ \\
\hline k1 & 50,63 & 0,07 & 0,07 & 48,20 & 0,19 & 0,19 & 47,76 & 0,11 & 0,11 & $\mathrm{mR} / \mathrm{h}$ \\
\hline L8 & 5,26 & 0,19 & 0,19 & 5,38 & 0,29 & 0,29 & 5,53 & 0,22 & 0,22 & $\mathrm{mR} / \mathrm{h}$ \\
\hline L9 & 5,16 & 0,25 & 0,25 & 4,72 & 0,11 & 0,10 & 4,72 & 0,14 & 0,14 & $\mathrm{mR} / \mathrm{h}$ \\
\hline L10 & 5,04 & 0,13 & 0,13 & 5,08 & 0,17 & 0,17 & 5,32 & 0,14 & 0,14 & $\mathrm{mR} / \mathrm{h}$ \\
\hline M1 & 5,18 & 0,20 & 0,20 & 7,26 & 0,19 & 0,19 & 7,14 & 0,14 & 0,13 & $\mathrm{mR} / \mathrm{h}$ \\
\hline N2 & 50,60 & 0,97 & 0,97 & 49,90 & 0,32 & 0,32 & 49,60 & 0,84 & 0,84 & $\mathrm{mR} / \mathrm{h}$ \\
\hline N3 & 53,80 & 0,63 & 0,63 & 53,10 & 0,99 & 0,99 & 53,80 & 0,63 & 0,63 & $\mathrm{mR} / \mathrm{h}$ \\
\hline 01 & 4,88 & 0,19 & 0,19 & 4,38 & 0,12 & 0,11 & 4,37 & 0,13 & 0,13 & $\mathrm{mR} / \mathrm{h}$ \\
\hline R2 & 3,64 & 0,20 & 0,19 & 4,49 & 0,17 & 0,17 & 4,80 & 0,36 & 0,36 & $\mathrm{mR} / \mathrm{h}$ \\
\hline S1 & 5,44 & 0,13 & 0,13 & 5,24 & 0,16 & 0,16 & 5,04 & 0,21 & 0,21 & $\mathrm{mR} / \mathrm{h}$ \\
\hline S2 & 53,40 & 0,97 & 0,97 & 48,00 & 0,02 & 0,00 & 48,00 & 0,02 & 0,00 & $\mathrm{mR} / \mathrm{h}$ \\
\hline T1 & 1,73 & 0,10 & 0,09 & 1,63 & 0,08 & 0,08 & 1,69 & 0,09 & 0,09 & $\mathrm{mR} / \mathrm{h}$ \\
\hline $\mathrm{X} 1$ & 454,00 & 14,25 & 14,25 & 424,40 & 13,66 & 13,66 & 398,90 & 16,56 & 16,56 & $\mu \mathrm{Sv} / \mathrm{h}$ \\
\hline
\end{tabular}


Tabela 4.12 Resposta das câmaras de ionização, para ângulos diferentes de incidência do feixe de radiação gama $\left({ }^{137} \mathrm{Cs}\right)$.

\begin{tabular}{|c|c|c|c|c|c|c|c|c|c|c|}
\hline \multicolumn{11}{|c|}{ Medições para ângulos } \\
\hline Código & $\begin{array}{c}M \\
\left(0^{0}\right)\end{array}$ & $\begin{array}{c}U_{c} \\
\left(0^{0}\right)\end{array}$ & $\begin{array}{c}u(A) \\
\left(\theta^{0}\right)\end{array}$ & $\begin{array}{c}M \\
\left(+45^{0}\right)\end{array}$ & $\begin{array}{c}U_{c} \\
\left(+45^{0}\right)\end{array}$ & $\begin{array}{c}u(A) \\
\left(+45^{\circ}\right)\end{array}$ & $\begin{array}{c}M \\
\left(-45^{0}\right)\end{array}$ & $\begin{array}{c}U_{c} \\
\left(-45^{0}\right)\end{array}$ & $\begin{array}{c}u(A) \\
\left(-45^{0}\right)\end{array}$ & Unidade \\
\hline B'1 $^{\prime}$ & 24,00 & 0,02 & 0,00 & 24,00 & 0,02 & 0,00 & 24,00 & 0,02 & 0,00 & \multirow{8}{*}{$\mathrm{mR} / \mathrm{h}$} \\
\hline$C^{\prime} 1$ & 22,55 & 0,52 & 0,52 & 23,73 & 0,47 & 0,47 & 24,00 & 0,45 & 0,45 & \\
\hline J'1 & 24,70 & 0,48 & 0,48 & 24,80 & 0,42 & 0,42 & 24,00 & 0,02 & 0,00 & \\
\hline$K^{\prime} 1$ & 420,00 & 0,02 & 0,00 & 448,00 & 4,22 & 4,22 & 444,00 & 5,16 & 5,16 & \\
\hline L'1 & 28,00 & 0,32 & 0,32 & 26,00 & 0,02 & 0,00 & 26,00 & 0,02 & 0,00 & \\
\hline L'2 & 10,51 & 0,15 & 0,15 & 10,59 & 0,09 & 0,09 & 10,58 & 0,11 & 0,11 & \\
\hline L'3 & 10,26 & 0,05 & 0,05 & 10,25 & 0,06 & 0,05 & 10,28 & 0,11 & 0,10 & \\
\hline L'4 & 10,26 & 0,06 & 0,05 & 10,22 & 0,09 & 0,09 & 10,21 & 0,08 & 0,07 & \\
\hline
\end{tabular}

Foi possível obter a dependência angular, apresentada nas Tabelas 4.13 e 4.14 e verificado se a dependência angular está de acordo com a norma internacional EN 60846 (EN, 2004), que determina que a variação das medições entre ângulos de $0^{\circ} \mathrm{e} \pm 45^{\circ}$ não deve ser maior que $40 \%$. 
Tabela 4.13 Dependência angular, DA, dos detectores Geiger-Müller e do detector semicondutor $\mathrm{X} 1$, para ângulos diferentes de incidência do feixe de radiação gama $\left({ }^{137} \mathrm{Cs}\right)$.

\begin{tabular}{c|cc|cc}
\hline Código & $\boldsymbol{D A}_{+}$ & $\boldsymbol{U}$ & $\boldsymbol{D A}$ & $\boldsymbol{U}$ \\
\hline A3 & 1,09 & 0,06 & 1,07 & 0,05 \\
\hline B2 & 1,04 & 0,06 & 0,96 & 0,05 \\
\hline C1 & 1,07 & 0,04 & 1,06 & 0,05 \\
C2 & 1,08 & 0,06 & 1,00 & 0,03 \\
C3 & 1,06 & 0,09 & 1,00 & 0,07 \\
C5 & 1,09 & 0,03 & 1,09 & 0,04 \\
\hline D1 & 1,09 & 0,33 & 1,11 & 0,28 \\
\hline E1 & 1,20 & 0,24 & 1,07 & 0,25 \\
E2 & 1,03 & 0,11 & 1,18 & 0,23 \\
\hline F1 & 1,07 & 0,03 & 1,06 & 0,03 \\
\hline G1 & 0,74 & 0,01 & 0,75 & 0,01 \\
G2 & 0,83 & 0,01 & 0,84 & 0,01 \\
G3 & 0,79 & 0,01 & 0,80 & 0,04 \\
\hline H1 & 0,99 & 0,05 & 0,99 & 0,05 \\
H2 & 1,08 & 0,05 & 1,09 & 0,04 \\
H3 & 1,05 & 0,11 & 1,05 & 0,11 \\
H4 & 1,09 & 0,13 & 1,00 & 0,00 \\
H5 & 1,00 & 0,05 & 1,11 & 0,09 \\
\hline I5 & 1,03 & 0,02 & 1,10 & 0,01 \\
I6 & 1,10 & 0,06 & 1,05 & 0,05 \\
\hline k1 & 1,05 & 0,01 & 1,06 & 0,01 \\
\hline L8 & 0,98 & 0,13 & 0,95 & 0,10 \\
L9 & 1,09 & 0,11 & 1,09 & 0,12 \\
L10 & 0,99 & 0,08 & 0,95 & 0,07 \\
\hline M1 & 0,71 & 0,07 & 0,73 & 0,06 \\
\hline N2 & 1,01 & 0,04 & 1,02 & 0,05 \\
N3 & 1,01 & 0,04 & 1,00 & 0,03 \\
\hline O1 & 1,11 & 0,11 & 1,12 & 0,11 \\
\hline R2 & 0,81 & 0,11 & 0,76 & 0,14 \\
\hline S1 & 1,04 & 0,08 & 1,08 & 0,10 \\
S2 & 1,11 & 0,04 & 1,11 & 0,04 \\
\hline T1 & 1,06 & 0,16 & 1,02 & 0,15 \\
\hline X1 & 1,07 & 0,10 & 1,14 & 0,12 \\
\hline & & & & \\
\hline
\end{tabular}


Tabela 4.14 Dependência angular, DA, das câmaras de ionização, para ângulos diferentes de incidência do feixe de radiação gama $\left({ }^{137} \mathrm{Cs}\right)$.

\begin{tabular}{c|cc|cc}
\hline Código & $\boldsymbol{D A}_{+}$ & $\boldsymbol{U}$ & $\boldsymbol{D} \boldsymbol{A}_{-}$ & $\boldsymbol{U}$ \\
\hline B'1 & 1,00 & 0,00 & 1,00 & 0,00 \\
\hline C'1 & 0,95 & 0,06 & 0,94 & 0,06 \\
\hline J'1 & 1,00 & 0,05 & 1,03 & 0,04 \\
\hline K'1 & 0,94 & 0,02 & 0,95 & 0,02 \\
\hline L'1 & 1,08 & 0,02 & 1,08 & 0,02 \\
L'2 & 0,99 & 0,03 & 0,99 & 0,04 \\
L'3 & 1,00 & 0,02 & 1,00 & 0,02 \\
L'4 & 1,00 & 0,02 & 1,00 & 0,02 \\
\hline
\end{tabular}

Todos os instrumentos apresentados nas Tabelas 4.13 e 4.14 apresentaram variações menores que $40 \%$ nas respostas entre $0^{\circ}$ e $\pm 45^{\circ}$, mostrando que os instrumentos estão de acordo com a norma internacional EN 60846 (EN, 2004), mesmo levando-se em conta as incertezas. As câmaras de ionização, Tabela 4.14, apresentaram uma dependência angular de apenas $6 \%$ para as câmaras de ionização K'1 $(0,94 \pm 0,02)$ com relação à dependência angular ao lado positivo e C'1 $(0,94 \pm 0,06)$ com relação à dependência angular ao lado negativo. Os detectores Geiger-Müller apresentaram uma dependência angular de até $27 \%$, Tabela 4.13 , do detector M1 $(0,73 \pm 0,06)$ no lado negativo. Mesmo levando-se em conta as incertezas, o detector R2 $(0,76 \pm 0,14)$ teria uma dependência angular no máximo de $38 \%$. 0 semicondutor $\mathrm{X} 1$ também correspondeu ao padrão normativo.

Nas Figuras 4.3 a 4.9, são apresentadas as curvas da resposta angular de alguns instrumentos para uma varredura entre $0^{\circ} \mathrm{e} \pm 90^{\circ}$. 

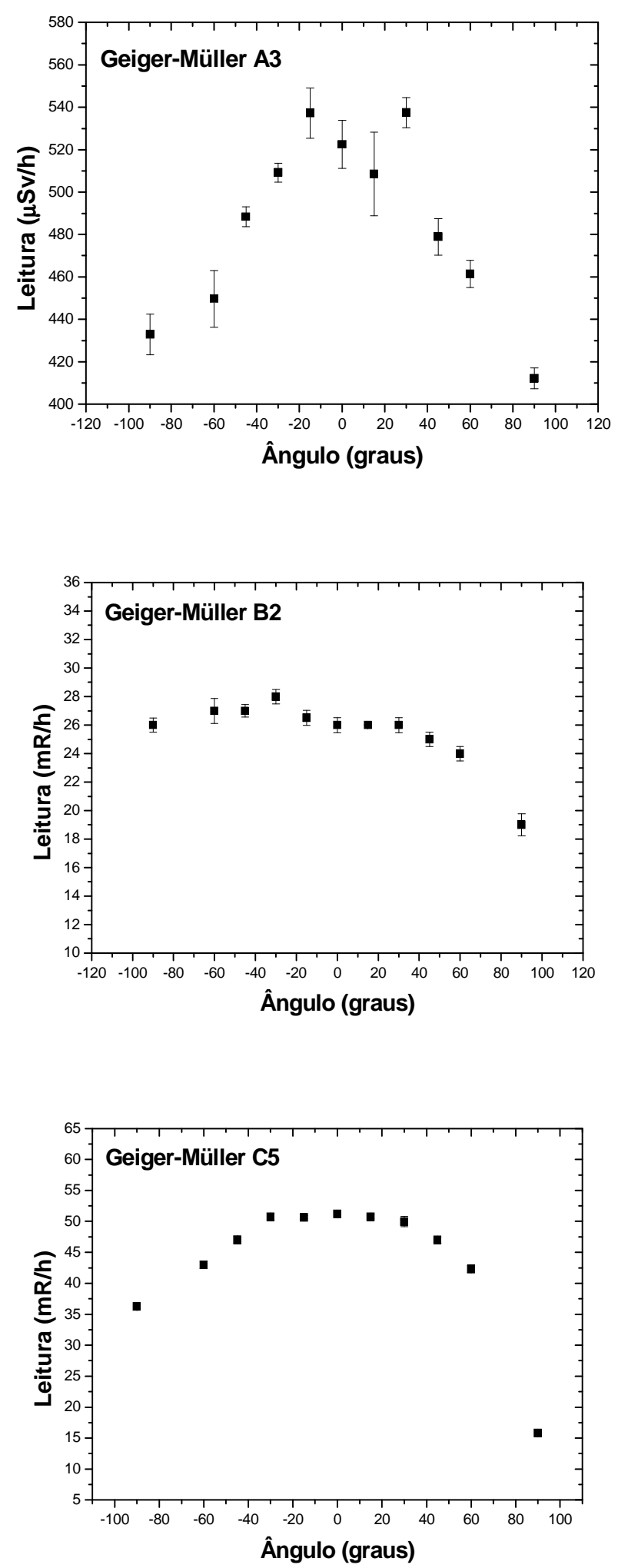

Figura 4.3 Resposta angular dos detectores Geiger-Müller A3, B2 e C5. 

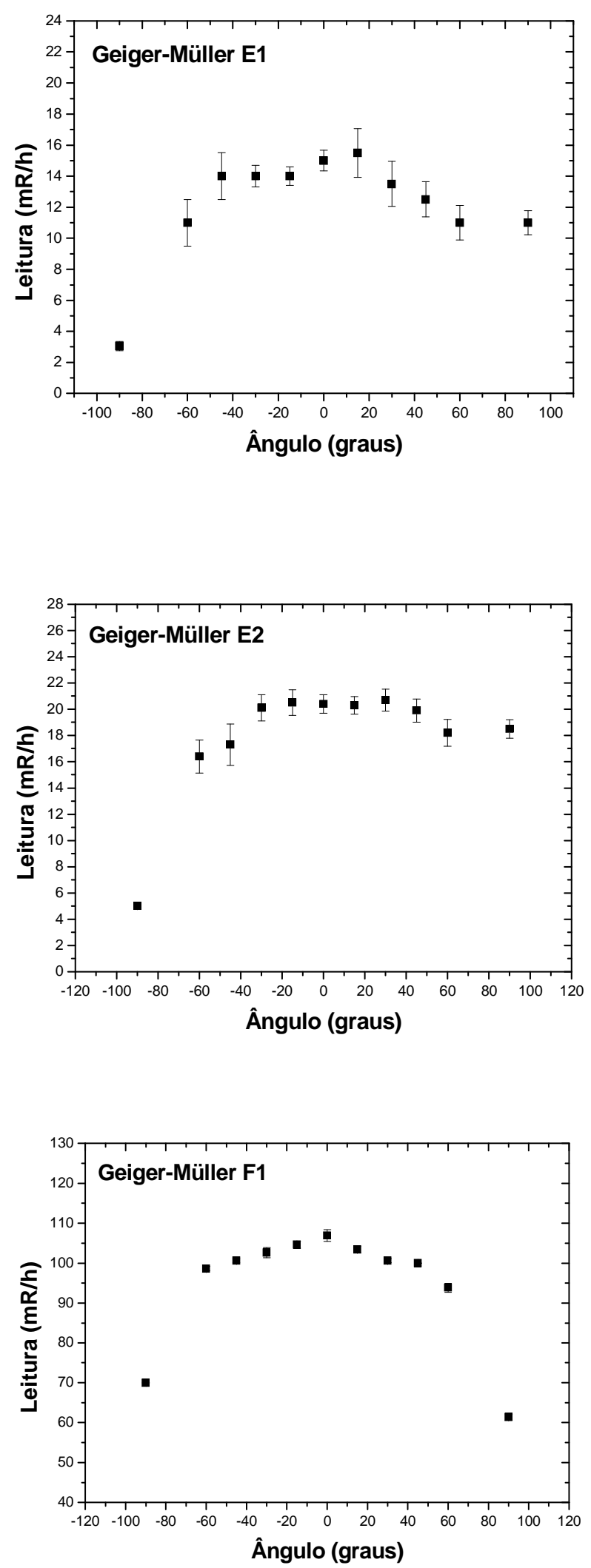

Figura 4.4 Resposta angular dos detectores Geiger-Müller E1, E2 e F1. 

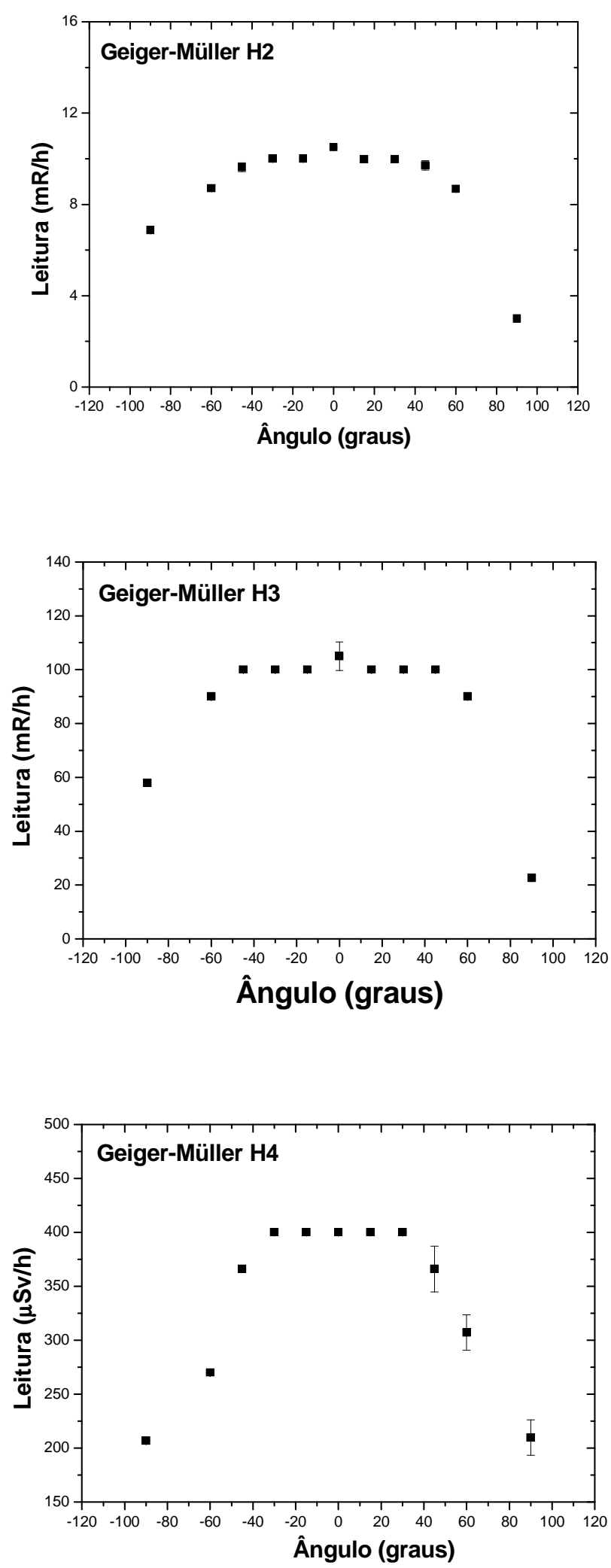

Figura 4.5 Resposta angular dos detectores Geiger-Müller H2, H3 e H4. 

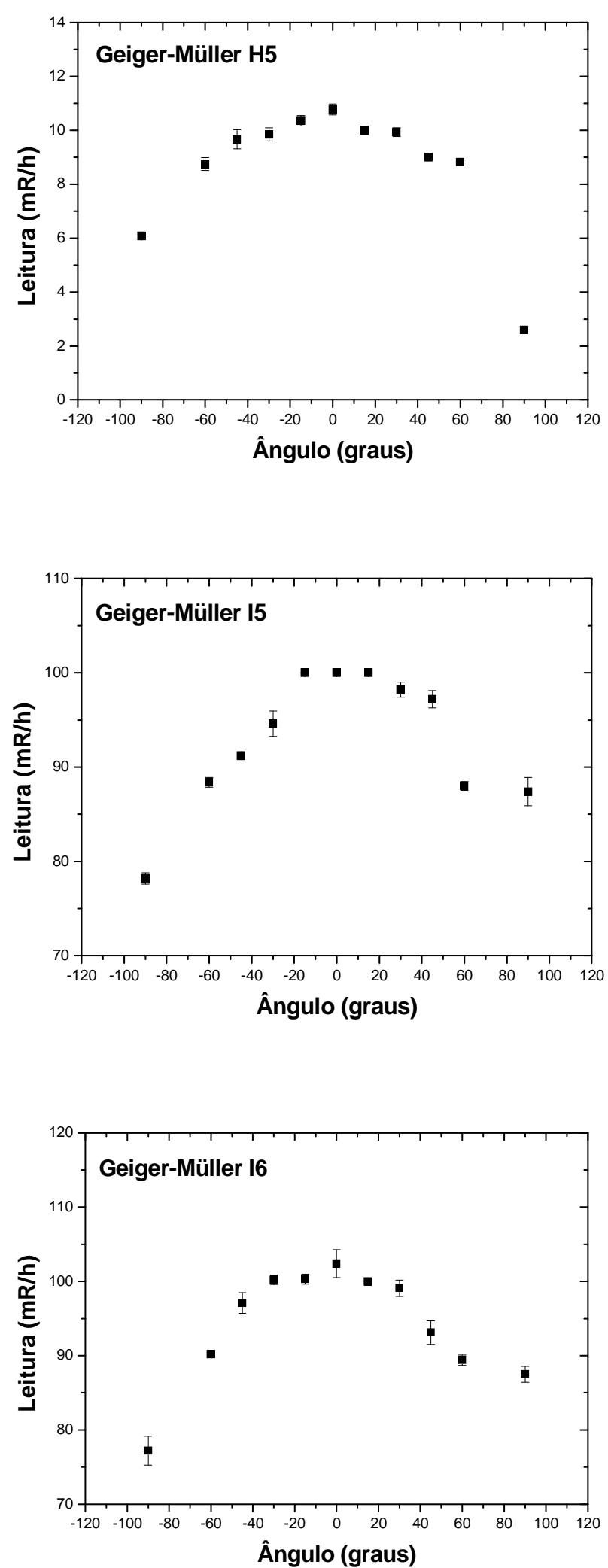

Figura 4.6 Resposta angular dos detectores Geiger-Müller H5, I5 e I6. 

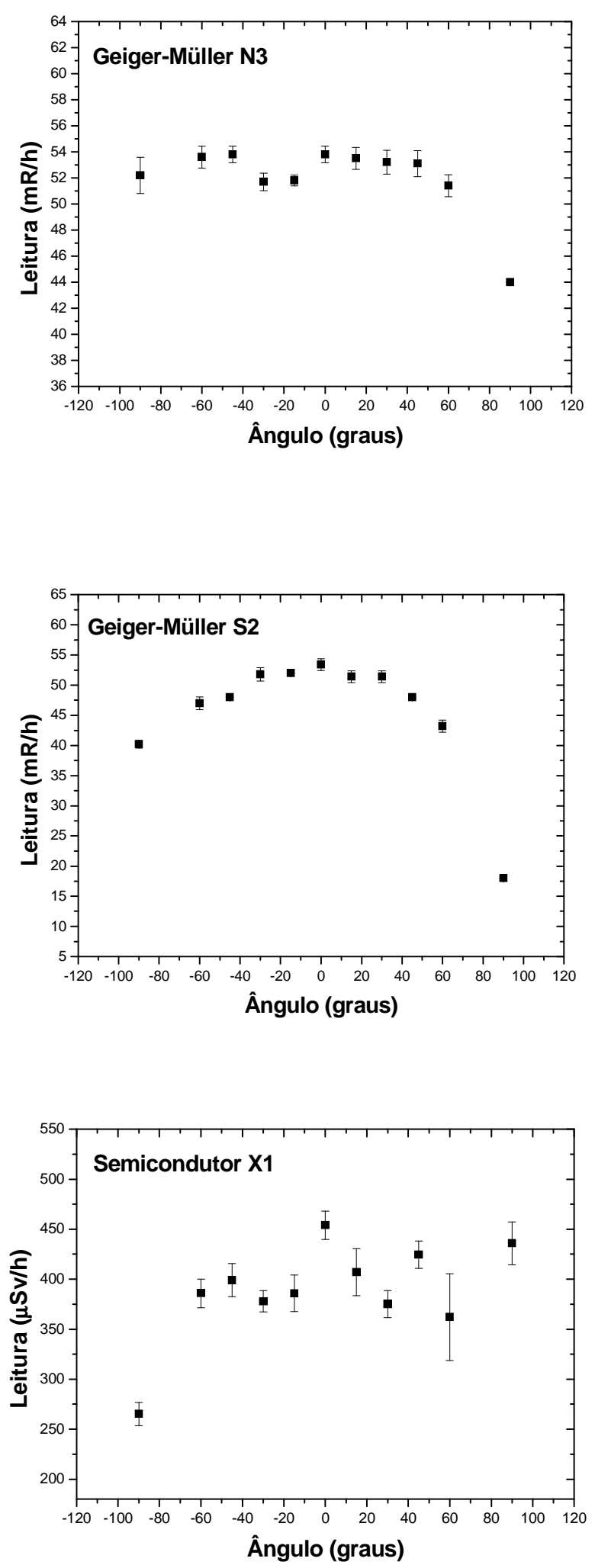

Figura 4.7 Resposta angular dos detectores Geiger-Müller N3 e S2 e do semicondutor $\mathrm{X} 1$. 

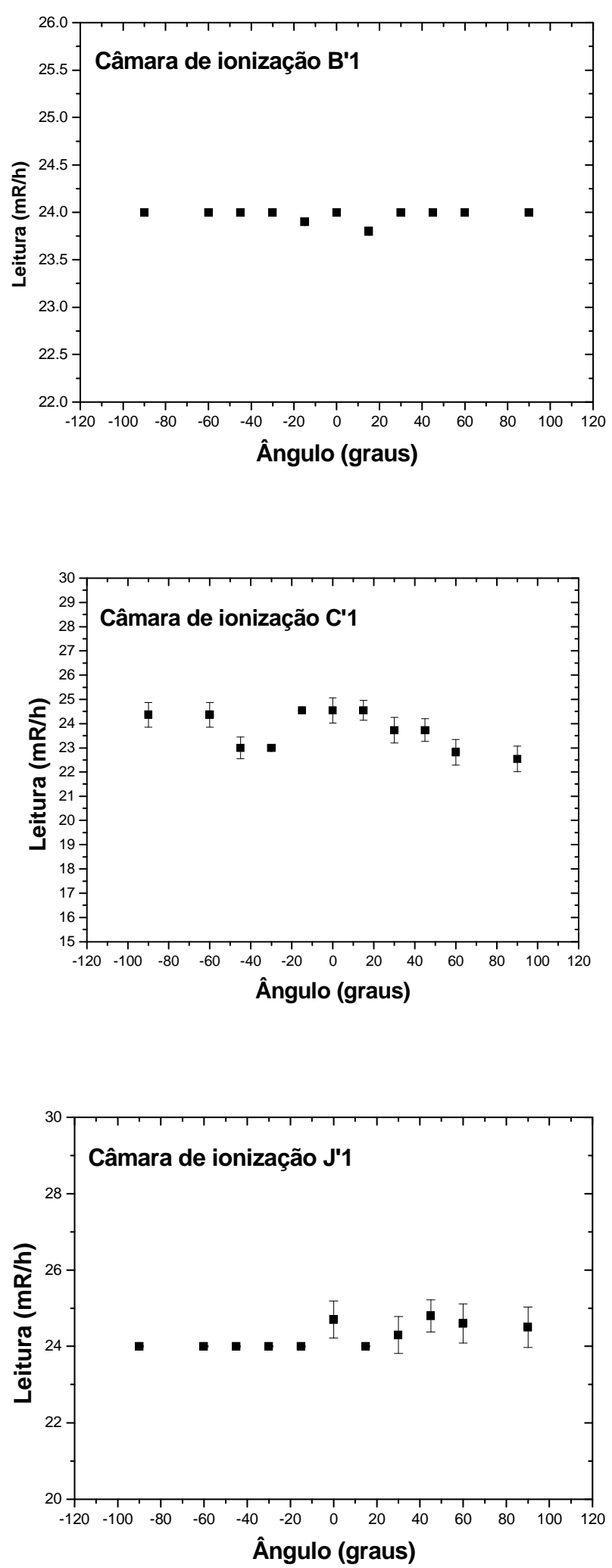

Figura 4.8 Resposta angular das câmaras de ionização B'1, C'1 e J'1. 


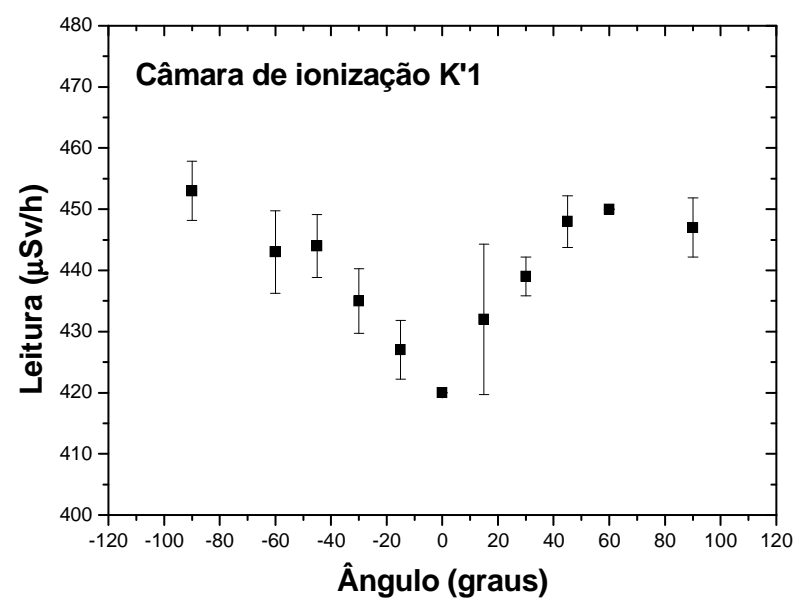

Figura 4.9 Resposta angular da câmara de ionização K'1.

As Figuras 4.3 a 4.7 apresentam o comportamento da resposta angular para vários modelos de detectores Geiger-Müller. Observa-se que 0 comportamento da resposta dos detectores é variado. Isto se deve a alguns fatores, como por exemplo a geometria do tubo do detector Geiger-Müller; se o tubo Geiger-Müller é interno ou externo ao instrumento; e no caso da sonda ser externa ao instrumento, ainda assim poderá ocorrer diferença de resposta entre os modelos, por causa do material que envolve o tubo, por exemplo. Mesmo para um mesmo modelo de detector pode-se observar algumas diferenças de comportamento, como nos detectores $\mathrm{H} 2, \mathrm{H} 3$ e H4 da Figura 4.5 e do detector H5 apresentado na Figura 4.6.

Observa-se na Figura 4.3 que o modelo A3 apresenta medições para ângulos de $\pm 30^{\circ}$ maiores do que para o ângulo de $0^{0}$; isto se deve à geometria do detector de radiação e à posição do tubo Geiger-Müller no interior do detector.

Para o semicondutor $\mathrm{X} 1$ da Figura 4.7, seu comportamento foi assimétrico, provavelmente pelo fato das suas medições sofrerem oscilações no momento da calibração; pode-se considerar também a sua geometria uma das causas desta assimetria. Assim como o detector semicondutor X1, que apresentou oscilações nas medições para a maioria dos ângulos de incidência de radiação gama, com um desvio padrão maior, outros detectores apresentaram também esta variação, para alguns ângulos, evidenciando um 
aumento do desvio padrão para alguns pontos. Como exemplo, têm-se os detectores: A3 da Figura 4.3; E1 da Figura 4.4; e H4 da Figura 4.5.

No caso das câmaras de ionização, que normalmente apresentam uma estabilidade boa quando são tomadas as medições, também sofreram algumas oscilações, como a câmara de ionização K'1, da Figura 4.9. As câmaras de ionização apresentaram pouca diferença nas medições efetuadas para ângulos diferentes. Pode ser observado na Figura 4.8 que as câmaras de ionização B'1, C'1 e J'1 apresentam pouca dependência angular.

\subsection{Testes com radiação beta}

Foram testados e calibrados com radiação beta vinte e oito detectores Geiger-Müller de oito marcas e doze modelos diferentes e seis câmaras de ionização de três marcas e quatro modelos diferentes. Os detectores semicondutores não foram estudados neste caso, pois não apresentam indicação de possibilidade de detecção de radiação beta.

\subsubsection{Resposta dos detectores de radiação}

Neste estudo, cada detector portátil foi posicionado sobre um suporte especial, a uma certa distância da fonte de radiação, sendo que o ponto de referência do aparelho foi sempre o centro geométrico do tubo (sensor) Geiger-Müller ou da câmara de ionização. Este centro geométrico era coincidente com o centro do campo de radiação da fonte utilizada. Foi escolhida uma escala do instrumento adequada à taxa de dose da fonte, de acordo com a distância entre a fonte e o instrumento. Foram obtidas dez medições cada vez que se submeteu o instrumento à radiação. Primeiramente foram efetuadas medições de radiação de fundo (sem exposição à fonte) e, a seguir, utilizando-se a fonte de ${ }^{90} \mathrm{Sr}+{ }^{90} \mathrm{Y}$ na posição frontal. Após a exposição à fonte de ${ }^{90} \mathrm{Sr}+{ }^{90} \mathrm{Y}$, cada monitor portátil foi submetido ao feixe de ${ }^{204} \mathrm{TI}$.

De acordo com 0 certificado das fontes de radiação beta (PTW,1981; PTW, 1990), as fontes de referência utilizadas neste estudo possuem as seguintes incertezas para a grandeza taxa de dose absorvida no 
ar, $D_{a r}:$ fonte de ${ }^{90} \mathrm{Sr}+{ }^{90} \mathrm{Y}$, incerteza de $1 \%$ (PTW, 1981) e fonte de ${ }^{204} \mathrm{TI}$, incerteza tipo A de 0,1\% e incerteza tipo B de 0,4\% (PTW, 1990). As incertezas das medições das fontes de referência e as medições obtidas pelos instrumentos calibrados foram determinadas de acordo com as recomendações de Gonçalves e Souza (GONÇALVES e SOUSA, 2008).

As incertezas das medições obtidas na calibração de cada instrumento estão de acordo com a Tabela 4.15. Foram calculadas três incertezas do tipo $\mathrm{B}$; a primeira incerteza foi determinada para o posicionamento do centro do volume sensor do tubo Geiger-Müller, com uma régua em $\mathrm{cm}$; a segunda incerteza foi calculada para a distância do instrumento em relação à fonte, dada pela incerteza da fita métrica do trilho que determina a distância do instrumento a ser calibrado em relação à fonte; e a terceira incerteza do tipo $B$ foi determinada para as câmaras de ionização cujas respostas necessitam ser corrigidas para as condições normais de temperatura e pressão. Também foi obtida a incerteza do tipo $A$, representada pelo valor do desvio padrão médio das medições.

Tabela 4.15 Incertezas das medições dos instrumentos testados/calibrados com radiação beta.

\begin{tabular}{ccccc}
\hline & Fontes de incerteza & Resolução & $\mathbf{1 / 2}$ Resolução & Incerteza \\
\hline Símbolo & Descrição & & - \\
\hline $\boldsymbol{u}(\boldsymbol{A})$ & $\begin{array}{c}\text { Incerteza tipo A/ } \\
\text { Desvio padrão }\end{array}$ & - & - \\
\hline $\boldsymbol{u}(\boldsymbol{B})_{\boldsymbol{1}}$ & Posição do tubo Geiger-Müller (cm) & $0,50 \times 10^{-1}$ & $0,25 \times 10^{-1}$ & $0,14 \times 10^{-1}$ \\
\hline $\boldsymbol{u}(\boldsymbol{B})_{2}$ & $\begin{array}{c}\text { Incerteza tipo B/ } \\
\text { Incerteza tipo B/ }\end{array}$ & $0,50 \times 10^{-1}$ & $0,25 \times 10^{-1}$ & $0,14 \times 10^{-1}$ \\
\hline $\boldsymbol{u}(\boldsymbol{B})_{3}$ & Fator de temperatura e pressão & $0,02 \times 10^{-1}$ & $0,01 \times 10^{-1}$ & $5,77 \times 10^{-4}$ \\
\hline $\boldsymbol{u}\left(\boldsymbol{V}_{\boldsymbol{c}}\right)$ & $\begin{array}{c}\text { Incerteza tipo B/ } \\
\text { Incerteza do valor }\end{array}$ & - & - & - \\
\hline $\boldsymbol{U}_{\boldsymbol{c}}$ & verdadeiro convencional & - & - & - \\
\hline $\boldsymbol{U}$ & Incerteza combinada & - & - & - \\
\hline
\end{tabular}

As respostas dos detectores Geiger-Müller e das câmaras de ionização para radiação beta estão apresentadas nas Tabelas 4.16 e 4.17. 
Tabela 4.16 Resposta dos detectores Geiger-Müller para radiação beta.

\begin{tabular}{|c|c|c|c|c|c|c|c|c|c|}
\hline \multicolumn{10}{|c|}{$V_{c}:$ Valor verdadeiro convencional } \\
\hline \multicolumn{10}{|c|}{$M:$ Valor médio das medições } \\
\hline \multirow[b]{2}{*}{ Código } & \multicolumn{4}{|c|}{$\left({ }^{90} \mathrm{Sr}+{ }^{90} \mathrm{Y}\right)$} & \multicolumn{4}{|c|}{$\left({ }^{204} \mathrm{Tl}\right)$} & \multirow{2}{*}{$\begin{array}{l}\text { Unidade } \\
\text { de } \\
M \text { e } U_{c}\end{array}$} \\
\hline & \multicolumn{2}{|c|}{$\begin{array}{c}V_{c} \quad u\left(V_{c}\right) \\
(\mu G y / h)\end{array}$} & \multirow{2}{*}{$\begin{array}{c}M \\
27,34\end{array}$} & $U_{c}$ & \multicolumn{2}{|c|}{$\begin{array}{c}V_{c} \quad u\left(V_{c}\right) \\
(\mu G y / h)\end{array}$} & \multirow{2}{*}{$\begin{array}{c}\boldsymbol{M} \\
0,39\end{array}$} & \multirow{2}{*}{$\begin{array}{c}\boldsymbol{U}_{\boldsymbol{c}} \\
0,03\end{array}$} & \\
\hline B2 & 339,91 & 3,40 & & 0,52 & 10,87 & 0,04 & & & $\mathrm{mR} / \mathrm{h}$ \\
\hline C1 & 776,10 & 7,76 & 67,55 & 0,69 & 48,54 & 0,20 & 0,63 & 0,00 & $\mathrm{mR} / \mathrm{h}$ \\
\hline C2 & 776,10 & 7,76 & 66,90 & 1,35 & 48,54 & 0,20 & 0,48 & 0,01 & $\mathrm{mR} / \mathrm{h}$ \\
\hline D1 & 345,07 & 3,45 & 27,74 & 0,92 & 48,69 & 0,20 & 0,40 & 0,08 & $\mathrm{mR} / \mathrm{h}$ \\
\hline F1 & 766,64 & 7,67 & 39,88 & 0,00 & 44,26 & 0,18 & 0,24 & 0,05 & $\mathrm{mR} / \mathrm{h}$ \\
\hline G1 & 776,05 & 7,76 & 235,10 & 0,35 & 48,52 & 0,20 & 5,23 & 0,27 & $\mu \mathrm{Sv} / \mathrm{h}$ \\
\hline G2 & 776,05 & 7,76 & 242,50 & 0,66 & 48,52 & 0,20 & 5,23 & 0,07 & $\mu \mathrm{Sv} / \mathrm{h}$ \\
\hline G3 & 776,05 & 7,76 & 236,40 & 0,6 & 48,52 & 0,20 & 5,33 & 0,08 & $\mu \mathrm{Sv} / \mathrm{h}$ \\
\hline $\mathrm{H} 2$ & 767,26 & $\begin{array}{l}7,67 \\
\end{array}$ & 59,90 & 1,46 & 100,18 & 0,41 & 0,50 & 0,04 & $\mathrm{mR} / \mathrm{h}$ \\
\hline H3 & 764,81 & 7,65 & 64,95 & 0,00 & 43,47 & 0,18 & 0,45 & 0,05 & $\mathrm{mR} / \mathrm{h}$ \\
\hline K1 & 3105,64 & 31,06 & 298,80 & 0,32 & 48,69 & 0,20 & 0,52 & 0,01 & $\mathrm{mR} / \mathrm{h}$ \\
\hline L8 & 775,22 & 7,75 & 32,16 & 0,63 & 109,00 & 0,45 & 1,96 & 0,00 & $\mathrm{mR} / \mathrm{h}$ \\
\hline L9 & 774,19 & 7,74 & 23,90 & 0,00 & 47,65 & 0,20 & 0,54 & 0,00 & $\mathrm{mR} / \mathrm{h}$ \\
\hline L10 & 774,19 & 7,74 & 23,96 & 0,00 & 47,65 & 0,20 & 0,55 & 0,00 & $\mathrm{mR} / \mathrm{h}$ \\
\hline L11 & 775,89 & 7,76 & 299,90 & 0,00 & 109,00 & 0,45 & 25,12 & 1,69 & $\mu \mathrm{Sv} / \mathrm{h}$ \\
\hline L12 & 775,89 & 7,76 & 319,90 & 0,00 & 109,00 & 0,45 & 26,33 & 1,58 & $\mu \mathrm{Sv} / \mathrm{h}$ \\
\hline L13 & 767,31 & 7,67 & 259,00 & 0,00 & 100,23 & 0,41 & 20,2 & 1,33 & $\mu \mathrm{Sv} / \mathrm{h}$ \\
\hline L14 & 766,28 & 7,66 & 243,38 & 0,00 & 99,23 & 0,41 & 18,28 & 0,05 & $\mu \mathrm{Sv} / \mathrm{h}$ \\
\hline L15 & 766,28 & 7,66 & 279,38 & 0,22 & 99,23 & 0,41 & 18,58 & 0,99 & $\mu \mathrm{Sv} / \mathrm{h}$ \\
\hline L16 & 765,67 & 7,66 & 247,20 & 0,22 & 43,84 & 0,18 & 5,00 & 0,92 & $\mu \mathrm{Sv} / \mathrm{h}$ \\
\hline L17 & 766,28 & 7,66 & 299,38 & 0,22 & 99,23 & 0,41 & 16,18 & 1,40 & $\mu \mathrm{Sv} / \mathrm{h}$ \\
\hline L18 & 766,28 & 7,66 & 251,38 & 7,89 & 99,23 & 0,41 & 18,18 & 1,40 & $\mu \mathrm{Sv} / \mathrm{h}$ \\
\hline N1 & 775,22 & 7,75 & 29,96 & 0,00 & 108,29 & 0,45 & 1,84 & 0,10 & $\mathrm{mR} / \mathrm{h}$ \\
\hline 01 & 775,89 & 7,76 & 31,80 & 0,32 & 109,00 & 0,45 & 2,42 & 0,11 & $\mathrm{mR} / \mathrm{h}$ \\
\hline Q8 & 764,86 & 7,65 & 17,94 & 0,00 & 97,85 & 0,40 & 0,88 & 0,10 & $\mathrm{mR} / \mathrm{h}$ \\
\hline Q9 & 764,86 & 7,65 & 196,48 & 9,49 & 97,85 & 0,40 & 7,18 & 1,26 & $\mu \mathrm{Sv} / \mathrm{h}$ \\
\hline S1 & 775,74 & 7,76 & 67,90 & 0,00 & 48,54 & 0,20 & 1,92 & 0,00 & $\mathrm{mR} / \mathrm{h}$ \\
\hline S2 & 764,81 & 7,65 & 71,42 & 0,52 & 43,47 & 0,18 & 0,71 & 0,03 & $\mathrm{mR} / \mathrm{h}$ \\
\hline
\end{tabular}


Tabela 4.17 Resposta das câmaras de ionização para radiação beta.

\begin{tabular}{|c|c|c|c|c|c|c|c|c|c|}
\hline \multicolumn{10}{|c|}{$V_{c}:$ Valor verdadeiro convencional } \\
\hline \multicolumn{10}{|c|}{$M:$ Valor médio das medições } \\
\hline \multirow[b]{2}{*}{ Código } & \multicolumn{4}{|c|}{$\left({ }^{90} \mathrm{Sr}+{ }^{90} \mathrm{Y}\right)$} & \multicolumn{4}{|c|}{$\left({ }^{204} \mathrm{Tl}\right)$} & \multirow[b]{2}{*}{$\begin{array}{l}\text { Unidade } \\
M \text { e } U_{c}\end{array}$} \\
\hline & \multicolumn{2}{|c|}{$(\mu G y / h)$} & $M$ & $U_{c}$ & \multicolumn{2}{|c|}{$\begin{array}{c}V_{c} \quad u\left(V_{c}\right) \\
(\mu G y / h)\end{array}$} & \multirow{2}{*}{$\begin{array}{c}M \\
0,01\end{array}$} & \multirow{2}{*}{$\begin{array}{c}\boldsymbol{U}_{\boldsymbol{c}} \\
0,05\end{array}$} & \\
\hline B'1 & 765,93 & 7,66 & 59,27 & 3,30 & 43,95 & 0,18 & & & \multirow{6}{*}{$\mathrm{mR} / \mathrm{h}$} \\
\hline D'1 & 3086,66 & 30,87 & 315,90 & 5,16 & 46,49 & 0,19 & 0,01 & 0,01 & \\
\hline l'1 & 776,10 & 7,76 & 58,40 & 1,17 & 48,54 & 0,20 & 0,01 & 0,04 & \\
\hline L'1 & 776,10 & 7,76 & 68,30 & 0,53 & 48,54 & 0,20 & 0,01 & 0,01 & \\
\hline L'3 & 773,47 & 7,73 & 64,90 & 0,01 & 47,31 & 0,20 & 0,01 & 0,01 & \\
\hline L'4 & 773,47 & 7,73 & 69,90 & 0,01 & 47,31 & 0,20 & 0,01 & 0,05 & \\
\hline
\end{tabular}

As grandezas apresentadas nas medições obtidas para ${ }^{90} \mathrm{Sr}_{+}^{90} \mathrm{Y}$ e ${ }^{204} \mathrm{TI}$ estão em taxa de exposição, taxa de equivalente de dose e taxa de equivalente de dose ambiente, portanto em grandezas diferentes da grandeza do valor verdadeiro convencional que está em taxa de dose absorvida; por isto ocorreu a grande diferença entre os valores de $M$ e $V_{c}$ apresentados nas Tabelas 4.16 e 4.17 .

\subsubsection{Determinação dos fatores de calibração para radiação beta}

Foram obtidos os fatores de calibração para radiação beta de ${ }^{90} \mathrm{Sr}^{90}{ }^{90} \mathrm{Ye}$ ${ }^{204} \mathrm{TI}$. O fator de calibração, $f_{c}$, foi obtido de acordo com a Equação 3.1; neste caso, o valor verdadeiro convencional, $V c$, é dado em taxa de dose absorvida no ar, $D_{a r}$, e a medida, $M$, de acordo com a grandeza em que o instrumento mede. Os fatores de calibração para ${ }^{90} \mathrm{Sr}_{+}{ }^{90} \mathrm{Y}$ e ${ }^{204} \mathrm{Tl}$ estão apresentados nas Tabelas 4.18 e 4.19 . 
Tabela 4.18 Fator de calibração dos detectores Geiger-Müller para radiação beta $\left({ }^{90} \mathrm{Sr}+{ }^{90} \mathrm{Y}\right.$ e $\left.{ }^{204} \mathrm{TI}\right)$.

\begin{tabular}{|c|c|c|c|c|c|}
\hline \multicolumn{6}{|c|}{$f_{c}:$ Fator de calibração } \\
\hline Código & $f_{c}\left({ }^{90} S r+{ }^{90} Y\right)$ & $\bar{U}$ & $f_{c}\left({ }^{204} T l\right)$ & $\bar{U}$ & Unidade \\
\hline B2 & 12,43 & 0,27 & 27,86 & 2,26 & $m G y / R$ \\
\hline C1 & 11,49 & 0,16 & 77,05 & 0,32 & $m G y / R$ \\
\hline C2 & 11,60 & 0,26 & 100,29 & 1,12 & $\mathrm{mGy} / \mathrm{R}$ \\
\hline D1 & 12,44 & 0,43 & 120,81 & 25,19 & $m G y / R$ \\
\hline F1 & 19,22 & 0,19 & 188,33 & 38,02 & $m G y / R$ \\
\hline G1 & 3,30 & 0,03 & 9,28 & 0,48 & Gy/Sv \\
\hline G2 & 3,20 & 0,03 & 9,28 & 0,13 & Gy/Sv \\
\hline G3 & 3,28 & 0,03 & 9,10 & 0,14 & $\mathrm{~Gy} / \mathrm{Sv}$ \\
\hline $\mathrm{H} 2$ & 12,81 & 0,34 & 202,39 & 14,74 & $m G y / R$ \\
\hline H3 & 11,77 & 0,12 & 97,24 & 10,67 & $\mathrm{mGy} / \mathrm{R}$ \\
\hline K1 & 10,39 & 0,10 & 93,27 & 1,65 & $m G y / R$ \\
\hline L8 & 24,11 & 0,53 & 55,61 & 0,23 & $m G y / R$ \\
\hline L9 & 32,39 & 0,32 & 87,59 & 0,36 & $m G y / R$ \\
\hline L10 & 32,31 & 0,32 & 86,79 & 0,36 & $m G y / R$ \\
\hline L11 & 2,59 & 0,03 & 4,34 & 0,29 & Gy/Sv \\
\hline L12 & 2,43 & 0,02 & 4,14 & 0,25 & Gy/Sv \\
\hline L13 & 2,96 & 0,03 & 4,96 & 0,33 & $\mathrm{~Gy} / \mathrm{Sv}$ \\
\hline L14 & 3,15 & 0,03 & 5,43 & 0,03 & $\mathrm{~Gy} / \mathrm{Sv}$ \\
\hline L15 & 2,74 & 0,03 & 5,34 & 0,29 & Gy/Sv \\
\hline L16 & 3,10 & 0,03 & 8,77 & 1,61 & Gy/Sv \\
\hline L17 & 2,56 & 0,03 & 6,13 & 0,53 & $\mathrm{~Gy} / \mathrm{Sv}$ \\
\hline L18 & 3,05 & 0,10 & 5,46 & 0,42 & $\mathrm{~Gy} / \mathrm{Sv}$ \\
\hline N1 & 25,88 & 0,26 & 58,85 & 3,30 & $m G y / R$ \\
\hline 01 & 24,40 & 0,34 & 45,04 & 2,13 & mGy/R \\
\hline Q8 & 42,64 & 0,43 & 111,44 & 12,19 & $m G y / R$ \\
\hline Q9 & 3,89 & 0,19 & 13,63 & 2,40 & Gy/Sv \\
\hline S1 & 11,42 & 0,11 & 25,28 & 0,10 & $m G y / R$ \\
\hline S2 & 10,71 & 0,13 & 61,57 & 2,72 & $m G y / R$ \\
\hline
\end{tabular}

Tabela 4.19 Fator de calibração das câmaras de ionização para radiação beta $\left({ }^{90} \mathrm{Sr}+{ }^{90} \mathrm{Y} \mathrm{e}{ }^{204} \mathrm{TI}\right)$.

\begin{tabular}{c|cc|cc|r}
\hline \multicolumn{7}{c}{$\boldsymbol{f}_{\boldsymbol{c}}:$ Fator de calibração } \\
\cline { 1 - 5 } Código & $\boldsymbol{f}_{\boldsymbol{c}}\left({ }^{\mathbf{9}} \boldsymbol{S} \boldsymbol{r}+{ }^{\mathbf{9}} \boldsymbol{Y}\right)$ & $\boldsymbol{U}$ & $\boldsymbol{f}_{\boldsymbol{c}}\left({ }^{\mathbf{2 0 4}} \boldsymbol{T l}\right)$ & $\boldsymbol{U}$ & Unidade \\
\hline B'1 & 12,92 & 0,73 & 19,40 & 0,43 & \\
\cline { 1 - 5 } D'1 & 9,77 & 0,19 & 18,52 & 0,13 & \\
\cline { 1 - 5 } I'1 & 13,29 & 0,30 & 22,90 & 0,39 & \multirow{2}{*}{$\mathrm{mGy} / \mathrm{R}$} \\
\cline { 1 - 5 } L'1 & 11,36 & 0,14 & 20,96 & 0,16 & \\
L'3 & 11,92 & 0,12 & 18,48 & 0,13 & \\
L'4 & 11,07 & 0,11 & 17,08 & 0,34 & \\
\hline
\end{tabular}


Os fatores de calibração para ${ }^{90} \mathrm{Sr}+{ }^{90} \mathrm{Y}$ e ${ }^{204} \mathrm{TI}$ apresentados nas Tabelas 4.18 e 4.19 são relativamente grandes. Seus valores apresentam uma grande variação: para os detectores Geiger-Müller, os valores vão de $(2,43 \pm 0,02) \mathrm{Gy} / \mathrm{Sv}$ para o modelo $\mathrm{L} 12$ a $(42,64 \pm 0,43) \mathrm{mGy} / \mathrm{R}$ para o modelo Q8, utilizando a fonte de ${ }^{90} \mathrm{Sr}+{ }^{90} \mathrm{Y}$; e para a fonte de ${ }^{204} \mathrm{TI}$ a variação é ainda maior, de $(4,14 \pm 0,25)$ Gy/Sv para o modelo L12 a $(202,39 \pm 14,74) \mathrm{mGy} / \mathrm{R}$ para o modelo H2. As câmaras de ionização, apesar de apresentarem valores de fatores de calibração menores em relação aos dos detectores Geiger-Müller, ainda são valores significativos, pois os fatores de calibração são os fatores multiplicativos com os quais o usuário do detector de radiação deve corrigir o valor indicado pelo instrumento ao medir uma quantidade de radiação proveniente de fonte beta. Os fatores de calibração para as câmaras de ionização variaram de $(9,77 \pm 0,19)$ para o modelo D'1 a $(13,29 \pm 0,30)$ para o modelo l'1 em relação à fonte de ${ }^{90} \mathrm{Sr}+{ }^{90} \mathrm{Y}$. Para a fonte de ${ }^{204} \mathrm{Tl}$, a variação foi ainda maior, de $(17,08 \pm 0,34)$ para o modelo L'4 a $(22,90 \pm 0,39)$ para 0 modelo l'1.

Imagine-se que alguém fazendo uma medição de uma fonte beta, por exemplo, com uma câmara de ionização de modelo L'4 para a fonte de ${ }^{204} \mathrm{TI}$, sem ter o fator de calibração, indicado no certificado de calibração beta. $O$ usuário do detector estaria errando por um fator de quase 23 vezes o valor da leitura indicado pelo instrumento. Se fosse um detector Geiger-Müller de modelo L12 para a mesma fonte beta, o usuário estaria errando de forma drástica a sua leitura, por um fator de 202 vezes em relação à leitura indicada pelo instrumento. Portanto, é imprescindível a determinação do fator de calibração para radiação beta quando 0 instrumento for utilizado para monitoração de radiação beta.

\subsubsection{Dependência energética dos detectores para radiação beta}

Neste item, foi determinada a dependência energética, DE, da resposta dos monitores para ${ }^{90} \mathrm{Sr}+{ }^{90} \mathrm{Y}$ e ${ }^{204} \mathrm{TI}$, de acordo com a Equação 4.4. Além disso, foi estudada a dependência da resposta dos detectores beta-gama com o tipo de radiação, DT, utilizando os fatores de calibração para fontes beta em 
relação aos fatores de calibração para fontes gama, no caso dos instrumentos testados com radiação beta, previamente calibrados e ajustados com radiação gama, de acordo com a Equação 4.5.

$$
\begin{gathered}
D E=\frac{f_{c}\left({ }^{204} \mathrm{Tl}\right)}{f_{c}\left({ }^{90} \mathrm{Sr}+{ }^{90} Y\right)} \\
D T=\frac{f_{c}(\text { fonte } \rightarrow \text { beta })}{f_{c}(\text { fonte } \rightarrow \text { gama })}
\end{gathered}
$$

Os resultados de dependência energética para ${ }^{90} \mathrm{Sr}+{ }^{90} \mathrm{Y}$ e ${ }^{204} \mathrm{TI}$ estão apresentados nas Tabelas 4.20 e 4.21 e da dependência com o tipo de radiação nas Tabelas 4.22 e 4.23 .

Tabela 4.20 Dependência energética da resposta dos detectores

\begin{tabular}{|c|c|c|c|c|c|}
\hline Código & $D E\left(\frac{{ }^{204} T l}{{ }^{90} S r+{ }^{90} Y}\right)$ & $\boldsymbol{U}$ & Código $D E$ & $\left(\frac{{ }^{204} \mathrm{Tl}}{{ }^{90} \mathrm{Sr}+{ }^{90} \mathrm{Y}}\right)$ & $\boldsymbol{U}$ \\
\hline B2 & 2,24 & 0,38 & L11 & 1,68 & 0,23 \\
\hline C1 & 6,71 & 0,20 & L12 & 1,71 & 0,21 \\
\hline C2 & 8,64 & 0,43 & L13 & 1,67 & 0,22 \\
\hline D1 & 9,71 & 4,11 & L14 & 1,72 & 0,04 \\
\hline F1 & 9,80 & 3,96 & L15 & 1,95 & 0,21 \\
\hline G1 & 2,81 & 0,29 & L16 & 2,83 & 1,04 \\
\hline G2 & 2,90 & 0,10 & L17 & 2,40 & 0,42 \\
\hline G3 & 2,77 & 0,10 & L18 & 1,79 & 0,30 \\
\hline $\mathrm{H} 2$ & 15,80 & 2,45 & N1 & 2,27 & 0,26 \\
\hline H3 & 8,26 & 1,82 & 01 & 1,85 & 0,18 \\
\hline K1 & 8,97 & 0,37 & Q8 & 2,61 & 0,57 \\
\hline L8 & 2,31 & 0,10 & Q9 & 3,50 & 1,28 \\
\hline L9 & 2,70 & 0,06 & S1 & 2,21 & 0,05 \\
\hline L10 & 2,69 & 0,06 & S2 & 5,75 & 0,53 \\
\hline
\end{tabular}
Geiger-Müller para radiação beta. 
Tabela 4.21 Dependência energética da resposta das câmaras de ionização para radiação beta.

\begin{tabular}{ccc}
\hline Código & $D E\left(\frac{{ }^{204} T l}{{ }^{90} S r+{ }^{90} \boldsymbol{Y}}\right)$ & $\boldsymbol{U}$ \\
\hline B'1 & 1,50 & 0,18 \\
\hline D'1 & 1,90 & 0,08 \\
\hline I'1 & 1,72 & 0,10 \\
\hline L'1 & 1,84 & 0,05 \\
L'3 & 1,55 & 0,04 \\
L'4 & 1,54 & 0,07 \\
\hline
\end{tabular}

Como se pode verificar, existe uma dependência energética muito grande em relação às radiações de ${ }^{90} \mathrm{Sr}_{+}^{90} \mathrm{Y}$ e ${ }^{204} \mathrm{TI}$. No caso dos detectores Geiger-Müller a dependência energética variou entre $(1,67 \pm 0,22)$ do detector L13 e $(15,80 \pm 2,45)$ do detector H2. Para as câmaras de ionização, os valores obtidos foram menores em relação aos dos detectores Geiger-Müller, entretanto são valores com um peso considerável, que variam de $50 \%$ para a câmara de ionização B'1 $(1,50 \pm 0,18)$ a 90\% para a câmara de ionização D'1 $(1,90 \pm 0,08)$. Esses resultados mostram os enormes erros que podem ser cometidos se as medições não forem devidamente interpretadas e corrigidas, mesmo no caso das câmaras de ionização.

Como os detectores de radiação são utilizados para verificação de níveis de radiação onde os usuários se localizam, pode-se concluir que há uma enorme responsabilidade no procedimento de calibração e na interpretação das medições.

Neste tipo de teste de desempenho nenhum detector de radiação seria aprovado pela norma internacional EN 60846 (EN, 2004), que determina que a dependência energética pode variar no máximo $40 \%$. 
Tabela 4.22 Dependência com o tipo de radiação, DT, dos detectores Geiger-Müller, para radiações gama e beta.

\begin{tabular}{|c|c|c|c|c|c|c|c|c|c|c|c|}
\hline Código & $D T$ & $\left(\frac{{ }^{90} S r+{ }^{90} \mathrm{Y}}{{ }^{137} \mathrm{Cs}}\right)$ & $U$ & $D T$ & $\left(\frac{{ }^{90} \mathrm{Sr}+{ }^{90} \mathrm{Y}}{{ }^{60} \mathrm{Co}}\right)$ & $U$ & $D T\left(\frac{\left.{ }^{204} \mathrm{Tl}\right)}{{ }^{137} \mathrm{CS}}\right)$ & $\boldsymbol{U}$ & $D T\left(\frac{204}{{ }^{60} \mathrm{Co}}\right)$ & $\boldsymbol{U}$ & Unidade \\
\hline B2 & & 12,07 & 0,70 & & 14,63 & 0,72 & 27,06 & 4,30 & 32,79 & 5,11 & $m$ my/R \\
\hline C1 & & 11,15 & 0,54 & & 12,63 & 0,46 & 74,80 & 2,97 & 84,67 & 1,99 & $m G y / R$ \\
\hline C2 & & 11,60 & 0,70 & & 12,75 & 0,64 & 101,13 & 5,90 & 111,13 & 5,31 & $\mathrm{mGy} / \mathrm{R}$ \\
\hline D1 & & 12,08 & 0,96 & & 16,37 & 1,21 & 118,18 & 47,50 & 160,16 & 64,22 & mGy/R \\
\hline F1 & & 19,22 & 0,86 & & 25,98 & 0,87 & 184,42 & 77,21 & 249,21 & 104,08 & $m$ mGy/R \\
\hline G1 & & 2,58 & 0,10 & & 3,44 & 0,10 & 7,25 & 0,78 & 9,66 & 1,02 & Gy/Sv \\
\hline G2 & & 2,78 & 0,11 & & 3,56 & 0,11 & 8,07 & 0,36 & 10,31 & 0,37 & Gy/Sv \\
\hline G3 & & 2,71 & 0,11 & & 3,77 & 0,12 & 7,52 & 0,34 & 10,46 & 0,40 & Gy/Sv \\
\hline $\mathrm{H} 2$ & & 12,68 & 0,84 & & 16,01 & 0,93 & 198,38 & 32,74 & 250,45 & 40,61 & $m G y / R$ \\
\hline H3 & & 11,78 & 0,53 & & 14,72 & 0,47 & 96,60 & 21,83 & 120,75 & 27,02 & mGy/R \\
\hline K1 & & 10,50 & 0,47 & & 13,16 & 0,43 & 94,58 & 5,33 & 118,52 & 5,54 & mGy/R \\
\hline L8 & & 24,11 & 1,43 & & $\overline{31,72}$ & 1,63 & 55,61 & 2,27 & 73,17 & 2,02 & mGy/R \\
\hline L9 & & 34,83 & 1,65 & & 45,62 & 1,58 & 94,88 & 4,16 & 124,28 & 3,65 & $\mathrm{mGy} / \mathrm{R}$ \\
\hline L10 & & 32,31 & 1,44 & & 41,43 & 1,35 & 86,64 & 3,54 & 111,07 & 3,00 & mGy/R \\
\hline N1 & & 26,40 & 1,20 & & 34,05 & 1,13 & 60,05 & 6,99 & 77,44 & 8,68 & $m$ mGy/R \\
\hline 01 & & 26,81 & 0,96 & & 35,36 & 1,43 & 49,50 & 4,65 & 65,28 & 6,25 & mGy/R \\
\hline S1 & & 12,42 & 0,37 & & 15,87 & 0,54 & 27,48 & 0,64 & 35,11 & 1,02 & $m G y / R$ \\
\hline S2 & & 10,93 & 0,52 & & 15,08 & 0,57 & 62,47 & 5,89 & 86,23 & 7,71 & $m G y / R$ \\
\hline
\end{tabular}

Tabela 4.23 Dependência com o tipo de radiação, DT, das câmaras de ionização, para radiações gama e beta.

\begin{tabular}{|c|c|c|c|c|c|c|c|c|c|c|c|}
\hline Código & $D T$ & $\left.\frac{{ }^{90} S r+{ }^{90} Y}{{ }^{137} C S}\right)$ & $U$ & $D T$ & $\left.\frac{{ }^{90} \mathrm{Sr}+{ }^{90} \mathrm{Y}}{{ }^{60} \mathrm{Co}}\right)$ & $U$ & $D T\left(\frac{{ }^{204} \mathrm{Tl}}{{ }^{137} \mathrm{Cs}}\right)$ & $\boldsymbol{U}$ & $D T\left(\frac{{ }^{204} \mathrm{Tl}}{{ }^{60} \mathrm{Co}}\right)$ & $U$ & Unidade \\
\hline B'1 & & 13,18 & 0,79 & & 13,32 & 0,80 & 19,80 & 0,60 & 20,00 & 0,61 & \multirow{6}{*}{ mGy/R } \\
\hline D'1 & & 10,98 & 0,25 & & 10,98 & 0,25 & 20,81 & 0,28 & 20,81 & 0,28 & \\
\hline l'1 & & 14,60 & 0,37 & & 14,77 & 0,37 & 25,16 & 0,51 & 25,44 & 0,52 & \\
\hline L'1 & & 14,02 & 0,24 & & 13,85 & 0,24 & 25,88 & 0,38 & 25,56 & 0,37 & \\
\hline L'3 & & 14,19 & 0,22 & & 14,19 & 0,22 & 22,00 & 0,30 & 22,00 & 0,30 & \\
\hline L'4 & & 11,90 & 0,17 & & 11,90 & 0,17 & 18,37 & 0,42 & 18,37 & 0,42 & \\
\hline
\end{tabular}

De acordo com os resultados apresentados nas Tabelas 4.22 e 4.23, a dependência da resposta dos detectores com o tipo de radiação, DT, é muito alto. A maior dependência com o tipo de radiação, DT, para os detectores Geiger-Müller, referente ao ${ }^{90} \mathrm{Sr}_{+}{ }^{90} \mathrm{Y}$, foi do modelo L9, que apresentou um valor de $(34,83 \pm 1,65)$ com relação ao ${ }^{137} \mathrm{Cs}$ e de $(45,62 \pm 1,88)$ com relação ao ${ }^{60} \mathrm{Co}$. 
Para a fonte de ${ }^{204} \mathrm{Tl}$, o detector $\mathrm{H} 2$ foi o que apresentou maior dependência com o tipo de radiação: com relação ao ${ }^{137} \mathrm{Cs}$ o valor foi de $(198,38 \pm 32,72)$ e com relação ao ${ }^{60} \mathrm{Co}$ o valor foi de $(250,45 \pm 40,61)$. O detector $\mathrm{H} 2$ possui uma sonda externa grossa e de metal, prejudicando a recepção da radiação beta.

As câmaras de ionização apresentaram uma dependência com o tipo de radiação menor, mas o que não deixa de ser significativo. A maior dependência com o tipo de radiação para estrôncio/césio e estrôncio/cobalto foi respectivamente de $(14,60 \pm 0,37)$ e $(14,77 \pm 0,37)$, ambos obtidos pela câmara de ionização l'1. Os maiores valores da dependência com o tipo de radiação para tálio/césio e tálio/cobalto foram respectivamente de $(25,88 \pm 0,38)$ e $(25,56 \pm 0,37)$, ambos obtidos pela câmara de ionização L'1.

Os detectores não puderam ser testados/calibrados no irradiador beta modelo BSS2, porque os detectores sofriam estouro de escala às distâncias de calibração.

Os resultados mostram a importância da calibração dos detectores beta-gama com radiação gama e beta para evitar possíveis erros na interpretação das medições quando calibrados apenas em campos de radiação gama. O detector de radiação calibrado somente para radiação gama não pode ser utilizado para quantificar medições em campos de radiação beta.

\subsubsection{Dependência angular dos detectores para radiação beta}

Foram selecionados alguns detectores Geiger-Müller e algumas câmaras de ionização para o estudo da dependência angular, aplicando-se as Equações 4.1 e 4.2. As medições obtidas para $\mathrm{M}\left(0^{\circ}\right), \mathrm{M}\left(+45^{\circ}\right)$ e $\mathrm{M}\left(-45^{\circ}\right)$ estão apresentadas nas Tabelas 4.24 e 4.25; e os resultados da dependência angular estão apresentados nas Tabelas 4.26 e 4.27.

Alguns desses instrumentos foram selecionados para a realização de uma varredura angular, com medições para ângulos de $0^{\circ}, \pm 15^{\circ}, \pm 30^{\circ}, \pm 45^{\circ}$, $\pm 60^{\circ} \mathrm{e} \pm 90^{\circ}$, com o objetivo de analisar o comportamento da resposta angular apresentada nas Figuras 4.10 a 4.12 . 
A dependência angular para radiação beta foi obtida da mesma forma que para radiação gama, assim como as suas incertezas, demonstradas de acordo com a Tabela 4.10.

Tabela 4.24 Resposta dos detectores Geiger-Müller para ângulos diferentes de incidência do feixe de radiação beta $\left({ }^{90} \mathrm{Sr}+{ }^{90} \mathrm{Y}\right)$.

\begin{tabular}{|c|c|c|c|c|c|c|c|c|c|c|}
\hline \multicolumn{11}{|c|}{ Medições para ângulos } \\
\hline Código & $\begin{array}{c}M \\
\left(0^{0}\right)\end{array}$ & $\begin{array}{c}U_{c} \\
\left(0^{0}\right)\end{array}$ & $\begin{array}{l}u(A) \\
\left(\theta^{0}\right)\end{array}$ & $\begin{array}{c}M \\
\left(+45^{\circ}\right)\end{array}$ & $\begin{array}{c}U_{c} \\
\left(+45^{0}\right)\end{array}$ & $\begin{array}{c}u(A) \\
\left(+45^{0}\right)\end{array}$ & $\begin{array}{c}M \\
\left(-45^{0}\right)\end{array}$ & $\begin{array}{c}U_{c} \\
\left(-45^{0}\right)\end{array}$ & $\begin{array}{c}u(A) \\
\left(-45^{0}\right)\end{array}$ & Unidade \\
\hline C1 & 67,55 & 0,43 & 0,22 & 33,70 & 0,70 & 0,17 & 35,20 & 0,23 & 0,17 & $\mathrm{mR} / \mathrm{h}$ \\
\hline C2 & 66,90 & 0,01 & 0,43 & 33,60 & 0,01 & 0,70 & 31,40 & 0,01 & 0,23 & $\mathrm{mR} / \mathrm{h}$ \\
\hline D1 & 27,80 & 0,17 & 0,29 & 18,70 & 0,10 & 0,15 & 17,90 & 0,01 & 0,18 & $\mathrm{mR} / \mathrm{h}$ \\
\hline G1 & 235,10 & 0,21 & 0,11 & 74,36 & 0,11 & 0,10 & 84,83 & 0,04 & 0,13 & $\mu \mathrm{Sv} / \mathrm{h}$ \\
\hline G2 & 242,50 & 0,20 & 0,21 & 89,00 & 0,10 & 0,11 & 89,45 & 0,30 & 0,04 & $\mu S v / h$ \\
\hline G3 & 236,40 & 0,01 & 0,20 & 57,40 & 0,01 & 0,10 & 59,48 & 0,01 & 0,30 & $\mu \mathrm{Sv} / \mathrm{h}$ \\
\hline H2 & 59,90 & 0,01 & 1,46 & 25,00 & 0,01 & 0,00 & 30,00 & 0,01 & 0,00 & $\mathrm{mR} / \mathrm{h}$ \\
\hline H3 & 64,95 & 0,52 & 0,00 & 30,00 & 0,01 & 0,00 & 40,00 & 0,01 & 0,00 & $\mathrm{mR} / \mathrm{h}$ \\
\hline L8 & 32,16 & 0,01 & 0,20 & 17,20 & 0,01 & 0,30 & 18,00 & 0,01 & 0,00 & $\mathrm{mR} / \mathrm{h}$ \\
\hline L9 & 23,90 & 0,01 & 0,00 & 14,00 & 0,01 & 0,00 & 14,00 & 0,01 & 0,00 & $\mathrm{mR} / \mathrm{h}$ \\
\hline L10 & 23,96 & 0,01 & 0,00 & 14,00 & 0,01 & 0,00 & 14,00 & 0,10 & 0,00 & $\mathrm{mR} / \mathrm{h}$ \\
\hline L11 & 299,90 & 0,10 & 0,00 & 200,00 & 0,30 & 0,00 & 200,00 & 0,30 & 0,00 & $\mu \mathrm{Sv} / \mathrm{h}$ \\
\hline L13 & 259,00 & 0,01 & 0,00 & 165,45 & 10,33 & 5,22 & 171,82 & 5,16 & 4,05 & $\mu \mathrm{Sv} / \mathrm{h}$ \\
\hline L14 & 243,38 & 0,22 & 0,00 & 152,00 & 0,01 & 10,33 & 154,00 & 0,01 & 5,16 & $\mu \mathrm{Sv} / \mathrm{h}$ \\
\hline L15 & 279,38 & 0,22 & 0,22 & 110,00 & 0,01 & 0,00 & 110,00 & 0,01 & 0,00 & $\mu \mathrm{Sv} / \mathrm{h}$ \\
\hline L16 & 247,20 & 0,22 & 0,22 & 160,00 & 8,43 & 0,00 & 160,00 & 8,43 & 0,00 & $\mu \mathrm{Sv} / \mathrm{h}$ \\
\hline L17 & 299,38 & 1,46 & 0,22 & 196,00 & 8,43 & 8,43 & 196,00 & 8,43 & 8,43 & $\mu \mathrm{Sv} / \mathrm{h}$ \\
\hline 01 & 31,80 & 0,20 & 0,10 & 21,40 & 0,30 & 0,30 & 20,60 & 0,01 & 0,30 & $\mathrm{mR} / \mathrm{h}$ \\
\hline Q8 & 17,94 & 9,49 & 0,00 & 6,00 & 0,01 & 0,00 & 6,90 & 0,32 & 0,32 & $\mathrm{mR} / \mathrm{h}$ \\
\hline Q9 & 196,48 & 3,30 & 9,49 & 57,00 & 4,83 & 4,83 & 58,00 & 4,22 & 4,22 & $\mu \mathrm{Sv} / \mathrm{h}$ \\
\hline S1 & 67,90 & 0,11 & 0,00 & 44,00 & 0,10 & 0,00 & 42,00 & 0,13 & 0,00 & $\mathrm{mR} / \mathrm{h}$ \\
\hline S2 & 71,42 & 0,01 & 0,52 & 40,80 & 1,03 & 1,03 & 48,00 & 0,01 & 0,00 & $\mathrm{mR} / \mathrm{h}$ \\
\hline
\end{tabular}


Tabela 4.25 Resposta das câmaras de ionização, para ângulos diferentes de incidência do feixe de radiação beta $\left({ }^{90} \mathrm{Sr}+{ }^{90} \mathrm{Y}\right)$.

\begin{tabular}{|c|c|c|c|c|c|c|c|c|c|c|}
\hline \multicolumn{11}{|c|}{ Medições para ângulos } \\
\hline Código & $\begin{array}{c}M \\
\left(0^{0}\right)\end{array}$ & $\begin{array}{c}U_{c} \\
\left(0^{0}\right)\end{array}$ & $\begin{array}{l}u(A) \\
\left(0^{0}\right)\end{array}$ & $\begin{array}{c}M \\
\left(+45^{0}\right)\end{array}$ & $\begin{array}{c}U_{c} \\
\left(+45^{0}\right)\end{array}$ & $\begin{array}{c}u(A) \\
\left(+45^{0}\right)\end{array}$ & $\begin{array}{c}M \\
\left(-45^{0}\right)\end{array}$ & $\begin{array}{c}U_{c} \\
\left(-45^{0}\right)\end{array}$ & $\begin{array}{c}u(A) \\
\left(-45^{0}\right)\end{array}$ & Unidade \\
\hline B'1 & 59,27 & 3,30 & 3,30 & 30,90 & 0,32 & 0,32 & 36,60 & 0,52 & 0,52 & \multirow{5}{*}{$\mathrm{mR} / \mathrm{h}$} \\
\hline D'1 & 315,90 & 0,01 & 5,10 & 149,40 & 5,22 & 0,70 & 167,70 & 4,05 & 0,82 & \\
\hline L'1 & 68,30 & 0,22 & 0,17 & 39,90 & 0,17 & 0,10 & 40,00 & 0,17 & 0,00 & \\
\hline L'3 & 64,90 & 0,01 & 0,00 & 39,00 & 0,16 & 0,00 & 34,10 & 0,01 & 0,10 & \\
\hline L'4 & 69,90 & 5,10 & 0,00 & 37,00 & 0,70 & 0,16 & 36,50 & 0,82 & 0,00 & \\
\hline
\end{tabular}

Tabela 4.26 Dependência angular, DA, dos detectores Geiger-Müller para ângulos diferentes de incidência do feixe de radiação beta $\left({ }^{90} \mathrm{Sr}+{ }^{90} \mathrm{Y}\right)$.

\begin{tabular}{c|cc|cc}
\hline Código & $\boldsymbol{D A}_{+}$ & $\boldsymbol{U}$ & $\boldsymbol{D A}_{-}$ & $\boldsymbol{U}$ \\
\hline C1 & 2,00 & 0,09 & 1,92 & 0,03 \\
C2 & 1,99 & 0,00 & 2,13 & 0,00 \\
\hline D1 & 1,49 & 0,02 & 1,55 & 0,02 \\
\hline G1 & 3,16 & 0,01 & 2,77 & 0,01 \\
G2 & 2,72 & 0,01 & 2,71 & 0,02 \\
G3 & 4,12 & 0,00 & 3,97 & 0,00 \\
\hline H2 & 2,40 & 0,00 & 2,00 & 0,00 \\
H3 & 2,17 & 0,03 & 1,62 & 0,03 \\
\hline L8 & 1,87 & 0,00 & 1,79 & 0,00 \\
L9 & 1,71 & 0,00 & 1,71 & 0,00 \\
L10 & 1,71 & 0,00 & 1,71 & 0,02 \\
L11 & 1,50 & 0,00 & 1,50 & 0,00 \\
L13 & 1,57 & 0,20 & 1,51 & 0,09 \\
L14 & 1,60 & 0,00 & 1,58 & 0,00 \\
L15 & 2,54 & 0,00 & 2,54 & 0,00 \\
L16 & 1,55 & 0,16 & 1,55 & 0,16 \\
L17 & 1,53 & 0,13 & 1,53 & 0,13 \\
\hline O1 & 1,49 & 0,05 & 1,54 & 0,02 \\
\hline Q8 & 2,99 & 3,16 & 2,60 & 2,76 \\
Q9 & 3,45 & 0,60 & 3,39 & 0,51 \\
\hline S1 & 1,54 & 0,01 & 1,62 & 0,01 \\
S2 & 1,75 & 0,09 & 1,49 & 0,00 \\
\hline
\end{tabular}


Tabela 4.27 Dependência angular, DA, das câmaras de ionização, para ângulos diferentes de incidência do feixe de radiação beta $\left({ }^{90} \mathrm{Sr}+{ }^{90} \mathrm{Y}\right)$.

\begin{tabular}{c|c|c|c|c}
\hline Código & $\boldsymbol{D A}_{+}$ & $\boldsymbol{U}$ & $\boldsymbol{D A}_{-}$ & $\boldsymbol{U}$ \\
\hline B'1 & 1,92 & 0,22 & 1,62 & 0,19 \\
\hline D'1 & 2,11 & 0,15 & 1,88 & 0,09 \\
\hline L'1 & 1,71 & 0,02 & 1,71 & 0,02 \\
L'3 & 1,66 & 0,01 & 1,90 & 0,00 \\
L'4 & 1,89 & 0,28 & 1,92 & 0,29 \\
\hline
\end{tabular}

Todos os monitores de radiação apresentaram valores de dependência angular, DA, maiores que $40 \%$, sendo este o valor máximo de variação estabelecido pela norma internacional EN 60846 (EN, 2004), para a dependência angular entre $0^{0} \mathrm{e} \pm 45^{\circ}$. Portanto, neste estudo, nenhum detector teria sido aprovado neste teste de desempenho.

Os detectores Geiger-Müller apresentaram uma variação nas respostas angulares: $D A_{+}$de até $(4,12 \pm 0,00)$ e $D A_{-}$de até $(3,97 \pm 0,00)$, que foi o caso do detector G3. As câmaras de ionização apresentaram uma variação na resposta angular: $D A_{+}$de até $(2,11 \pm 0,15)$ para o detector $D^{\prime} 1$, e $D A_{-}$de até $(1,92 \pm 0,29)$ para o detector L'4. 

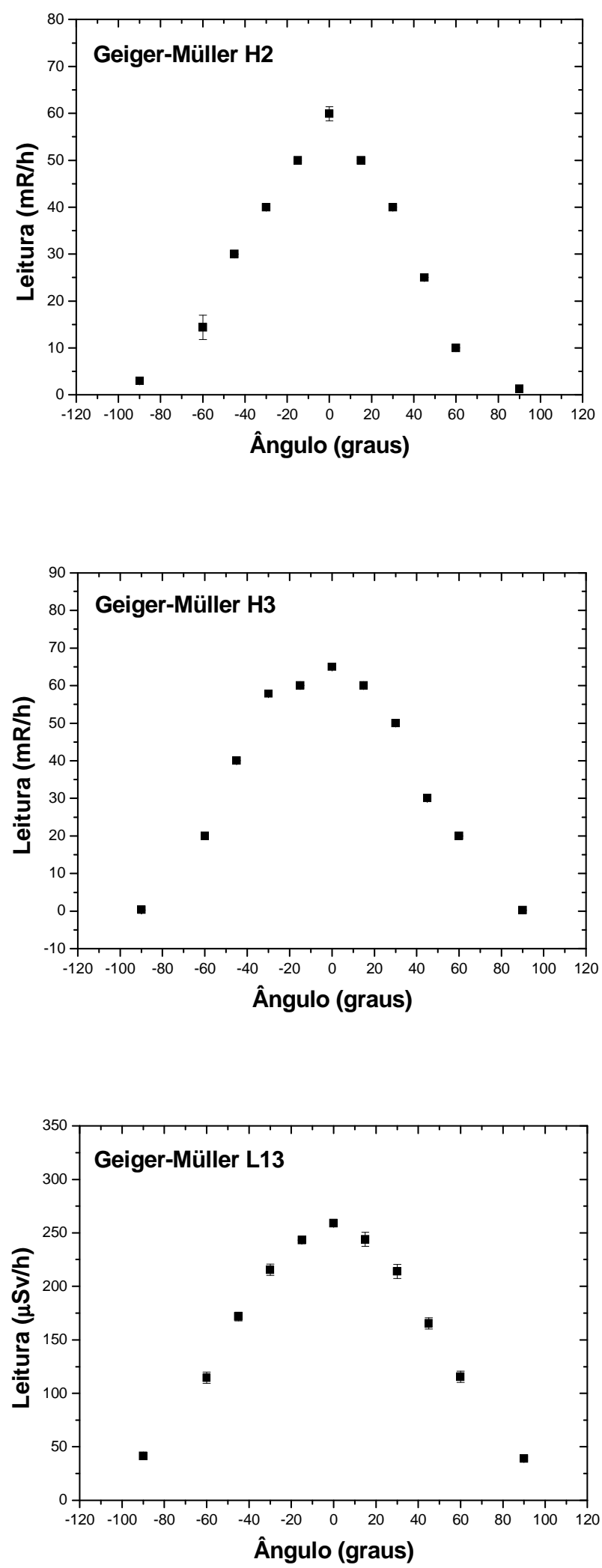

Figura 4.10 Resposta angular dos detectores Geiger-Müller H2, H3 e L13. 

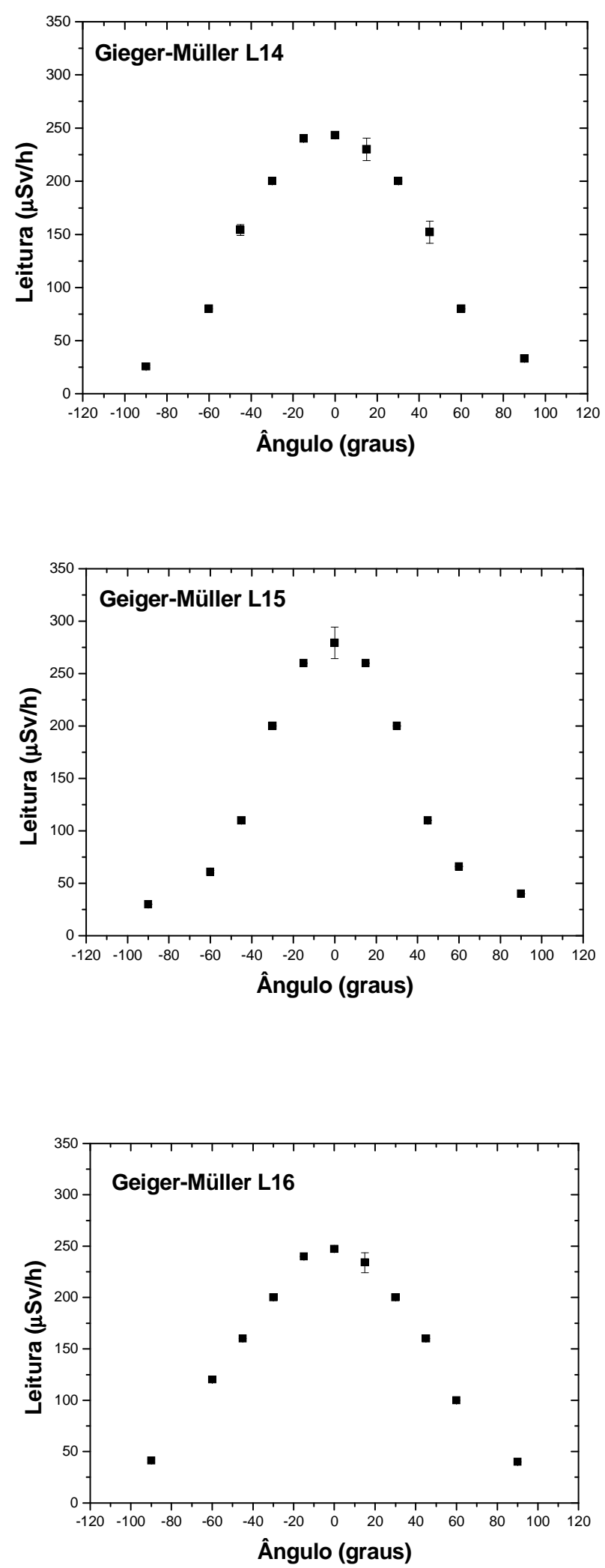

Figura 4.11 Resposta angular dos detectores Geiger-Müller L14, L15 e L16. 

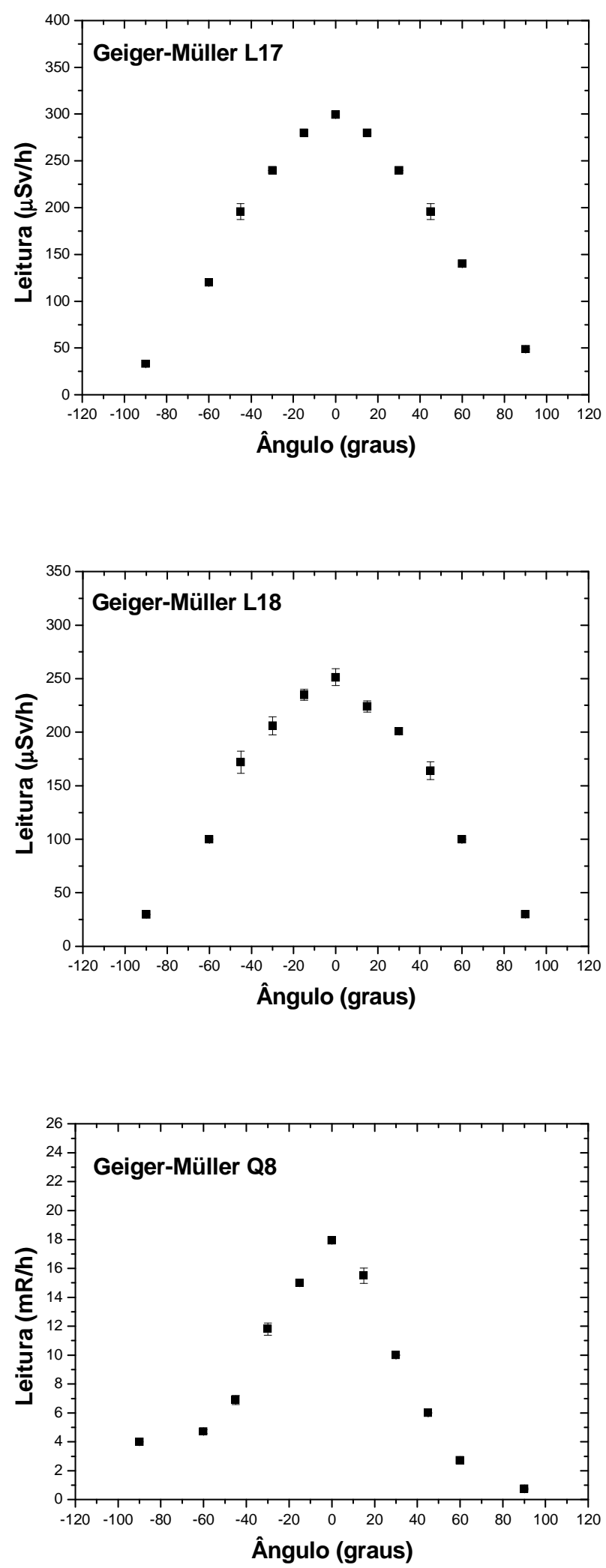

Figura 4.12 Resposta angular dos detectores Geiger-Müller L17, L18 e Q8. 

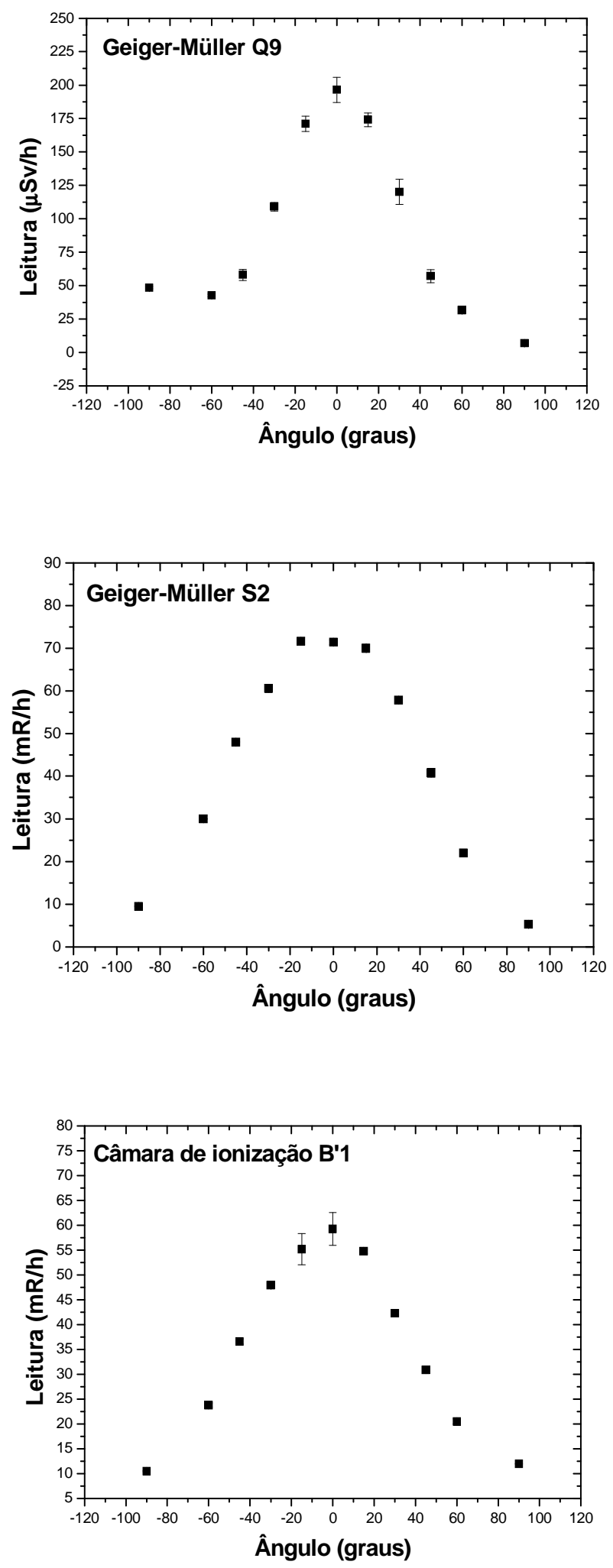

Figura 4.13 Resposta angular dos detectores Geiger-Müller Q9 e S2 e da câmara de ionização B'1. 
Apesar do comportamento diferente dos modelos dos detectores de radiação apresentados nas Figuras 4.10 a 4.13, todos apresentaram uma certa simetria nas suas medições, diferentemente dos detectores em campos de radiação gama. A diferença obtida nas medições em ângulos de sentidos opostos pode ser considerada devido ao posicionamento do detector e no momento de girar o goniômetro: uma pequena diferença angular pode fazer grande diferença no momento de obter as medições em campos de radiação beta.

\subsection{Testes com radiação $X$}

A calibração em campos de radiação $X$ permitiu a obtenção da dependência energética e dependência angular. Só foi possível calibrar as câmaras de ionização em campos de radiação X, pois os detectores GeigerMüller sofriam estouro de escala por não conseguirem mensurar a quantidade de radiação no ponto de calibração (taxas de kerma no ar altas demais).

As câmaras de ionização foram testadas a uma distância de $2,5 \mathrm{~m}$ do tubo de raios $X$ e para as qualidades de radiação $\mathrm{N}-60, \mathrm{~N}-80, \mathrm{~N}-100$ e N-150, sendo que para cada caso foram tomadas cinco medições e assim obtidos valores médios. Foi possível determinar a quantidade de radiação nas grandezas taxa de exposição, taxa de kerma no ar e taxa de equivalente de dose ambiente, conforme a indicação da grandeza de cada equipamento.

A câmara de ionização Physikalisch-Technische Werkstätten (PTW), modelo 32002, série 035 , possui uma incerteza expandida de $3,0 \%$ e está acoplada a um eletrômetro tipo UNIDOS da PTW, modelo 10001 com uma incerteza estimada em $0,5 \%$, constituindo um sistema de medição com uma incerteza total de $3,5 \%$, para o valor correspondente ao fator de calibração.

Foram testadas 21 câmaras de ionização, de 6 marcas e 11 modelos diferentes em feixes padronizados de radiação $X$. Das 21 câmaras de ionização, 19 foram estudadas quanto à dependência energética de sua resposta. Para as câmaras de ionização que oferecem medições em taxa de exposição ou em taxa de kerma no ar, as medições foram convertidas para taxa de equivalente de dose ambiente, de acordo com os coeficientes de 
conversão apresentados na Tabela 2.1. A dependência energética da resposta das câmaras de ionização foi obtida utilizando-se os fatores de calibração obtidos para as qualidades de radiação N-60, N-80, N-100 e N-150 (feixe estreito).

\subsubsection{Resposta dos detectores de radiação}

As medições tomadas para as qualidades de radiação, feixe estreito, nível radioproteção, estão apresentadas na Tabela 4.28.

Tabela 4.28 Resposta das câmaras de ionização para radiação X.

\begin{tabular}{|c|c|c|c|c|c|c|c|c|c|}
\hline \multirow{2}{*}{ Código } & \multicolumn{4}{|c|}{$\begin{array}{l}\text { Medições efetuadas pela } \\
\text { câmara monitora }\end{array}$} & \multicolumn{4}{|c|}{$\begin{array}{c}\text { Medições efetuadas pelo instrumento a } \\
\text { ser testado }\end{array}$} & \multirow{2}{*}{ Unidade } \\
\hline & $(N-60)$ & $(N-80)$ & $(N-100)$ & $(N-150)$ & $(N-60)$ & $(N-80)$ & $(N-100)$ & $(N-150)$ & \\
\hline$A^{\prime} 1$ & 3,26 & 1,33 & $6,48 \mathrm{E}-1$ & 5,16 & 3,24 & 1,29 & $6,47 \mathrm{E}-1$ & 5,74 & $R / h$ \\
\hline$B^{\prime} 3$ & 2,39 & 1,31 & $6,39 \mathrm{E}-1$ & 5,11 & 2,72 & 1,61 & 0,82 & 6,32 & $R / h$ \\
\hline$B^{\prime} 4$ & 33,20 & 19,8 & 9,53 & 70,5 & 33,6 & 20,10 & 9,79 & 67,4 & $\mathrm{mSv} / \mathrm{h}$ \\
\hline$C^{\prime} 2$ & 2,39 & 1,31 & $6,39 \mathrm{E}-1$ & 5,11 & 2,20 & 1,25 & $6,07 \mathrm{E}-1$ & 5,60 & $R / h$ \\
\hline$C^{\prime} 3$ & 3,23 & 1,31 & $6,35 \mathrm{E}-1$ & 5,10 & 2,48 & 1,04 & $5,29 \mathrm{E}-1$ & 5,06 & $R / h$ \\
\hline D'2 & 45,50 & 20,10 & 9,67 & 71,50 & 47,60 & 21,70 & 10,10 & 72,10 & $\mathrm{mSv} / \mathrm{h}$ \\
\hline E'1 & 54,10 & 22,00 & 10,80 & 85,90 & 54,20 & 21,40 & 9,87 & 81,90 & $\mathrm{mR} / \mathrm{min}$ \\
\hline E'2 & 54,20 & 22,10 & 10,80 & 86,00 & 55,40 & 21,90 & 10,00 & 81,50 & $\mathrm{mR} / \mathrm{min}$ \\
\hline$E^{\prime} 3$ & 54,20 & 22,10 & 10,80 & 86,00 & 53,90 & 21,20 & 9,81 & 81,50 & $\mathrm{mR} / \mathrm{min}$ \\
\hline$E^{\prime} 4$ & 3,25 & 1,33 & $6,51 \mathrm{E}-1$ & 5,16 & 3,32 & 1,32 & $6,00 \mathrm{E}-1$ & 4,87 & $R / h$ \\
\hline$F^{\prime} 1$ & 3,27 & 1,34 & $6,54 \mathrm{E}-1$ & 5,19 & 3,37 & 1,34 & $6,09 \mathrm{E}-1$ & 4,92 & $R / h$ \\
\hline G'1 & 3,24 & 1,32 & $6,46 \mathrm{E}-1$ & 5,14 & 3,22 & 1,27 & $5,92 \mathrm{E}-1$ & 4,95 & $R / h$ \\
\hline $\mathrm{H}^{\prime} 1$ & 33,5 & 20,10 & 9,51 & 71,4 & 32,6 & 17,80 & 8,67 & 73,2 & $\mathrm{mSv} / \mathrm{h}$ \\
\hline$K^{\prime} 3$ & 2,39 & 1,31 & 6,39 E-1 & 5,11 & 2,00 & 1,16 & $5,57 \mathrm{E}-1$ & 5,60 & $R / h$ \\
\hline L'5 & 45,00 & 19,90 & 9,55 & 69,50 & 42,70 & 20,30 & 9,37 & 75,10 & $\mathrm{mSv} / \mathrm{h}$ \\
\hline L'6 & 3,22 & 1,31 & $6,4 \mathrm{E}-1$ & 5,09 & 2,90 & 1,32 & 0,67 & 6,22 & $\mathrm{R} / \mathrm{h}$ \\
\hline M'2 & 3,24 & 1,32 & $6,45 \mathrm{E}-1$ & 5,12 & 2,81 & 1,22 & $6,04 \mathrm{E}-1$ & 5,42 & $\mathrm{R} / \mathrm{h}$ \\
\hline M'3 & 3,25 & 1,33 & $6,51 \mathrm{E}-1$ & 5,16 & 2,91 & 1,24 & $6,11 \mathrm{E}-1$ & 5,44 & $R / h$ \\
\hline M'4 & 3,25 & 1,33 & $6,51 \mathrm{E}-1$ & 5,16 & 3,38 & 1,43 & $6,85 \mathrm{E}-1$ & 5,21 & $\mathrm{R} / \mathrm{h}$ \\
\hline
\end{tabular}

As câmaras de ionização testadas para feixes padronizados de radiação $X$ apresentaram, em sua maioria, respostas próximas aos valores das medições determinadas pela câmara monitora do tubo de raios X. Pelos dados apresentados na Tabela 4.28, foi possível determinar os fatores de calibração. 


\subsubsection{Determinação dos fatores de calibração para radiação $X$}

Os fatores de calibração foram determinados de acordo com a Equação 3.1 e os resultados estão apresentados na Tabela 4.29.

\section{Tabela 4.29 Fatores de calibração das câmaras de ionização para radiação $X$.}

\begin{tabular}{|c|c|c|c|c|c|c|c|c|}
\hline \multicolumn{9}{|c|}{$f_{c}:$ Fator de calibração } \\
\hline \multicolumn{9}{|c|}{$u f_{c}$ : Inceteza do fator de calibração } \\
\hline Código & $\begin{array}{c}f_{c} \\
(N-60)\end{array}$ & $\begin{array}{c}u f_{c} \\
(N-60)\end{array}$ & $\begin{array}{c}f_{c} \\
(N-80)\end{array}$ & $\begin{array}{c}u f_{c} \\
(N-80)\end{array}$ & $\begin{array}{c}f_{c} \\
(N-100)\end{array}$ & $\begin{array}{c}u f_{c} \\
(N-100)\end{array}$ & $\begin{array}{c}f_{c} \\
(N-150)\end{array}$ & $\begin{array}{c}u f_{c} \\
(N-150)\end{array}$ \\
\hline$A^{\prime} 11$ & 1,01 & 0,02 & 1,03 & 0,02 & 1,00 & 0,02 & 0,90 & 0,02 \\
\hline$B^{\prime} 3$ & 0,88 & 0,02 & 0,81 & 0,01 & 0,78 & 0,01 & 0,81 & 0,01 \\
\hline$B^{\prime} 4$ & 0,99 & 0,02 & 0,99 & 0,02 & 0,97 & 0,02 & 1,05 & 0,02 \\
\hline$C^{\prime} 2$ & 1,09 & 0,02 & 1,05 & 0,02 & 1,05 & 0,02 & 0,91 & 0,02 \\
\hline$C^{\prime} 3$ & 1,30 & 0,02 & 1,26 & 0,02 & 1,20 & 0,02 & 1,01 & 0,02 \\
\hline D'2 & 0,96 & 0,02 & 0,93 & 0,02 & 0,95 & 0,02 & 0,99 & 0,02 \\
\hline E'1 & 1,00 & 0,02 & 1,03 & 0,02 & 1,09 & 0,02 & 1,05 & 0,02 \\
\hline E'2 & 0,98 & 0,02 & 1,01 & 0,02 & 1,08 & 0,02 & 1,06 & 0,02 \\
\hline E'3 & 1,01 & 0,02 & 1,04 & 0,02 & 1,11 & 0,02 & 1,06 & 0,02 \\
\hline E'4 & 0,98 & 0,02 & 1,01 & 0,02 & 1,09 & 0,02 & 1,06 & 0,02 \\
\hline F'1 & 0,97 & 0,02 & 1,00 & 0,02 & 1,07 & 0,02 & 1,06 & 0,02 \\
\hline G'1 & 1,01 & 0,02 & 1,04 & 0,02 & 1,09 & 0,02 & 1,04 & 0,02 \\
\hline H'1 & 1,03 & 0,02 & 1,13 & $\overline{0,02}$ & 1,10 & $\overline{0,02}$ & 0,98 & 0,02 \\
\hline$k^{\prime}$ 3 & 1,20 & 0,02 & 1,14 & 0,02 & 1,15 & 0,02 & 0,91 & 0,02 \\
\hline L'5 & 1,05 & 0,02 & 0,98 & 0,02 & 1,02 & 0,02 & 0,93 & 0,02 \\
\hline L'6 & 1,11 & 0,02 & 1,00 & 0,02 & 0,96 & 0,02 & 0,82 & 0,01 \\
\hline M'2 & 1,15 & 0,02 & 1,08 & 0,02 & 1,07 & 0,02 & 0,94 & 0,02 \\
\hline M'3 & 1,12 & 0,02 & 1,07 & 0,02 & 1,07 & 0,02 & 0,95 & 0,02 \\
\hline M'4 & 0,96 & 0,02 & 0,93 & 0,02 & 0,95 & 0,02 & 0,99 & 0,02 \\
\hline
\end{tabular}

O fator de calibração não pode variar mais que $20 \%$ (IRD, 2004). Neste caso, a câmara de ionização B'3 não estaria apta a medir uma quantidade de radiação na qualidade de radiação $\mathrm{N}-100$ e a câmera de ionização C'3 não estaria apta a medir uma quantidade de radiação nas qualidades de radiação $\mathrm{N}-60$ e $\mathrm{N}-80$. 


\subsubsection{Dependência energética dos detectores para radiação $X$}

Utilizando-se os dados obtidos na Tabela 4.29, foi possível obter as curvas da resposta das câmeras de ionização em função da energia média dos feixes padronizados de radiação X: Figuras 4.14 a 4.19. Também foram obtidas três curvas comparando-se as respostas de três câmaras de ionização C'2, D'2 e H'1 em função da energia média para as qualidades de radiação $X$, e para a radiação gama $\left({ }^{137} \mathrm{Cs} \mathrm{e}{ }^{60} \mathrm{Co}\right)$.

Pode-se observar comportamentos diferentes nas respostas das câmaras de ionização de modelos diferentes. Quando são comparadas as curvas das respostas das câmaras de ionização para um mesmo modelo, o comportamento é bem semelhante, como no caso das câmaras de ionização E'1, E'2, E'3 e E'4.

Na Figura 4.19, o modelo C'2 possui valores dos fatores de calibração para radiação $X$ e radiação gama próximos. No modelo $D$ '2, os valores do fator de calibração para radiação $X$ foram maiores em relação aos valores obtidos para radiação gama. No modelo H'1 essa diferença foi mais acentuada, mostrando que as câmaras de ionização variam o seu comportamento, tanto para radiação $\mathrm{X}$ como para radiação gama, de acordo com o modelo.

Por meio dos fatores de calibração, foi possível estudar a dependência energética, DE, da resposta de cada câmara de ionização, que está apresentada na Tabela 4.30 . 

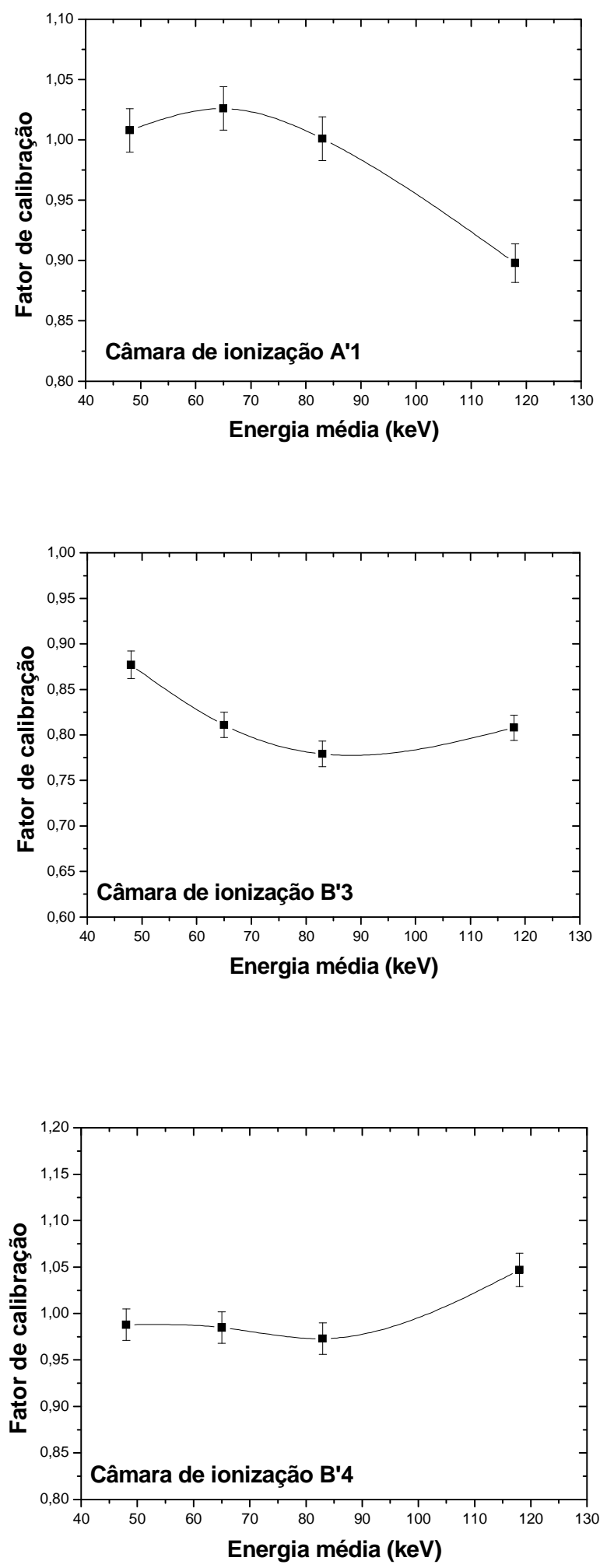

Figura 4.14 Fatores de calibração das câmaras de ionização A'1, B'3 e B'4, para radiação $X$. 

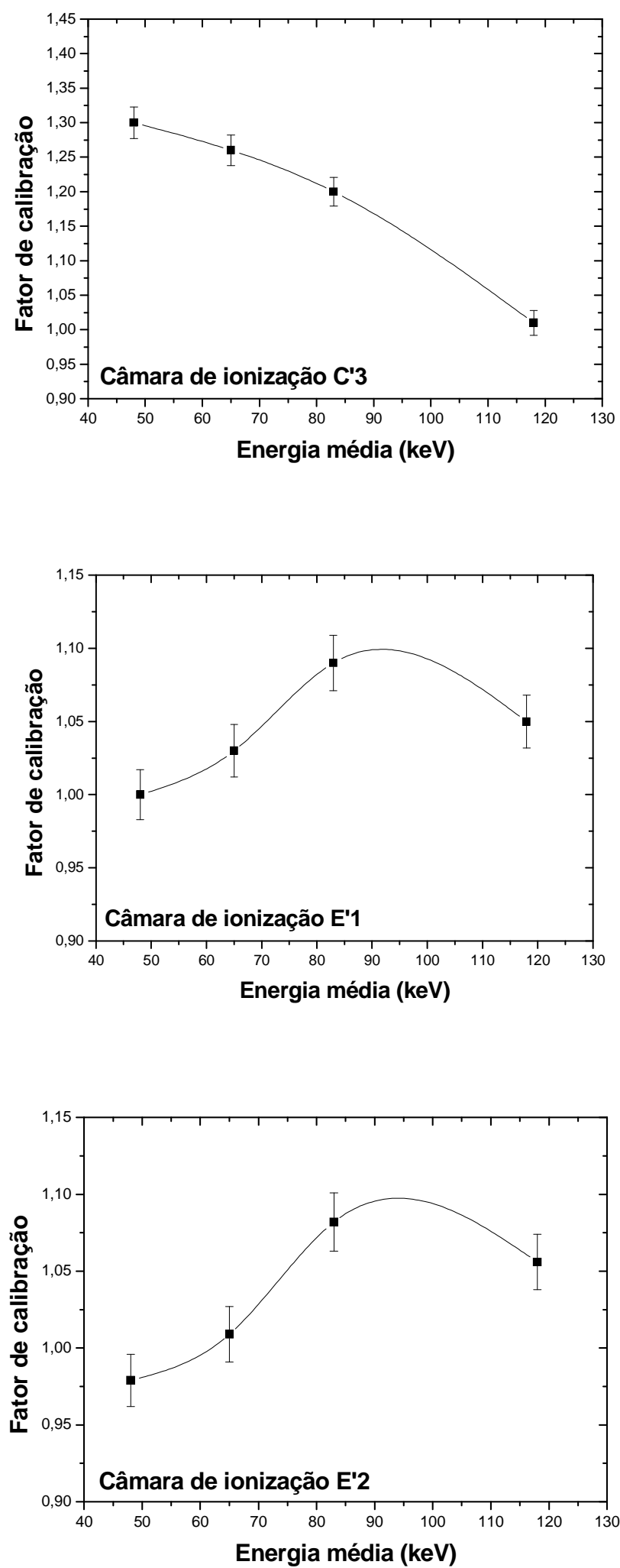

Figura 4.15 Fatores de calibração das câmaras de ionização C'3, E'1 e E'2, para radiação $X$. 

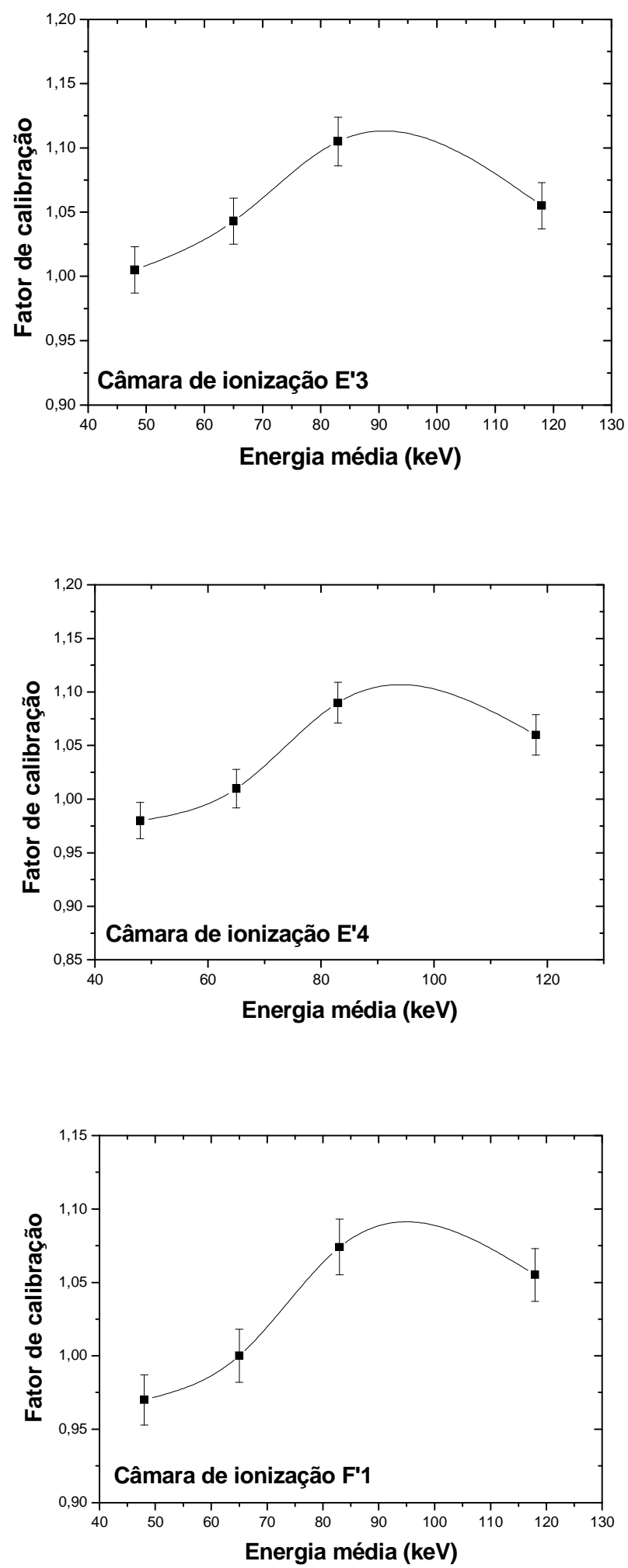

Figura 4.16 Fatores de calibração das câmaras de ionização E'3 e E'4 e $F$ '1, para radiação $X$. 

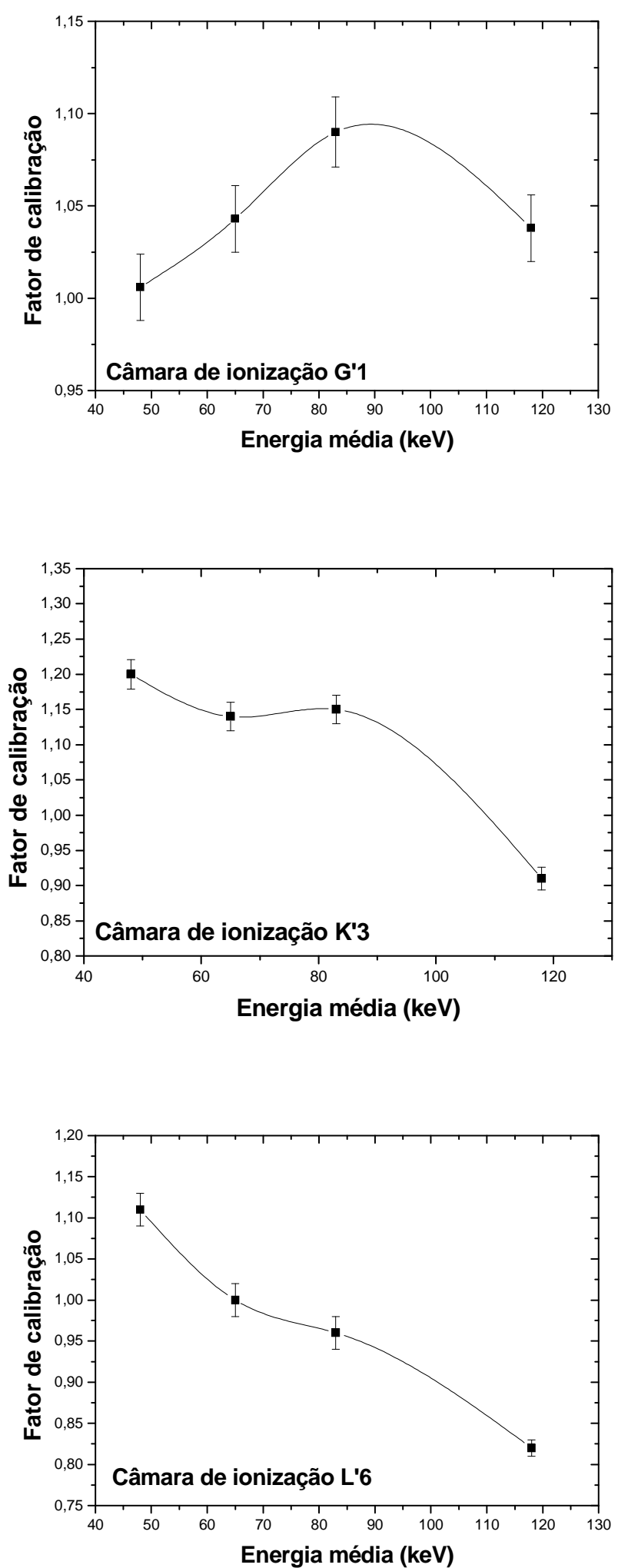

Figura 4.17 Fatores de calibração das câmaras de ionização G'1, K’3 e L'6, para radiação $X$. 

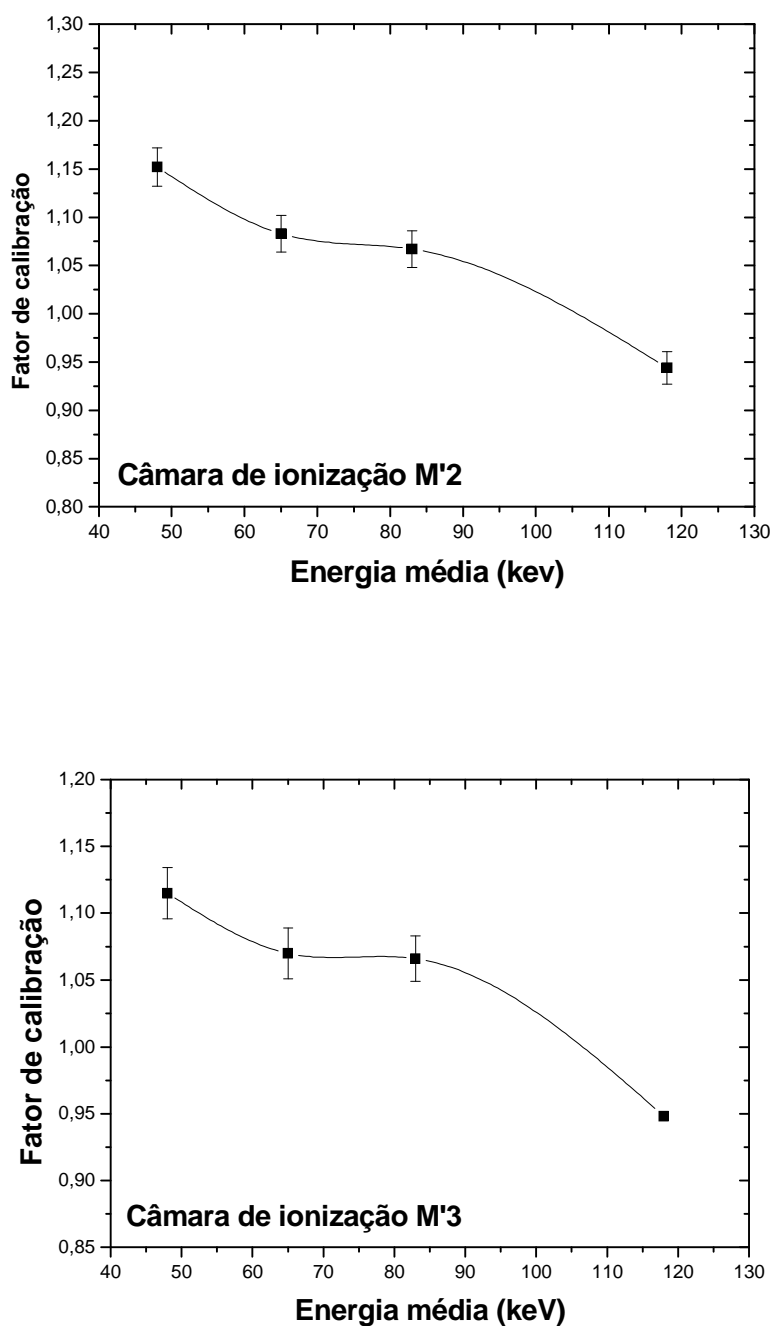

Figura 4.18 Fatores de calibração das câmaras de ionização M'2 e M'3, para radiação $X$. 

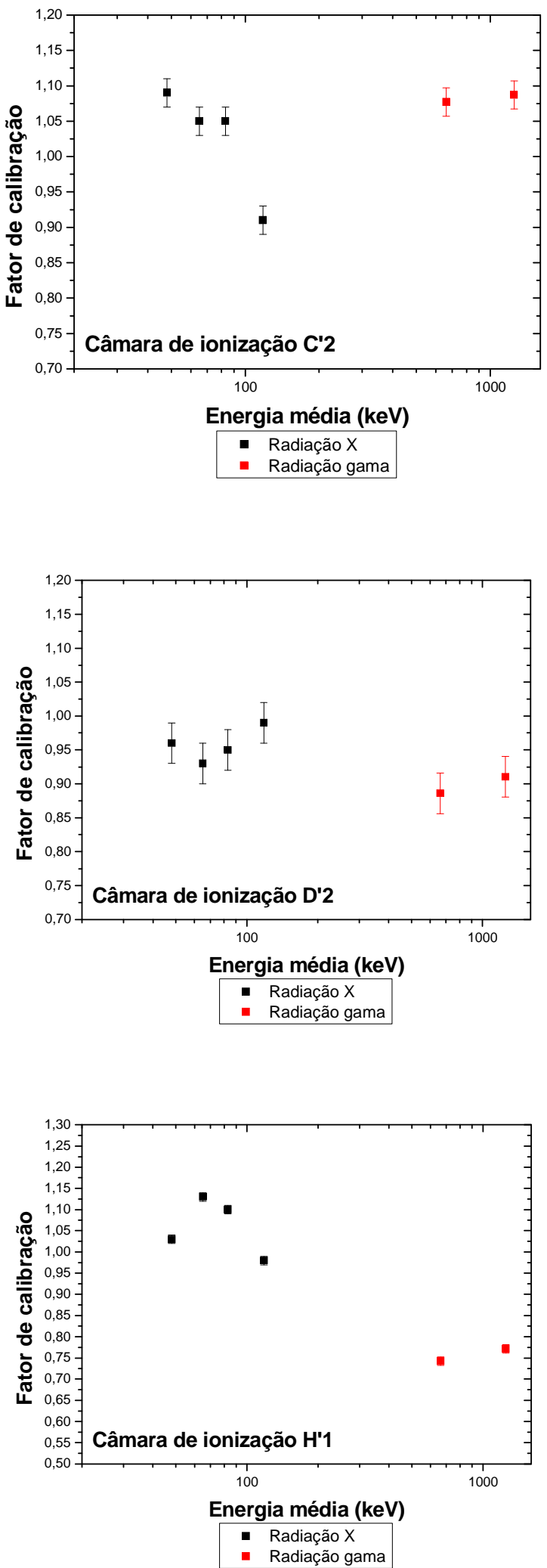

Figura 4.19 Fatores de calibração das câmaras de ionização C'2, D'2 e $H$ '1, para radiação $X$ e gama. 
Tabela 4.30 Dependência energética das câmaras de ionização, nível radioproteção, para raios $X(48 \mathrm{keV}-118 \mathrm{keV})$.

\begin{tabular}{c|cc}
\hline Código & DE & $\mathbf{U}$ \\
\hline A'1 & 1,14 & 0,07 \\
\hline B'3 & 1,13 & 0,06 \\
\hline B'4 & 1,08 & 0,06 \\
\hline C'2 & 1,20 & 0,07 \\
\hline C'3 & 1,29 & 0,06 \\
\hline D'2 & 1,06 & 0,06 \\
\hline E'1 & 1,09 & 0,06 \\
\hline E'2 & 1,10 & 0,06 \\
\hline E'3 & 1,10 & 0,06 \\
\hline E'4 & 1,11 & 0,06 \\
\hline F'1 & 1,10 & 0,06 \\
\hline G'1 & 1,08 & 0,06 \\
\hline H'1 & 1,15 & 0,06 \\
\hline k'3 & 1,32 & 0,07 \\
\hline L'5 & 1,13 & 0,06 \\
\hline L'6 & 1,35 & 0,08 \\
\hline M'2 & 1,22 & 0,07 \\
\hline M'3 & 1,18 & 0,07 \\
\hline M'4 & 1,06 & 0,06 \\
\hline & &
\end{tabular}

A dependência energética variou entre $6 \%$ e $35 \%$, de acordo com os detectores M'4 e L'6, que apresentaram respectivamente dependência energética de $(1,06 \pm 0,06)$ e de $(1,35 \pm 0,08)$. Os monitores de radioproteção são divididos em diferentes classes, de acordo com a norma ABNT 10011 (ABNT, 1987). Neste trabalho, as câmaras de ionização estão dentro da classificação de classe II, onde a variação máxima pode ser de até $\pm 25 \%$. Apenas a câmara de ionização L'6 apresentou um valor insatisfatório, levando-se em conta a incerteza, de acordo com a Tabela 4.30.

\subsubsection{Dependência angular dos detectores para radiação $X$}

Foi estudada a dependência angular da resposta das câmaras de ionização A'1, C'3, L'7 e L'8. A varredura angular foi de $0^{\circ}$ a $90^{\circ}$ e foi realizada 
apenas para a qualidade de radiação $\mathrm{N}-150$. As curvas estão apresentadas nas Figuras 4.20 e 4.21 .
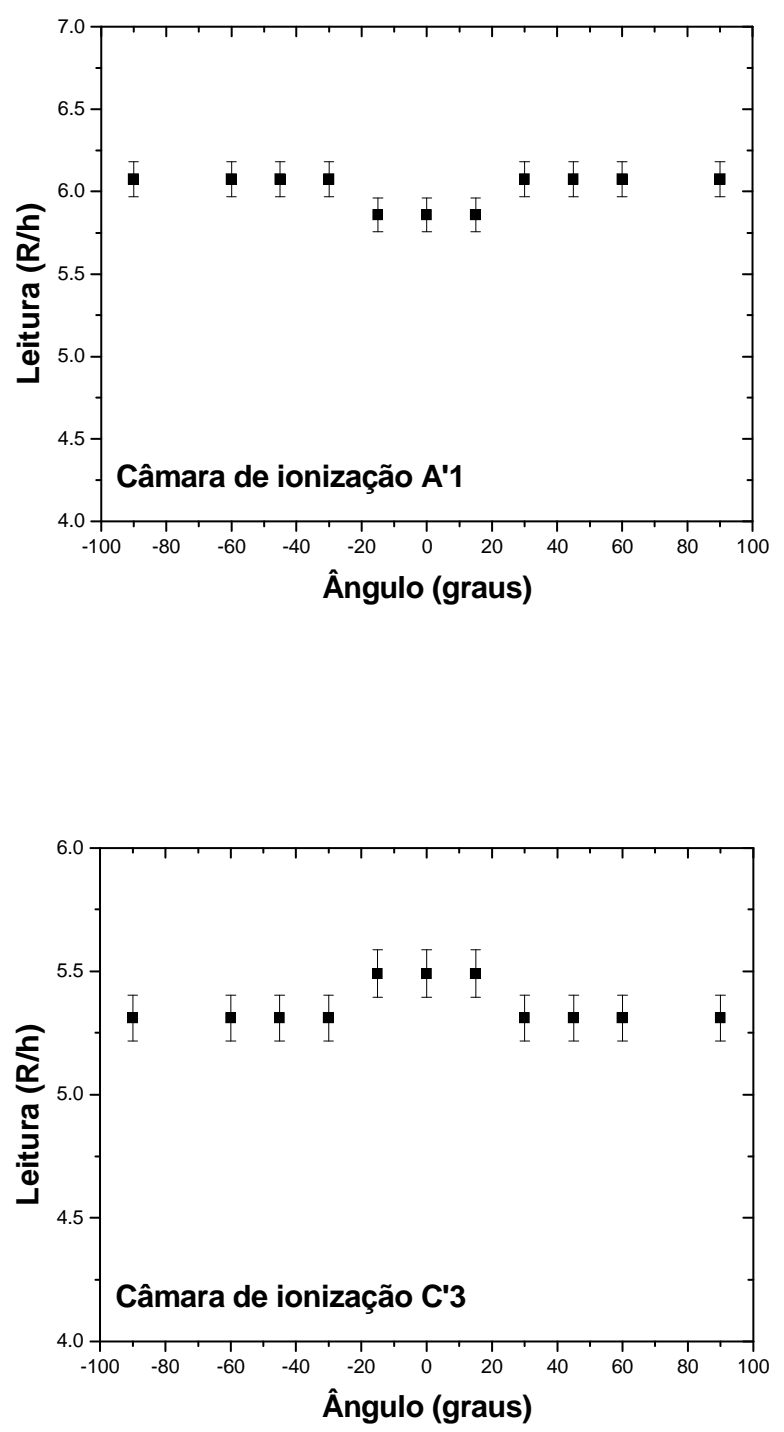

Figura 4.20 Resposta angular das câmaras de ionização A'1 e C'3, em feixes de radiação $X(\mathrm{~N}-150)$. 

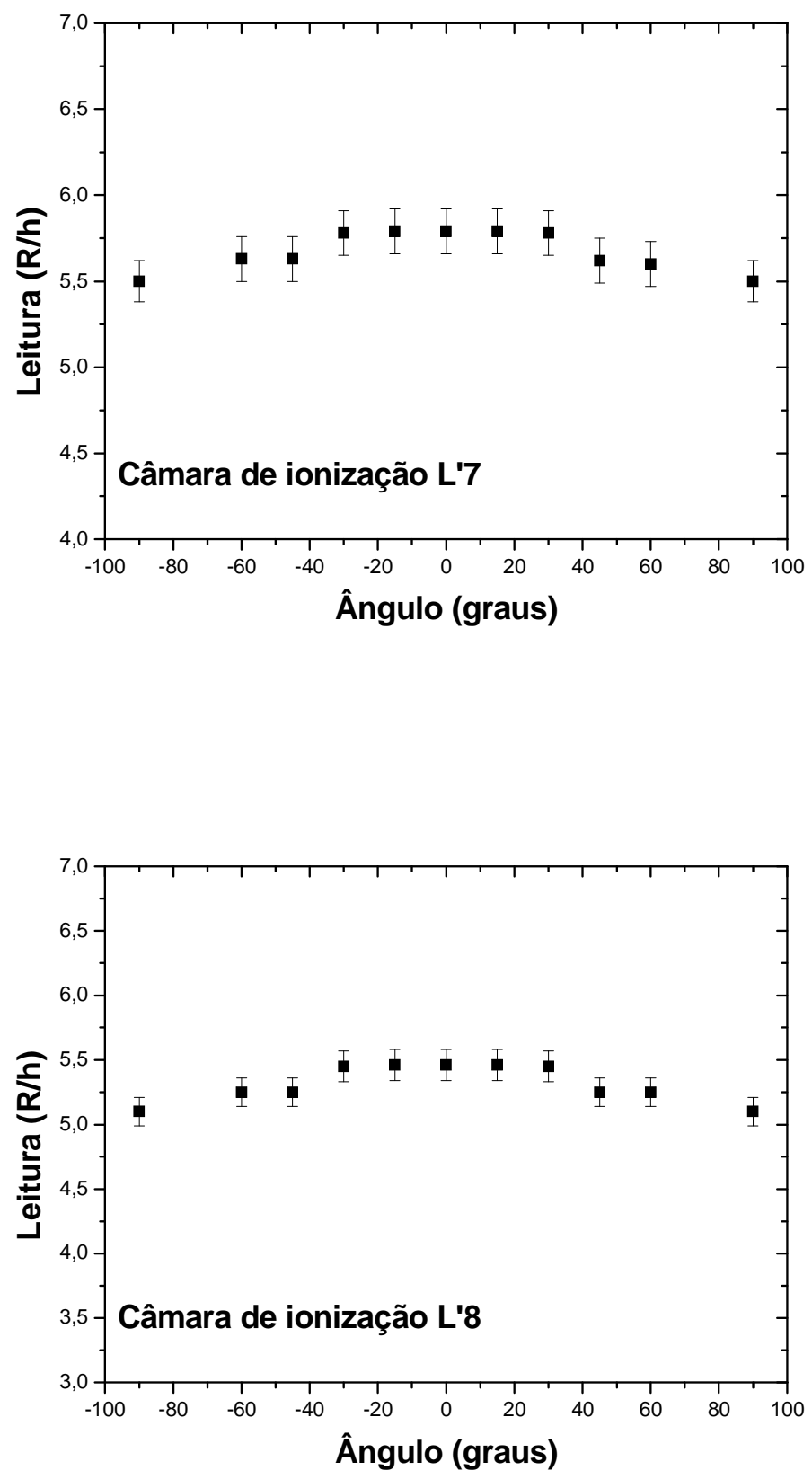

Figura 4.21 Resposta angular das câmaras de ionização L'7 e L'8, em feixes de radiação $X(N-150)$.

As câmaras de ionização apresentadas nas Figuras 4.20 e 4.21 possuem pouca ou nenhuma dependência angular. Como apresentaram uma dependência angular menor que $40 \%$ entre os ângulos de $0^{0}$ e $\pm 45^{\circ}$, os resultados estão de acordo com a norma européia (EN, 2004). As câmaras de ionização L'7 e L'8 apresentam uma variação um pouco mais acentuada em 
relação às câmaras de ionização A'1 e C'3, porque possuem janelas de entrada que permitem a medição de radiação beta. A borda de cada janela prejudica um pouco a entrada da radiação no volume sensível da câmara de ionização, quando a câmara de ionização não é posicionada frontalmente ao feixe de incidência. 


\section{Conclusões}

Os monitores de radiação calibrados neste trabalho em campos de radiação gama $\left({ }^{137} \mathrm{Cs}\right)$ apresentaram fatores de calibração próximos ao valor unitário, especialmente as câmaras de ionização; dos sessenta e seis detectores Geiger-Müller, apenas 7 instrumentos obtiveram fatores de calibração maiores que $10 \%$ em relação à unidade. Dos 4 detectores semicondutores estudados, dois detectores apresentaram fatores de calibração maiores que $10 \%$. Os instrumentos calibrados e ajustados inicialmente para radiação de ${ }^{137} \mathrm{Cs}$, quando foram testados em feixes de ${ }^{60} \mathrm{Co}$, apresentaram fatores de calibração maiores que $\pm 10 \%$; os valores foram menores que 0 valor unitário tanto para os detectores Geiger-Müller quanto para os detectores semicondutores. Essa diferença foi observada a partir dos resultados do estudo da dependência energética de cada instrumento. As câmaras de ionização, previamente calibradas com feixes de ${ }^{137} \mathrm{Cs}$, apresentaram, para feixes de ${ }^{60} \mathrm{Co}$, fatores de calibração próximos de um.

Ao se testar os monitores de radiação em campos de radiação beta, observou-se, tanto para a fonte de ${ }^{90} \mathrm{Sr}+{ }^{90} \mathrm{Y}$ como de ${ }^{204} \mathrm{Tl}$, que os fatores de calibração obtidos foram substancialmente altos, até para as câmaras de ionização.

Os fatores de calibração obtidos para as câmaras de ionização, para radiação $X$, foram próximos ao valor unitário. Apenas duas das 19 câmaras de ionização testadas não se apresentaram de acordo com os requisitos nacionais (IRD, 2004), que determinam que os fatores de calibração não podem ser maiores que $20 \%$.

$\mathrm{O}$ estudo da dependência energética para radiação gama $\left({ }^{137} \mathrm{Cs}\right.$ e $\left.{ }^{60} \mathrm{Co}\right)$ possibilitou verificar que dos sessenta e seis detectores Geiger-Müller testados, aproximadamente $15 \%$ dos detectores Geiger-Müller não estariam de acordo com a norma nacional ABNT NBR 10011 (ABNT, 1987), que estabelece que a dependência energética possa variar até $25 \%$, muito menos com a norma internacional ISO 4037-2 (ISO, 1997), que estabelece que os instrumentos não podem apresentar uma dependência energética maior que $10 \%$. Todos os detectores semicondutores e câmaras de ionização estão de acordo com a norma nacional e a norma internacional. 
Em decorrência dos altos valores dos fatores de calibração para campos de radiação beta em relação aos fatores obtidos para radiação gama, a dependência energética em relação à radiação de ${ }^{90} \mathrm{Sr}+{ }^{90} \mathrm{Y}$ e ${ }^{204} \mathrm{TI}$ foi muito grande, tanto para os detectores Geiger-Müller quanto para as câmaras de ionização. Neste tipo de teste de desempenho nenhum detector de radiação seria aprovado pela norma europeia EN 60846 (EN, 2004), que determina que a dependência energética pode variar no máximo de $40 \%$.

Também foram analisados os fatores de calibração obtidos para fontes de radiação beta com relação à radiação gama: a dependência da resposta dos detectores com o tipo de radiação foi muito alta, até para as câmaras de ionização. Os resultados mostram a importância da calibração dos detectores beta-gama com radiação gama e beta. $O$ detector de radiação calibrado somente com radiação gama não pode ser utilizado para quantificar medições em campos de radiação beta.

No caso dos resultados obtidos para as câmaras de ionização testadas com fonte de radiação $X$, a dependência energética variou entre $6 \%$ e $35 \%$. De acordo com a norma ABNT NBR 10011 (ABNT, 1987) a variação da dependência energética pode ser de no máximo $\pm 25 \%$ para radiação de fótons no intervalo de $50 \mathrm{keV}$ a $3 \mathrm{MeV}$. Das 19 câmaras de ionização testadas, apenas uma delas (L'6) apresentou um valor insatisfatório.

Além da calibração dos instrumentos que possibilitou o estudo da dependência energética, também foi realizado um estudo da dependência angular da resposta dos monitores de radiação. De acordo com a norma europeia EN 60846 (EN, 2004), a dependência angular não pode apresentar uma variação maior que $40 \%$, quando são comparados os valores obtidos com ângulo de $0^{\circ}$ em relação a ângulos de $\pm 45^{\circ}$, para radiações gama e beta. Todos os detectores de radiação submetidos à radiação gama $\left({ }^{137} \mathrm{Cs}\right)$ apresentaram valores de dependência energética menores que 40\%. Resultado diferente foi obtido para os detectores de radiação submetidos à radiação beta $\left({ }^{90} \mathrm{Sr}+{ }^{90} \mathrm{Y}\right)$; nenhum deles foi aprovado neste tipo de teste de desempenho.

Também foram obtidas as curvas da resposta dos instrumentos em relação a uma varredura angular de $0^{\circ} \mathrm{a} \pm 90^{\circ}$ para radiação gama, beta e $\mathrm{X}$. Para radiação gama, os detectores Geiger-Müller e os detectores 
semicondutores apresentaram comportamentos variados, dependendo da geometria do tubo do detector Geiger-Müller, se a sonda é interna ou externa e também do material de cobertura do volume sensível do instrumento. As câmaras de ionização testadas com radiação gama e $\mathrm{X}$, em sua maioria, apresentaram dependência angular menor que $40 \%$, como esperado. No caso dos detectores Geiger-Müller e das câmaras de ionização, testados em feixes de radiação beta, eles apresentaram uma certa simetria nas curvas da resposta em função do ângulo de incidência de radiação para os lados positivo e negativo, diferentemente do comportamento dos detectores em campos de radiação gama.

De acordo com os resultados obtidos neste trabalho concluí-se que a calibração é de extrema importância para assegurar a qualidade dos instrumentos a serem utilizados em radioproteção principalmente em feixes de radiação $X$ e beta. 
Apêndice A - Procedimentos de calibração de detectores de radiação na grandeza equivalente de dose ambiente $e$ determinação do fator de correção em relação à grandeza taxa de dose absorvida.

São apresentados os procedimentos de calibração em campos de radiação gama, beta e X para detectores de radiação Geiger-Müller, detectores semicondutores e câmaras de ionização. Primeiramente são apresentados os procedimentos de calibração de uma forma geral e posteriormente os procedimentos são subdivididos conforme o tipo de radiação a ser utilizado e por último são apresentados os fatores de conversão para as grandezas operacionais de radiação.

A1 Procedimento geral de calibração de monitores portáteis em campos de radiação gama, beta e $X$.

\section{A1.1 Objetivo:}

Descrever o processo de calibração realizado nos detectores portáteis de radiação na grandeza equivalente de dose ambiente.

A1.2 Campo de aplicação:

\begin{tabular}{|c|c|c|c|}
\hline \multirow{2}{*}{$\begin{array}{c}\text { Aplicação em } \\
\text { monitores }\end{array}$} & Quem & Quando & Onde \\
\cline { 2 - 4 } $\begin{array}{c}\text { portáteis de } \\
\text { radiação }\end{array}$ & $\begin{array}{c}\text { Técnico } \\
\text { Tecnologista } \\
\text { Gerente técnico }\end{array}$ & $\begin{array}{c}\text { calibração das } \\
\text { fontes, conforme } \\
\text { o laboratório de } \\
\text { calibração }\end{array}$ & $\begin{array}{c}\text { No laboratório de } \\
\text { calibração: gama, } \\
\text { beta ou X }\end{array}$ \\
\hline
\end{tabular}




\section{A1.3 Condições e recursos de trabalho:}

> Técnico com conhecimento em proteção radiológica

> Mesa de irradiação com deslocamento de distância e altura ajustável.

> Circuito interno fechado de TV para a leitura da resposta do instrumento exposto ao feixe de radiação.

$>$ Microcomputador com impressora.

> Instrumentos para medidas de condições ambientais: barômetro, termômetro e higrômetro.

$>$ Desumificador.

> Jogos de ferramentas: Trenas, chaves, arcos e alicates.

> Multímetro digital com capacidade de medição de tensão contínua e alternada e resistência de até $M \Omega$ e resistência de entrada maior ou igual a $10 \mathrm{M} \Omega$.

> Arquivo técnico composto pelos manuais dos diversos tipos de modelos de detectores de radiação.

\section{A1.4 Cuidados especiais:}

Na forma de manusear, armazenar e transportar os equipamentos.

> As condições ambientais de referência de um laboratório de calibração devem ser: temperatura entre $18{ }^{\circ} \mathrm{C}$ e $22{ }^{\circ} \mathrm{C}$, pressão entre $86 \mathrm{kPa}$ e $106 \mathrm{kPa}$ e umidade relativa do ar entre $50 \%$ e $75 \%$.

\section{A1.5 Descrição das atividades:}

Neste tópico são apresentadas as etapas a serem seguidos na calibração em campos de radiação gama, beta e X. Posteriormente serão criados tópicos ressaltando diferentes pontos no processo de calibração para cada tipo de radiação. 


\section{Etapa Descrição}

1 Inspecionar o instrumento e comparar seu estado físico com a descrição contida no formulário preenchido pelo laboratório de calibração no ato do recebimento do instrumento.

2 Ligar o equipamento na função teste de bateria (quando existir) e verificar a tensão nominal das baterias. Caso haja necessidade, substituir as baterias. Se não houver a função teste de bateria, medir a tensão nominal utilizando-se um multímetro.

3 Deixar o instrumento ligado por aproximadamente 15 minutos até a sua estabilização, antes de iniciar os testes.

$4 \quad$ Verificar se o modelo do instrumento a ser calibrado está registrado no diretório das planilhas eletrônicas. Os laboratórios de calibração gama, beta e $\mathrm{X}$ contêm planilhas eletrônicas adequadas à grandeza de medição para cada um dos modelos de instrumentos.

5 Se sim, preencher nas planilhas eletrônicas os seguintes campos: data de calibração, marca, modelo e número de série do instrumento e da sonda, se houver; nome da empresa e o número do protocolo do instrumento que será gerado no momento do recebimento do instrumento.

6 Se não, consultar o manual técnico do instrumento a especificação da energia de radiação durante a calibração, o posicionamento correto do instrumento no campo de radiação e a possibilidade de ajustes.

7 Preencher na planilha eletrônica a grandeza de referência de acordo com a escala do instrumento sob calibração e selecionar a unidade de escala.

Posicionar o instrumento tomando-se como referência o centro geométrico do detector ou de acordo com a recomendação do fabricante. 


\section{Etapa Descrição}

9 Anotar as condições ambientais: temperatura, pressão e umidade.

10 Anotar os valores de radiação de fundo, no caso de radiação gama e beta.

11 Realizar as medições de acordo com a grandeza operada pelo instrumento na posição de irradiação.

12 Imprimir a planilha eletrônica, que calculará o valor médio das leituras corrigidas para temperatura e pressão no caso das câmaras de ionização não seladas.

13 Preencher o certificado de calibração caso o instrumento estiver em conformidade com as recomendações e normas e etiquetar 0 instrumento com a etiqueta de calibração.

\section{A1.5.1 Descrição das atividades para radiação gama, complementar as etapas apresentadas em A1.5:}

> O irradiador gama do laboratório de calibração de Instrumentos (LCl) contém fontes radioativas de ${ }^{60} \mathrm{Co},{ }^{137} \mathrm{Cs},{ }^{226} \mathrm{Ra}$ e ${ }^{241} \mathrm{Am}$.

> O método de calibração foi "o uso de campos de radiação conhecidos", determinando-se, de acordo com a distância fonte-detector e atenuadores de chumbo, o valor verdadeiro convencional.

$>$ Realizar etapas de 1 a 7.

> De acordo com etapa 7, após selecionar a unidade de cada escala, deve-se definir as taxas de referências em 20, 50 e 80\% de cada escala. Isto é realizado mudando-se a distância fonte/detector e escolhendo-se o número de atenuadores de chumbo que, para este caso, é três (com fator de atenuação de até x1000).

$>$ Realizar etapas 8 a 10.

$>$ De acordo com a etapa 11, primeiramente são tomadas medições utilizando-se a fonte de ${ }^{137} \mathrm{Cs}$.

- Deslocar a fonte para o ponto central do irradiador por meio de um sistema pneumático e um painel de controle, localizado na sala de comando, externamente à sala do irradiador. 
> Para cada escala deve-se tomar 10 medições e obter uma média.

$>$ Caso as medições do instrumento variem $\pm 10 \%$ em relação ao valor verdadeiro convencional no ponto correspondente a $50 \%$ da escala sob calibração, o instrumento pode ser ajustado neste ponto de escala ou de acordo com a recomendação do fabricante em relação à fonte de referência ${ }^{137} \mathrm{Cs}$.

> A 20 e $80 \%$ de cada escala, a medição realizada pelo instrumento não deve variar mais que $\pm 20 \%$ em relação ao valor verdadeiro convencional.

> Após calibrar com ${ }^{137} \mathrm{Cs}$, realizar teste utilizando a fonte de radiação de ${ }^{60} \mathrm{Co}$ no ponto correspondente a $50 \%$ de uma escala estável do detector de radiação, obtendo-se uma média de 10 medições, com o objetivo de verificar a dependência energética.

Realizar etapas 12 e 13.

\section{A1.5.2 Descrição das atividades para radiação beta, complementar às etapas apresentadas em A1.5:}

> O LCl dispõe de dois irradiadores: o irradiador beta modelo BSS1 que possui quatro fontes radioativas, duas de ${ }^{90} \mathrm{Sr}+{ }^{90} \mathrm{Y}$, uma de ${ }^{147} \mathrm{Pm} \mathrm{e}$ uma de ${ }^{204} \mathrm{TI}$ e o irradiador beta modelo BSS2 que possui três fontes radioativas de ${ }^{90} \mathrm{Sr}+{ }^{90} \mathrm{Y},{ }^{147} \mathrm{Pm}$ e ${ }^{85} \mathrm{Kr}$.

> As fontes fazem parte do sistema de referência do laboratório; o valor verdadeiro convencional encontra-se no manual com a data de calibração das fontes.

$>$ O irradiador utilizado para calibração no LCl é o de modelo BSS1.

> Realizar etapas 1 a 10.

> Utilizar a mesma distância fonte-detector empregada na calibração das fontes.

> Colocar as fontes no irradiador por meio de um suporte.

> $\mathrm{Na}$ etapa 11 são tomadas as medições; para o caso beta, a fonte radioativa a ser utilizada é a de ${ }^{90} \mathrm{Sr}+{ }^{90} \mathrm{Y}$ com taxa de dose absorvida de $1,71 \mu \mathrm{Gy} . \mathrm{s}^{-1}$.

$>$ Colocar um filtro correspondente à fonte de ${ }^{90} \mathrm{Sr}+{ }^{90} \mathrm{Y}$. 
> Tomar 10 medições e obter uma média.

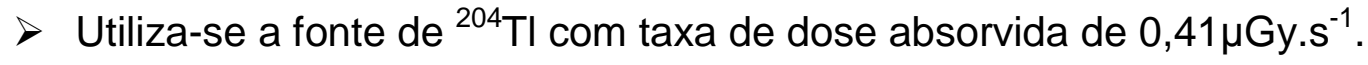

$>$ Colocar um filtro correspondente à fonte de ${ }^{204} \mathrm{TI}$.

D Tomar 10 medições e obter uma média.

> Determinar o fator de correção em relação à taxa de dose absorvida de acordo com a secção A1.8.

$>$ Realizar etapas 12 e 13.

\section{A1.5.3 Descrição das atividades para radiação $X$, complementar às etapas apresentadas em A1.5:}

> $\mathrm{OLCl}$ possui um equipamento de raios X Pantak/Seifert e, para nível radioproteção, a calibração é realizada para as qualidades de radiação $\mathrm{N}-60, \quad \mathrm{~N}-80, \mathrm{~N}-100, \mathrm{~N}-150$ (conforme recomendado pela norma ISO - 4037 (ISO, 1999)).

> Realizar etapas 1 a 9.

Procedimentos a serem tomados com o equipamento após etapa 9:

- Ligar o equipamento de raios $X$.

- Virar a chave do obturador para a direita e colocar uma chave no painel de controle.

- Realizar um pré-aquecimento.

- Escolher a tensão $(\mathrm{kV})$ e o filtro adicional, de acordo com a qualidade de radiação, tabela $1 \mathrm{~A}$, e escolher o valor de corrente de $20 \mathrm{~mA}$. 
Tabela 1A - Características das qualidades de radiação.

\begin{tabular}{ccc}
\hline $\begin{array}{c}\text { Qualidade da } \\
\text { radiação } \\
(\text { ISO - 4037) }\end{array}$ & $\begin{array}{c}\text { Tensão } \\
(\mathbf{k V})\end{array}$ & $\begin{array}{c}\text { Filtração } \\
\text { adicional } \\
(\mathbf{m m})\end{array}$ \\
\hline $\mathbf{N}-60$ & 60 & $0,6(\mathrm{Cu})+4 \mathrm{~mm}(\mathrm{Al})$ \\
\hline $\mathbf{N}-80$ & 80 & $2,0(\mathrm{Cu})+4 \mathrm{~mm}(\mathrm{Al})$ \\
\hline $\mathbf{N}-100$ & 100 & $5,0(\mathrm{Cu})+4 \mathrm{~mm}(\mathrm{Al})$ \\
\hline $\mathbf{N}-150$ & 150 & $2,5(\mathrm{Sn})+4 \mathrm{~mm}(\mathrm{Al})$
\end{tabular}

Há uma câmara monitora à frente do tudo de raios X, calibrada contra um instrumento de referência.

> Esta câmara de ionização é a câmara monitora padrão de trabalho, que determina o valor verdadeiro convencional.

$>$ Realizar etapa 11 :

- Primeiro, escolher a qualidade $\mathrm{N}-60$, a tensão (kV) e colocar o filtro adicional correspondente à qualidade à frente do tubo de raios $\mathrm{X}$.

- Abrir o software responsável pelos cálculos.

- Ligar o equipamento de raios $X$.

- Inserir no programa do software a qualidade de radiação a ser utilizada e são acrescentados ao programa 5 medições das respostas dos instrumentos.

- O software calcula o valor verdadeiro convencional de acordo com a câmara monitora e oferece as medições obtidas pelos instrumentos juntamente com o fator de correção para as condições normais de temperatura e pressão.

> Inserir esses valores na planilha eletrônica.

$>$ Verificar se o fator de calibração não variou mais que $\pm 20 \%$ em relação ao valor verdadeiro convencional.

> Realizar o mesmo procedimento para todas as qualidades.

> Realizar etapas 12 e 13. 


\section{A1.6 Observações importantes:}

No momento da escolha da grandeza de referência, na etapa 7, o técnico deverá identificar qual a grandeza em que o instrumento opera, o que pode ser verificado no manual do instrumento. Atualmente existem no mercado instrumentos que medem nas grandezas taxa de exposição, taxa de kerma no ar, taxa de equivalente de dose ambiente e taxa de equivalente de dose direcional. Caso a unidade do instrumento seja $\mathrm{mSv} / \mathrm{h}$, o técnico deverá redobrar a atenção e verificar se o equipamento está medindo na grandeza equivalente de dose ambiente $H^{*}(10)$ ou equivalente de dose para fótons, $H x$, porque infelizmente em alguns manuais não se encontra especificada qual a grandeza do instrumento a ser medida. Hx foi muito utilizado nas práticas de radioproteção e as grandezas taxa de exposição e taxa de kerma no ar estão sendo substituídas, aos poucos, pelas grandezas taxa de equivalente de dose ambiente e taxa de equivalente de dose direcional, como por exemplo, nas câmaras de ionização da marca Victoreen. 
A1.7 Obtenção das medições dos instrumentos na grandeza equivalente de dose ambiente, para radiação gama e $X$ :

Nos instrumentos que medem na grandeza taxa de equivalente de dose, $\dot{H}_{x}$, pode-se converter a grandeza para taxa de exposição $\dot{X}$ por meio do coeficiente de conversão, $F=\frac{\dot{H}_{x}}{\dot{H}}=0,01 S v / R$.

As medições obtidas em taxa de exposição, $\dot{X}$, são convertidas para taxa de kerma no ar, $K_{a r}$, por meio do coeficiente de conversão $\dot{\mathrm{K}}_{\mathrm{ar}}=8,76 \cdot 10^{-3} \cdot \dot{\mathrm{X}}$.

$>$ Os coeficientes para fótons de taxa de kerma no ar para equivalente de dose ambiente estão apresentados na Tabela 2A.

Tabela 2A - Coeficientes de conversão de kerma no ar para e equivalente de dose ambiente, de acordo com a norma ISO 4037-3 (ISO,1999).

\begin{tabular}{c|c|c|c} 
Radiação & $\begin{array}{c}\text { Qualidade de } \\
\text { radiação }\end{array}$ & $\begin{array}{c}\text { Distância } \\
\text { fonte-detector }\end{array}$ & $\begin{array}{c}\text { Coeficiente } \\
\text { de } \\
\text { conversão } \\
\boldsymbol{H}^{*}(\mathbf{1 0})\end{array}\left(\frac{\boldsymbol{S} \boldsymbol{v}}{\boldsymbol{G y}}\right)$ \\
\hline \multirow{3}{*}{$\mathbf{K})$} & $\mathrm{N}-25$ & $1,0-2,0$ & 0,52 \\
& $\mathrm{~N}-30$ & $1,0-2,0$ & 0,80 \\
& $\mathrm{~N}-40$ & $1,0-3,0$ & 1,18 \\
& $\mathrm{~N}-60$ & $1,0-3,0$ & 1,59 \\
& $\mathrm{~N}-80$ & $1,0-3,0$ & 1,73 \\
& $\mathrm{~N}-100$ & $1,0-3,0$ & 1,71 \\
& $\mathrm{~N}-120$ & $1,0-3,0$ & 1,64 \\
& $\mathrm{~N}-150$ & $1,0-3,0$ & 1,58 \\
& $\mathrm{~N}-200$ & $1,0-3,0$ & 1,46 \\
Gama & $\mathrm{N}-250$ & $1,0-3,0$ & 1,39 \\
& $\mathrm{~N}-300$ & $1,0-3,0$ & 1,35 \\
\hline & $\mathrm{S}-\mathrm{Cs}$ & $1,0-3,0$ & 1,20 \\
& $\mathrm{~S}-\mathrm{Co}$ & $1,0-3,0$ & 1,16 \\
\hline
\end{tabular}


A1.8 Determinação do fator de correção de detectores beta-gama em relação à grandeza taxa de dose absorvida para radiação beta:

> Obter as médias, $\bar{M}$, das medições dos instrumentos para as fontes de ${ }^{90} \mathrm{Sr}+{ }^{90} \mathrm{Y}$ e ${ }^{204} \mathrm{Tl}$ após etapa 11.

> Calcular os fatores de correção, $\mathrm{F}_{\mathrm{c}}$, para ${ }^{90} \mathrm{Sr}+{ }^{90} \mathrm{Y}$ e ${ }^{204} \mathrm{TI}$ de acordo com as Equações $1 \mathrm{~A}$ e $2 \mathrm{~A}$, sendo $\mathrm{V}_{{ }^{90} \mathrm{Sr}_{+}{ }^{90} \mathrm{Y}}$ e $\mathrm{V}_{204 \mathrm{Tl}}$ os valores verdadeiros convencionais na grandeza taxa de dose absorvida.

Fator de correção para ${ }^{90} \mathrm{Sr}+{ }^{90} \mathrm{Y}$ :

$$
F_{c}=\frac{V_{90} \mathrm{Sr}^{90} \mathrm{Y}}{\overline{\mathrm{M}}}
$$

Fator de correção para ${ }^{204} \mathrm{TI}$ :

$$
\mathrm{F}_{\mathrm{c}}=\frac{\mathrm{V}_{204 \mathrm{~T}}}{\overline{\mathrm{M}}}
$$

Observação: A unidade do fator de correção dependerá da grandeza operacional medida pelo instrumento testado. 


\section{Referências Bibliográficas}

ANSI, AMERICAN INTERNATIONAL STANDARD INSTITUTE. Radiation protection instrumentation test and calibration of portable survey instruments. New York, 1997 (ANSI N323A, 1997).

ATTIX, F.H. Introduction to radiological physics and radiation dosimetry. New York. John Wiley \& Sons, 1986.

ABNT, ASSOCIAÇÃO BRASILEIRA DE NORMAS TÉCNICAS. Medidores e monitores portáteis de taxa de exposição de raios $X$ e gama, para uso em radioproteção. ABNT NBR 10011, Rio de Janeiro, 1987 (ABNT NBR 10011).

ABNT, ASSOCIAÇÃO BRASILEIRA DE NORMAS TÉCNICAS. Requisitos gerais para a competência de laboratórios de ensaio e calibração. ABNT NBR ISO/IEC 17025, Rio de Janeiro, 2005 (ABNT NBR ISO/IEC 17025).

ALBERTS, W.G.; AMBROSI, P.; BÖHM, J.; DIETZE, G.; New dose quantities in radiation protection. Physikalisch Technische Bundesanstalt. (PTB-DOS-23 e) Braunschweig, 1995.

AMBROSI, P.; BUCHHOLZ, G.; HELMSTÄDTER, K. The PTB Beta Secondary Standard BSS 2 for radiation protection. Jornal of Instrument. v. 2, http://iopscience.iop.org/1748-0221/2/11/P11002/Germany, 2007.

BARBOSA, M. V.; CALDAS, L. V. E. Dependência angular e energética de dosímetros fotográficos para a radiação beta. Anais do II Congresso Brasileiro de Físicos em Medicina, São Paulo, 1987.

CALDAS, L.V.E.; BATISTELLA, M.A. Dependência energética de uma câmara de ionização de placas paralelas em campos padrões de radiação-X e gama. Publicação IPEN, São Paulo, v. 207, 1988. 
CALDAS, L.V.E.; ALBUQUERQUE, M.P.P. Angular dependence of parallel plate ionization chambers. Radiation Protection Dosimetry, Inglaterra, v. 37, n. 1 , p. 55-57, 1991.

CECATTI, S.G.P.; GRONCHI, C.C.; CALDAS, L.V.E. Dependência angular de detectores termoluminescentes para radiação gama e beta em Medicina. Nuclear. Anais do 1ํ Congresso Brasileiro de Proteção Radiológica, Rio de janeiro, 2005 (CD-rom).

CNEN, COMISSÃO NACIONAL DE ENERGIA NUCLEAR. Fatores de ponderação para as grandezas de proteção radiológica. Posição regulatória $3.01 / 002,2005$.

DIAS, S. K.; CALDAS, L. V. E. Desempenho de detectores de contaminação em campos padrões de radiação alfa. Anais do 1 Encontro Nacional de Aplicações Nucleares, p. 315-325, 1991.

DKD, DEUTSCHER KALIBRIERDIENST. Certificado de radiação X: 951361, 1995.

EN, EUROPEAN STANDARD. Radiation protection instruments - Ambient and/or directional dose equivalent (rate) meters and/or monitors for beta, $X$ and gamma radiation. EN, Brussels, 2004. (EN 60846).

EISBERG, R; RESNICK, R. Física quântica. Átomos, moléculas, sólidos, núcleos e Partículas. Rio de Janeiro, Brasil.: Editora Campus LTDA, 1983.

GRECCO, C.H.S.; ESTRADA, J.J.S.; RAMOS M.M.O.; OBADIA I.J. Monitor de radiação para medidas de $\mathrm{H}^{*}(10)$. Anais do VI Congresso Brasileiro de Física Médica, Rio de Janeiro, 2001(CD-rom).

GONÇALVES, A.A.Jr.; SOUSA, A.R. Fundamentos de metrologia científica e industrial. Barueri; Manole, 2008. 
GUIMARÃES, C.C Aplicação de grandezas operacionais na monitoração individual e de área. São Paulo, 2000. Dissertação (Mestrado em Física) Instituto de Física, Universidade de São Paulo.

HALL, E.J.; GIACCIA, A.J. Radiobiology for the radiologist. Philadelphia, USA.: Lippincott Williams \& Wilkins, 2000.

IAEA, INTERNATIONAL ATOMIC ENERGY AGENCY. Calibration of radiation protection monitoring instruments. IAEA, Vienna, 2000 (IAEA SRS-16).

IAEA, INTERNATIONAL ATOMIC ENERGY AGENCY. Calibration of reference dosimeters for external beam radiotherapy. IAEA, Vienna, 2009 (IAEA-TRS-469).

ICRP, INTERNATIONAL COMMISSION ON RADIOLOGICAL PROTECTION. Conversion coefficients for use in radiological protection against external radiation. Oxford, 1995 (ICRP 74).

ICRU, INTERNATIONAL COMMISSION ON RADIATION UNITS AND MEASUREMENTS. Quantities and units in radiation protection dosimetry. Maryland, 1993 (ICRU 51).

ICRUa, INTERNATIONAL COMMISSION ON RADIATION UNITS AND MEASUREMENTS. Conversion coefficients for use in radiological protection against external radiation. Maryland, 1998 (ICRU 57).

ICRUb, INTERNATIONAL COMMISSION ON RADIATION UNITS AND MEASUREMENTS. Fundamental quantities and units for ionization radiation. Maryland, 1998 (ICRU 60).

IRD, INSTITUTO DE RADIOPROTEÇÃO E DOSIMETRIA. Requisitos para operação de laboratórios de calibração de instrumentos de medição para radiação ionizante usados em radioproteção / Laboratório Nacional de 
Metrologia das Radiações lonizantes, IRD / RJ / CNEN / revisão 2004. (Documento CRIOLAB 06.DOC)

IRD, INSTITUTO DE RADIOPROTEÇÃO E DOSIMETRIA. Certificado de radiação gama: C02/102007, 2007.

ISOa, INTERNATIONAL ORGANIZATION FOR STANDARDIZATION. Reference beta radiations for calibrating dosemeters and dose-rate meters and for determining their response as a function of beta-radiation energy. ISO, Geneva, 1996 (ISO 6980).

ISOb, INTERNATIONAL ORGANIZATION FOR STANDARDIZATION. $\boldsymbol{x}$ and gamma reference radiation for calibrating dosemeters and doserate meters and for determining their response as a function of photon energy - Part 1: Radiation characteristics and production methods. ISO, Geneva, 1996 (ISO 4037-1).

ISO, INTERNATIONAL ORGANIZATION FOR STANDARDIZATION. $\boldsymbol{x}$ and gamma reference radiation for calibrating dosemeters and doserate meters and for determining their response as a function of photon energy -- Part 2: Dosimetry for radiation protection over the energy ranges from 8 keV to 1,3 MeV and $4 \mathrm{MeV}$ to $9 \mathrm{MeV}$. ISO, Geneva, 1997 (ISO 4037-2).

ISO, INTERNATIONAL ORGANIZATION FOR STANDARDIZATION. Guide for stimulation uncertainties in dosimetry for radiation processing. ISO, Geneva, 1998 (ISO 15572).

ISO, INTERNATIONAL ORGANIZATION FOR STANDARDIZATION. $\boldsymbol{x}$ and gamma reference radiation for calibrating dosemeters and doserate meters and for determining their response as a function of photon energy -- Part 3: Calibration of area and personal dosemeters and the measurement of their response as a function of energy and angle of incidence. ISO, Geneva, 1999 (ISO 4037-3). 
ISO, INTERNATIONAL ORGANIZATION FOR STANDARDIZATION, Guia para a expressão da incerteza de medição. Terceira edição brasileira em língua portuguesa. ABNT, Rio de Janeiro, 2003.

ISOa, INTERNATIONAL ORGANIZATION FOR STANDARDIZATION. Nuclear energy - Reference beta-particle radiation - Parte 2: Calibration fundamentals related to basic quantities characterizing the radiation field. ISO, Genève, 2004 (ISO/FDIS 6980-2).

ISOb, INTERNATIONAL ORGANIZATION FOR STANDARDIZATION. $\boldsymbol{X}$ and gamma reference radiation for calibrating dosemeters and doserate meters and for determining their response as a function of photon energy -- Part 4: Calibration of area and personal dosemeters in low energy $X$ reference radiation fields. ISO, Geneva, 2004 (ISO 4037-4).

ISO, INTERNATIONAL ORGANIZATION FOR STANDARDIZATION. Nuclear energy - Reference beta-particle radiation - Parte 3: Calibration of area and personal dosimeters and determination of their response as a function of beta radiation energy and angle of incidence. ISO, Genève, 2006 (ISO/FDIS 6980-3).

JOHNS, H. E; CUNNINGHAM, J, R. The physics of radiology. Springfield, Illinois, USA. Charles C. Thomas Publisher, 1983.

KNOLL, G.F. Radiation detection and measurement. New York. John Wiley \& Sons, 1989.

MAIA, A.F; CALDAS, L.V.E. A rotational calibration method using thermoluminescent dosemeters for dose determination in computed tomography beams. Nuclear Instruments \& Methods in Physics Research. Section B. Beam Interactions with Materials and Atoms, v. 226, p. 107-110, 2008. 
NOGUEIRA, M.S. Determinação dos fatores de conversão de kerma no ar e de fluência para o equivalente de dose ambiental para raios $X$ gerados no intervalo de $50 k V_{p}$ a $125 k V_{p}$. São Paulo, 1997. Tese (Doutorado em Tecnologia Nuclear) - Instituto de Pesquisas Energéticas e Nucleares, Universidade de São Paulo.

PTB, PHYSIKALISCH-TECNISCHE BUNDESANSTALT. Calibration certificate of a ${ }^{90} \mathrm{Sr}+{ }^{90} \mathrm{Y}$ source. PTB-6.61/25, Braunschweig, 1981.

PTB, PHYSIKALISCH-TECNISCHE BUNDESANSTALT. Calibration certificate of a ${ }^{204} \mathrm{Tl}$ source. PTB-6.21/E9, Braunschweig, 1990.

POTIENS, M.P.A; CALDAS, L.V.E. Calibração de detectores de radiação utilizados em radiodiagnóstico. Anais do VI Congreso Regional sobre Seguridad Radiologica y Nuclear, v. 1. p. 4-6, 2004.

RAMOS, M.M.O. O que muda na monitoração de área com a introdução das grandezas operacionais do ICRU para radiação de fótons? Anais do V Regional Congress on Radiation Protection and Safety. Recife, 2001. (CD-rom).

THOMPSON, I.M.G. The adoption of the new ICRU dose equivalent operational quantities within the Central Electricity Generating Board of the United Kingdom. Radiation Protection Dosimetry. v. 28, n. 1, p. 149-155, 1989.

VIVOLO, V. Aplicação de metodologia de testes de desempenho para monitores portáteis de radiação. São Paulo, 2000. Dissertação (Mestrado em Tecnologia Nuclear) - Instituto de Pesquisas Energéticas e Nucleares, Universidade de São Paulo.

VIVOLO, V ; CALDAS, L.V.E. Dependência angular de monitores portáteis em feixes padronizados de radiação gama. Revista Brasileira de Pesquisa e Desenvolvimento, Rio de Janeiro, v. 4, n. 3, p. 946-946, 2002. 
WAGNER, S.R.; GROSSWENDT, B.; HARVEY, J.R.; MILL, A.J.; SELBACH,H.J.; SIEBERRT, B.R.L. Unified conversion functions for the new ICRU operational radiation protection quantities. Radiation Protection Dosimetry. v. 12, p. 231-235, 1985. 